Florida International University FIU Digital Commons

FIU Electronic Theses and Dissertations

University Graduate School

$7-2017$

\title{
An Empirical Study of Health Information Exchange Success Factors
}

peng zhang

Florida International University, pzhan005@fiu.edu

DOI: 10.25148 /etd.FIDC004029

Follow this and additional works at: https://digitalcommons.fiu.edu/etd

Part of the Management Information Systems Commons

\section{Recommended Citation}

zhang, peng, "An Empirical Study of Health Information Exchange Success Factors" (2017). FIU Electronic Theses and Dissertations. 3537.

https://digitalcommons.fiu.edu/etd/3537

This work is brought to you for free and open access by the University Graduate School at FIU Digital Commons. It has been accepted for inclusion in FIU Electronic Theses and Dissertations by an authorized administrator of FIU Digital Commons. For more information, please contact dcc@fiu.edu. 


\title{
FLORIDA INTERNATIONAL UNIVERSITY
}

\author{
Miami, Florida
}

\section{AN EMPIRICAL STUDY OF HEALTH INFORMATION EXCHANGE SUCCESS FACTORS}

\author{
A dissertation submitted in partial fulfillment of the \\ requirements for the degree of \\ DOCTOR OF PHILOSOPHY \\ in \\ BUSINESS ADMINISTRATION \\ by
}

Peng Zhang 
To: Dean Joanne Li

College of Business

This dissertation, written by Peng Zhang, and entitled An Empirical Study of Health Information Exchange Success Factors, having been approved in respect to style and intellectual content, is referred to you for judgment.

We have read this dissertation and recommend that it be approved.

Mido Chang

Min Chen

Monica Chiarini Tremblay, Co-Major Professor

Weidong Xia, Co-Major Professor

Date of Defense: July 21, 2017

The dissertation of Peng Zhang is approved.

Dean Joanne Li
College of Business

Andrés G. Gil

Vice President for Research and Economic Development and Dean of the University Graduate School

Florida International University, 2017 
ㄷ Copyright 2017 by Peng Zhang

All rights reserved. 


\section{DEDICATION}

I dedicate this dissertation to my parents, FengChun Wen and FuLai Zhang; to my sister, Yu Zhang. Without them, the completion of this dissertation would not have been possible. 


\section{ACKNOWLEDGMENTS}

I first would like to thank my two advisors, Dr. Weidong Xia and Dr. Monica Chiarini Tremblay for their guidance. Both professors were my mentors since I entered the program. Dr. Xia spent countless hours working with me during the most difficult time of my dissertation. What I vividly remember and will never forget are the many phone calls that I made, often late at night, not only for technical issues but also for the overwhelming stress that I felt that I could not overcome. And each time he would be there, patiently listening and readily to assist. His mentorship helped me to continuously grow till I had the knowledge and full confidence as an independent researcher. Dr. Tremblay guided me to gradually discover my interest for my dissertation topic and has been providing with me guidance and support throughout the journey of my dissertation. More than once, when people had lost faith in me, she still believed that I could pick myself up and keep going. I am so thankful that today I can finally finish and present this piece of

work and make her proud. Against all difficulties, I was able to continue my dissertation till its final completion, only through their on-going consulting, support, and encouragement.

I would also like to thank my committee members, Dr. Min Chen and Dr. Mido Chang for spending time reading my dissertation and providing constructive feedback so I could further improve my work. I can never forget their dedication, care, and professionalism. They have been always available and accommodating to me and ready to help whenever I asked. A special blessing for me was that it has always been a great pleasure to work with all my committee members. 
Through my interactions with them, I not only increased my knowledge but also grew my character, which help me to become a better human being.

My deepest gratitude to many faculty and staff members of both inside and outside the Department of Information Systems and Business Analytics (ISBA). They provided for me with advice and support throughout my Ph.D. program. My sincere thanks to all my Ph.D. classmates for their collegiality, companionship and support for me. I also would like to give my special thanks to people, many of whom were healthcare professionals, who spent their precious time helping with my data collection which made this dissertation possible. Thank you! 


\section{ABSTRACT OF THE DISSERTATION}

AN EMPIRICAL STUDY OF HEALTH INFORMATION EXCHANGE

SUCCESS FACTORS

by

Peng Zhang

Florida International University, 2017

Miami, Florida

\section{Professor Weidong Xia, Co-Major Professor \\ Professor Monica Chiarini Tremblay, Co-Major Professor}

The healthcare system in the US faces substantial challenges related to cost, access and quality. Health Information Exchange (HIE) has been widely viewed as a viable solution for dealing with those challenges. Despite the potential contributions to the healthcare system that HIE promises, adoption and use of HIE have always been difficult, and the past two decades have witnessed significant HIE implementation failures.

The limited understanding of HIE is a major obstacle for HIE success. Only recently in-depth research about HIE starts to appear in top IS journals. In addition, the uniqueness of healthcare industry adds to the complexity to HIE. Our study attempts to address this research gap by systematically examining multiple factors that influence HIE adoption and use. Using social exchange theory (SET) and diffusion of innovations theory, a research model was developed to empirically test major factors that impact healthcare providers' relative advantages and risks 
perceptions for adopting and using HIE. It is further proposed that relative advantages and risks in turn impact organizations' intentions for adopting and continuously using HIE. As such, we posit that organizations' assessments of relative advantages and risks associated with HIE mediate the impacts of organizational and technological factors on organizations' adoption and use intentions.

This study uses questionnaire surveys for data collection. Out of a total of 163 responses, 117 surveys were completed and were analyzed using Partial Least Square software SmartPLS 3. Data analysis finds that most of the relationships were in the hypothesized directions with some of the relationships being significant. Specifically, top management support, absorptive capacity, trust, and HIE innovation characteristics positively affect relative advantages and negatively affect risk. Furthermore, relative advantages positively affect adoption/continuance intentions, whereas risk negatively affects adoption/continuance intentions.

This study contributes to the literature and offers important practical implications. It is one of the early empirical attempts to understand the key factors that affect HIE's adoptions and use. The research can also serve as a starting point for more in-depth studies in the future. Moreover, practitioners can use the several newlydeveloped scales to empirically examine healthcare providers' adoption and use intentions. 


\section{TABLE OF CONTENTS}

CHAPTER

PAGE

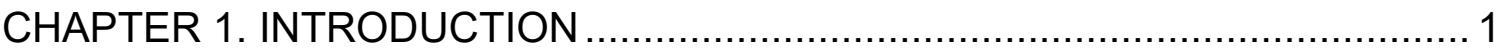

US healthcare challenges — costs and quality .......................................... 2

HIE's benefits - cost and quality ......................................................... 4

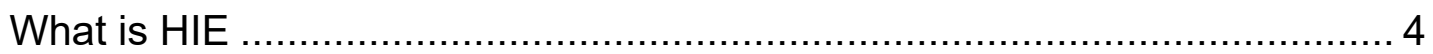

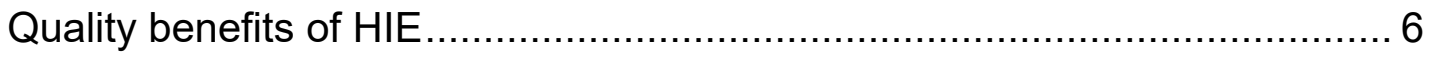

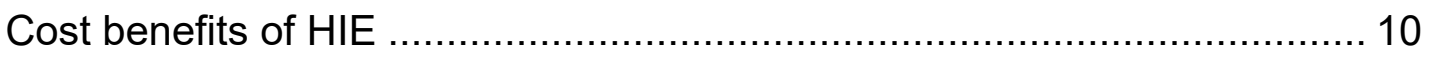

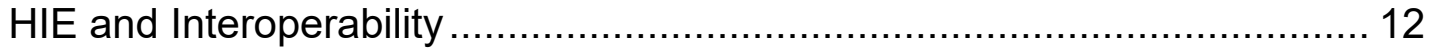

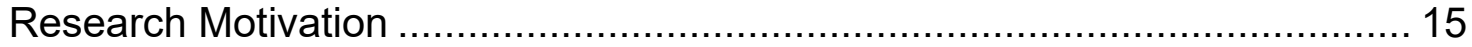

General MIS research applies to HIT ….............................................. 15

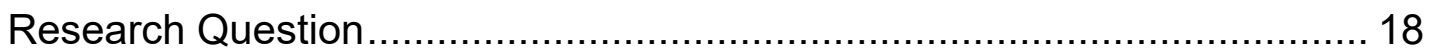

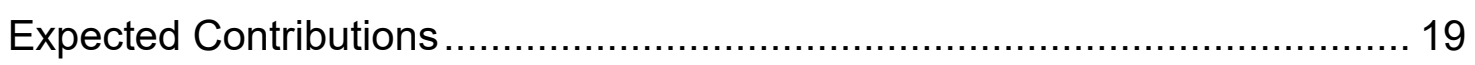

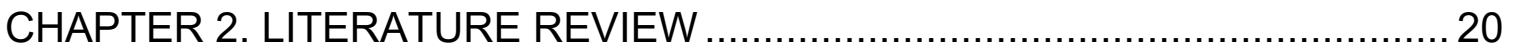

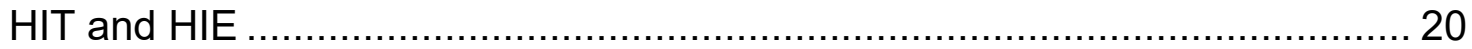

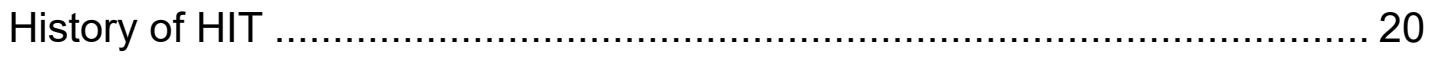

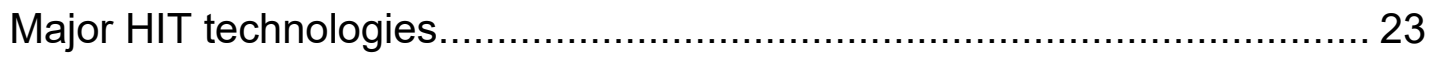

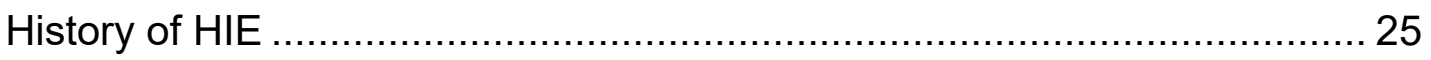

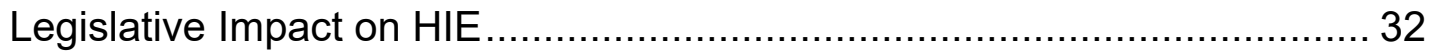

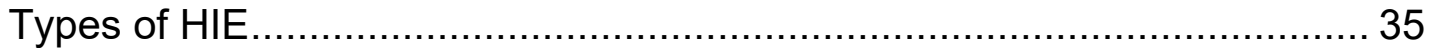

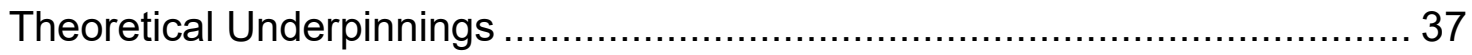

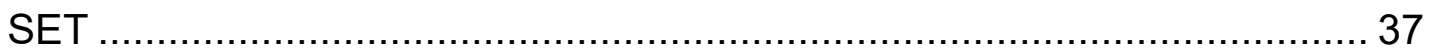

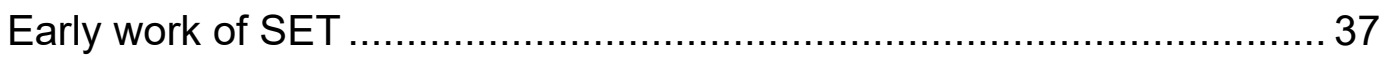

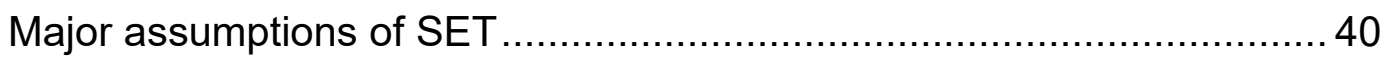

Restricted and generalized exchanges ............................................ 42

SET's application in macro research............................................... 44

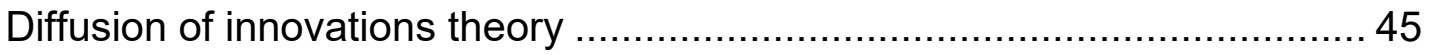

Prior Research on Inter-Organizational Relationships ................................ 46

CHAPTER 3. RESEARCH MODEL AND HYPOTHESES DEVELOPMENT ...... 48 ix 
Factors impacting HIE's adoption and use ............................................ 48

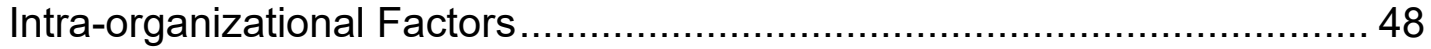

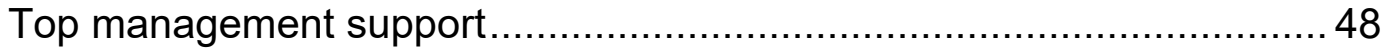

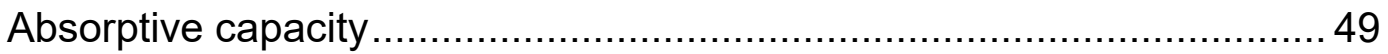

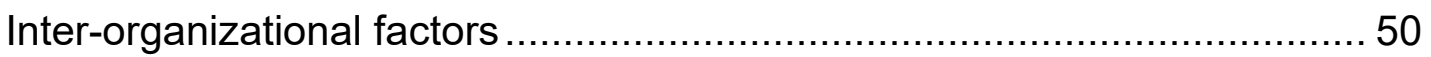

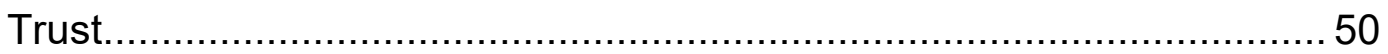

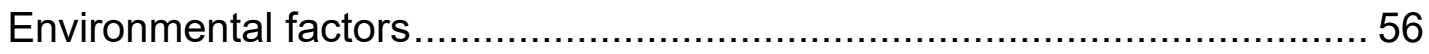

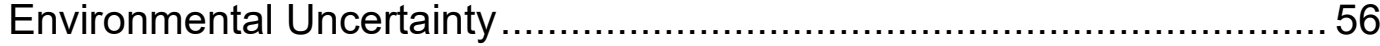

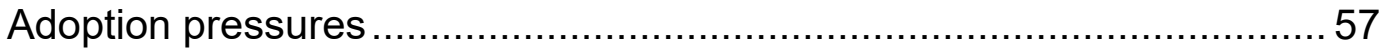

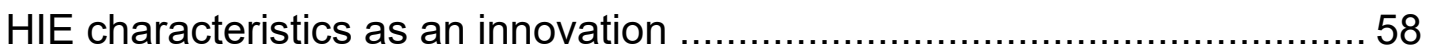

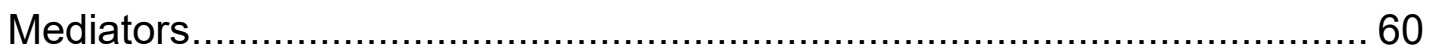

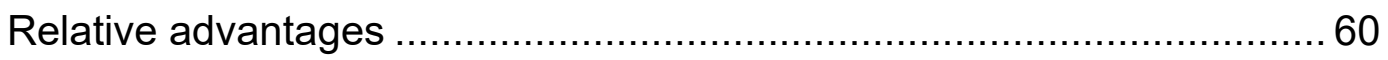

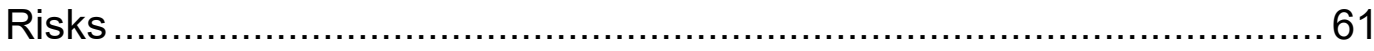

The dependent variables_-HIE adoption and continuance intentions ............ 62

Adoption intentions for IS pre-adoption ............................................... 62

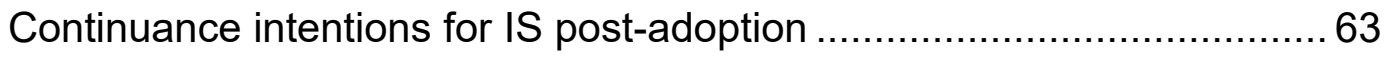

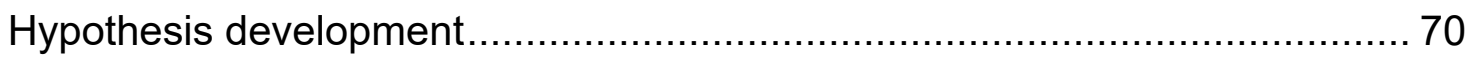

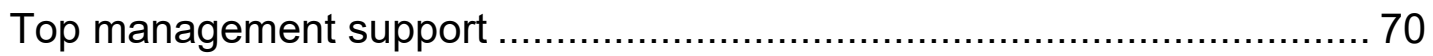

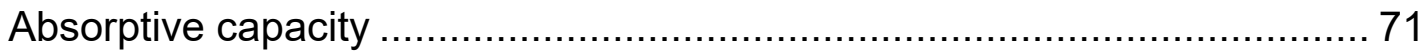

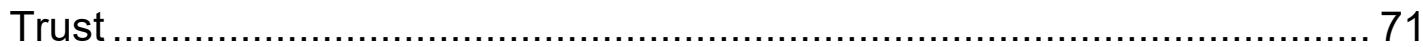

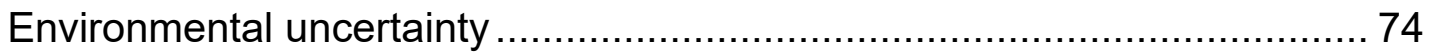

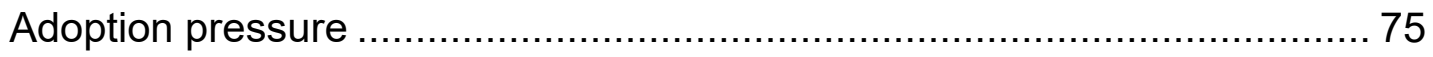

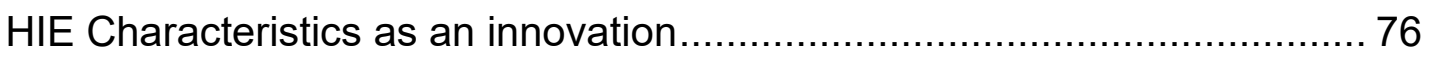

Mediating roles of relative advantage and risk ...................................... 77

CHAPTER 4. RESEARCH METHODOLOGY ................................................ 77

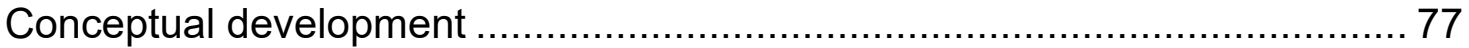

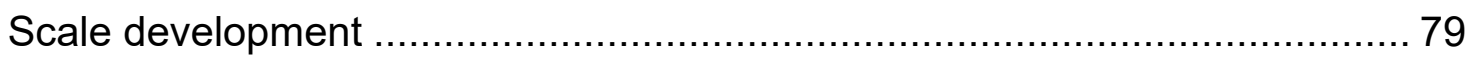

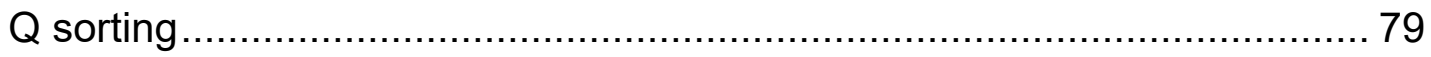

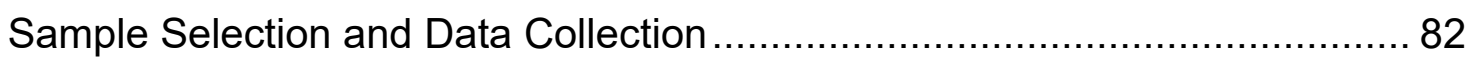

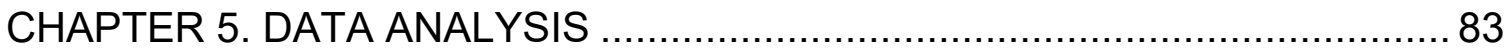

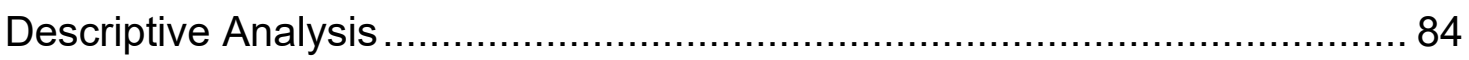




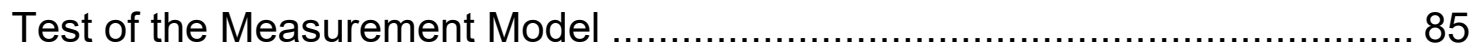

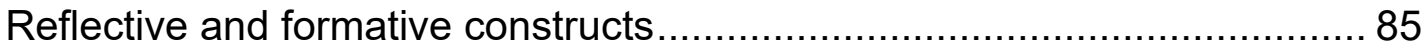

Determination of formative and reflective constructs ............................ 86

Measurement Model Assessment - Reflective......................................... 89

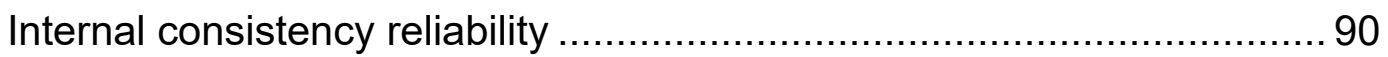

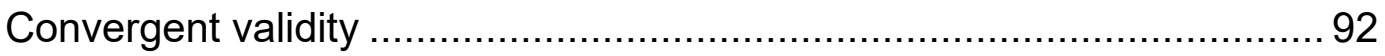

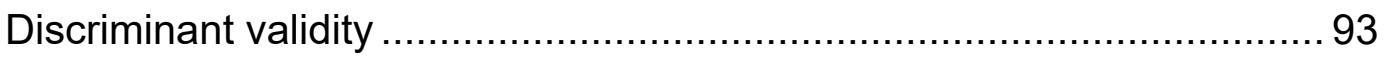

Measurement Model Assessment_Formative ......................................... 96

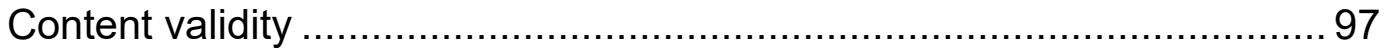

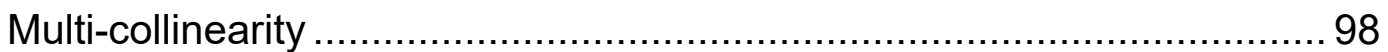

Significance and Relevance of the Formative Indicators ...................... 100

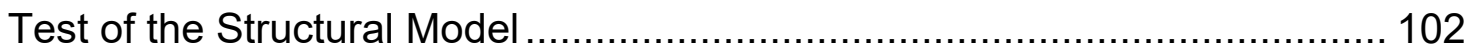

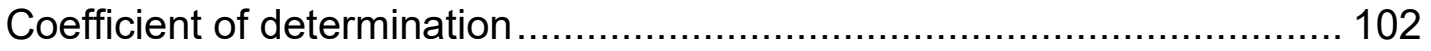

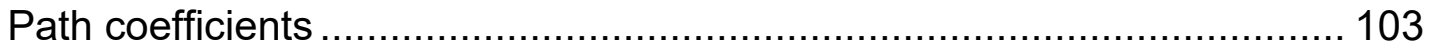

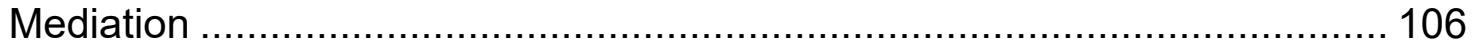

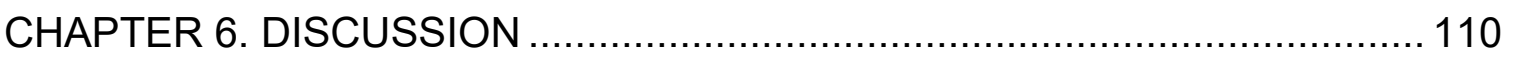

Uniqueness of the healthcare industry ....................................................... 111

For-profit and not-for-profit organizations........................................ 111

Complexity of healthcare industry ..................................................... 114

Policy influence in healthcare industry ............................................ 117

Inter-organizational relationship in healthcare industry ....................... 118

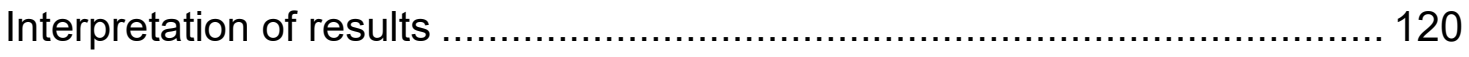

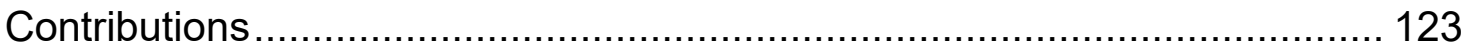

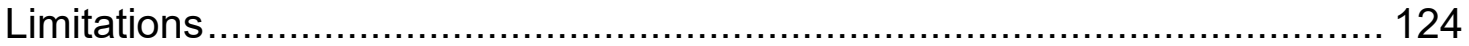

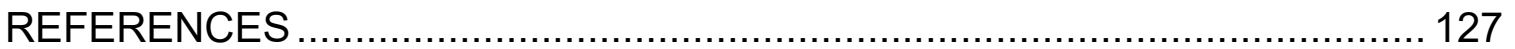

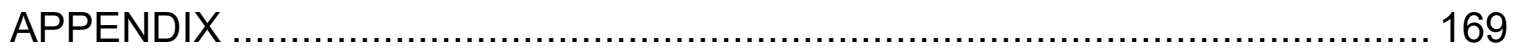

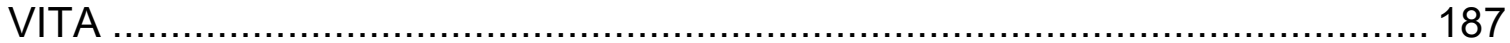




\section{LIST OF TABLES}

TABLE

PAGE

1 Operational definitions for all constructs

82

$2 \quad$ Respondents by job title

84

3 Demographics data of healthcare providers

85

$4 \quad$ Internal consistency reliability values for reflective

92 measures

$5 \quad$ Outer loadings of reflective indicators

6 Cross-loadings of reflective indicators

94

$7 \quad$ Fornell-Larcker criterion

94

8

HTMT correlation

95

9

HTMT statistic and significance

95

10

HTMT confidence interval

96

11 HTMT confidence interval bias corrected

96

13 Outer weights of all indicators

$14 \quad \mathrm{R}$ square values

$15 \quad \mathrm{R}$ square values adjusted

16 Path coefficients and significance

17 Indirect and total effects 108

$18 \quad$ Hypothesis testing results

A1 Operationalizations of all constructs for adopt intentions 
A2 Operationalizations of all constructs for continuous intentions

B1 Descriptive statistics of all items 


\section{CHAPTER 1. INTRODUCTION}

In 2007, a frustrated physician, Cara Litvin MD, published a paper describing a bleak picture of how doctors could not get needed patient information during patient handoffs - "I felt as though I were practicing medicine in the dark (Litvin 2007)." The doctor commented: "it was unfair to all of us especially to the patients - that care was suboptimal simply because records were not available." It has been ten years since then. What is the state of patient record sharing today?

Patient information sharing of today, in many aspects, is just as inadequate as 10 years ago. A recent article published in JAMA described the experience of David Ross, MD, an emergency department physician, and the problem was almost identical in nature to what Dr. Litvin described ten years ago: often a patient would arrive at the emergency department unconscious or incoherent. Without access to the patient's records, doctors would not know anything about his or her medical history (Jacob 2015a). In an era in which data flows freely on the Internet, it is unacceptable that healthcare providers often do not have even their patients' most basic medical information.

The benefits of health information exchange (HIE) is apparent to many healthcare providers (Kaelber and Bates 2007). The implementation of HIE however is fraught with failures and frustrations (e.g. Wu and Larue 2015). This study tries to answer the question: what are the factors that would lead to the success of HIE adoption and use? 
This thesis is structured as follows. We first review major challenges faced by the US healthcare system, namely cost (Auerbach and Kellermann 2011) and quality (Agrawal et al. 2004). We then proceed to discuss HIE as a potential solution for cost containment and quality improvement. The history, technology and policy components of both Health Information Technology (HIT) and Health Information Exchange (HIE) were also reviewed for this thesis.

In the realm of information systems (IS) research, HIE adoption falls into a broader scope of IT adoption. Scholars distinguish pre-adoption and post adoption (e.g. Ahuja and Thatcher 2005; Karahanna et al. 1999). Our study is concerned with both pre-and post-adoption. Although research on IT adoption is abundant, studies on HIE adoption have been scarce. We caution that findings in general IS adoption research may not be readily applied to the healthcare industry because of fundamental differences between healthcare and other industries. As such, this study is vital to deepening our understanding of HIE adoption and use in particular, and HIT adoption and use in general. Through the lens of SET and diffusion of innovations theory, this research investigates several major antecedents' impacts on HIE adoption and use (Bhattacherjee 2001). In the end, we discussed this study's findings and its academic and industrial implications. Lastly, we address limitations of the study and make suggestions for future HIE research and implementation.

US healthcare challenges—costs and quality

The healthcare system in the US faces substantial challenges. For example, Cutler and Sahni (2013) reported that the total healthcare expenditure 
of the US in 2012 was $\$ 514$ billion, or 18 percent of the nation's economy (Werling et al. 2014). The World Health Organization (WHO) reported that healthcare expenditure per capita was substantially higher in the US than in any other Organization for Economic Cooperation and Development (OECD) country in the world. For example, Norway's healthcare cost per capita was the next highest in OECD countries. The US healthcare expenditure per capita was still $50 \%$ higher than that of Norway.

Despite high cost, the quality of healthcare is very much in doubt (Reckmann et al. 2009, Panel on Understanding Cross-National Health Differences Among High-Income Countries et al. 2013). For example, a recently published news report stated the US ranked the last in healthcare outcomes of all 17 OECD countries (Rubenstein 2013). In another study, the Commonwealth Fund (2014), a private research agency, reported in 2014 that the US health system ranked last among eleven countries on measures of access, equity, quality, efficiency, and healthy lives. The U.S. also ranked last in year 2004, 2006, 2007, and 2010 (The Commonwealth Fund 2014). The performance of the US healthcare system has raised many concerns, and researchers (e.g. Hillestad et al. 2005) believe that HIT at least offers a viable solution to mitigate the problems that the US healthcare system faces. HIE, a component of HIT, has seen much growth in the healthcare industry in the past decade, although its development is plagued by a multitude of setbacks (Wu and Larue 2015). This slow progress is partially due to the lack of understanding of HIE (Eden et al. 2016). Better understanding of technology leads to its better adoption and 
implementation. In the ensuing section, we discuss the definition of HIE and how it positively contributes to healthcare cost and quality.

HIE's benefits - cost and quality

What is HIE

Magrabi et al. (2012) consider that HIT "broadly includes computer hardware and software used by health professionals and consumers to support care." Major HIT includes electronic medical record (EMR), electronic health record (EHR) and HIE. These systems are often integrated with computerized physician order entry (CPOE) and decision support systems (DSS). Although some researchers question HIT's role in reducing cost and improving quality (Moses III et al. 2013), the overwhelming research and heuristic evidence, nonetheless, shows that HIT is indispensable for the healthcare industry.

Vest and Gamm (2010) define HIE as the process of sharing patient-level electronic health information between different organizations. According to HealthIT.gov (n.d.), HIE allows doctors, nurses, pharmacists, other healthcare providers and patients to appropriately access and securely share a patient's vital medical information electronically - improving the speed, quality, safety and cost of patient care. Fontaine et al. (2010) summarize that the stated goals of HIE are improvements in healthcare quality, efficiency, and cost. Similarly, Greenberger (2015) stated that the goal of HIE is to facilitate access to and retrieval of clinical data to provide safe, timely, efficient, effective, and equitable patient-centered care. 
The Office of the National Coordinator (ONC) for HIE, the principal federal agency charged with coordination of nationwide efforts to implement and use the most advanced health information technology and the electronic exchange of health information, describes a list of HIE benefits on its website, HealthIT.gov (n.d.):

- Provides a vehicle for improving quality and safety of patient care by reducing medication and medical errors;

- Stimulates consumer education and patients' involvement in their own healthcare;

- Increases efficiency by eliminating unnecessary paperwork;

- Provides caregivers with clinical decision support tools for more effective care and treatment;

- Eliminates redundant or unnecessary testing;

- Improves public health reporting and monitoring;

- Creates a potential loop for feedback between health-related research and actual practice;

- Facilitates efficient deployment of emerging technology and healthcare services;

- Provides the backbone of technical infrastructure for leverage by national and State-level initiatives;

- Provides a basic level of interoperability among electronic health records (EHRs) maintained by individual physicians and organizations;

- Reduces health related costs. 
Research to date has difficulty reaching a consensus regarding the benefits of HIE (Rahurkar et al. 2015). Khurshid et al. (2015) note that while the value HIEs bring to a fragmented healthcare system is generally recognized, questions related to how to estimate, operationalize, and sustain such values remain topics of much debate. At the same time, participation in HIEs continues to be an integral part of several federal and state-level regulations, including meaningful use requirements and those related to accountable care organizations (Khurshid et al. 2015). We broadly summarize two major HIE benefits, cost and quality, which we discuss in detail below.

Quality benefits of HIE

One reason that HIE improves healthcare quality is that it improves healthcare coordination. LaBorde et al. (2011) summarize that sharing records between medical institutions has the potential to significantly improve the quality of patient care including medical error reduction, better surveillance of infectious diseases, and improved delivery of standardized care. A lack of coordination might lead to undesirable outcomes, such as duplication of care, increased error rates, adverse drug events, and higher patient risk.

Ranji et al. (2013) report that adverse drug events are one of the most common types of harmful errors in both hospitalized and ambulatory patients. Studies have shown that preventable adverse drug events occur in 7 to 10 of every 100 hospital admissions (Lazarou J et al. 1998), and may occur even more frequently in the ambulatory setting (Gandhi et al. 2003). Prescribing errors are likely responsible for at least half of these events (Nebeker et al. 2005). A 2007 
report from the Institute of Medicine (IOM) on medication errors estimated that between 380,000 and 450,000 preventable ADEs occur annually in a hospital setting, resulting in a cost of $\$ 3.5$ billion annually in the United States. With the inclusion of estimates from ambulatory and long-term care settings, this report projected that over 1.5 million preventable ADEs occur annually in the United States (Wolfstadt et al. 2008).

HIE improves healthcare quality by providing more complete and more timely access to clinical data, which in turn could improve medical decision making (Kern et al. 2012). Ideally, when a patient is treated at any hospital, providers should have access to all prior relevant medical records of the patient (LaBorde et al. 2011). This goal can only be accomplished with HIE. Over the course of a lifetime, individuals may receive treatments from a variety of providers within the same geographic area. Patients also often change their providers because they believe they can receive better patient care (LaBorde et al. 2011). Other factors contributing to patients visiting different hospitals may include emergency needs, second opinions, referral to specialty services, economic hardship, preferences, and relocating (LaBorde et al. 2011). This leads to each patient's medical data being scattered in different provider offices and healthcare systems, which can contribute to errors in diagnosis or treatment and create unnecessary costs due to duplicate testing (LaBorde et al. 2011). As populations become more mobile, patients' records will be increasingly dispersed. A study by Rudin et al. (2011) shows that "on average, excluding radiology and pathology, approximately $51 \%$ of visits involved care transitions 
between individual providers in a community and $36 \%-41 \%$ involved transitions between medical groups. There were substantial variations in transition percentages across medical specialties, within specialties and across medical groups" (p.853).

Kern et al. (2012) report that without HIE, clinical information is "missing in 1 out every 7 primary care visits, because the data resides elsewhere and is not accessible at the point of care" (p. 198). With HIE, physicians could "determine if tests recommended by clinical guidelines have been done for their patients or not... If access to external clinical data reveals that recommended tests have not been done, then those tests could be ordered; if it reveals that recommended tests have been done, then physicians could document those tests and avert duplicated ordering" (Kern et al. 2012, p. 198).

Kho et al. (2008)'s study in 2006 of patient crossover of methicillinresistant staphylococcus aureus (MRSA) infections is a good example of the potential damage to quality due to the fragmentation of patient healthcare when HIE is absent. There were three healthcare systems operating six hospitals in the Indianapolis area. Each hospital shared information about MRSA status within their "in-system" hospitals but not with the other healthcare systems. A significant portion of patients already known to be colonized or infected with MRSA by one system were not identified at admissions by neighboring healthcare systems. Only three MRSA positive patients, a mere $0.03 \%$ of the total MRSA patients in the pool, were registered at all healthcare systems (Figure 1 - the central area of overlap represents patients known by multiple systems to have a history of 
MRSA). The remaining $8,438(1,663$ to 4,731$)$ patients were only on the MRSA list of their "home" system. The bulk of patients on the list were unknown to neighboring systems (Kho et al. 2008). The consequences of missing patient information can be severe. The same colonized/infected patient may later present to other hospitals, unbeknownst to the other health systems. These patients may never be known to be MRSA positive, all the while serving as a potential source of infection at these naïve hospitals (Kho et al. 2008, p.212).

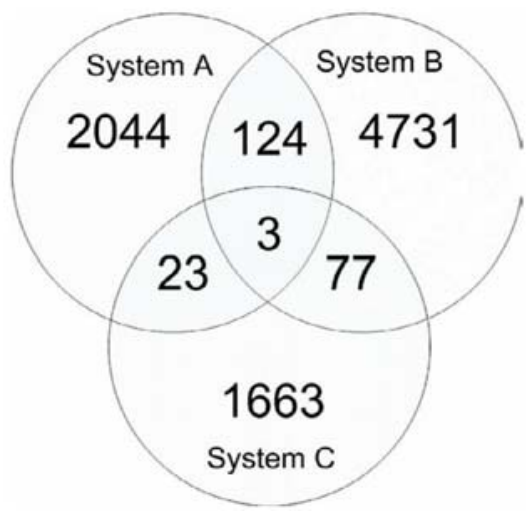

Figure 1. Overlap of MRSA lists

Scholars have identified areas where quality improvements are most significant when HIE presents, such as laboratory and imaging tests. Ross et al. (2013) observe that a central anticipated benefit of HIE implementation is its potential to reduce unnecessary testing by providing a consolidated, timely, and easily accessible summary of patient information across organizations. The fragmented patients' laboratory information damages patient care quality in several ways. First, fragmentation of patient information causes duplicated laboratory and imaging records. Duplicated testing can either be caused by inaccessibility of paper records when patients are transferred between care 
facilities, or by incomplete electronic record transferring among incompatible electronic medical record systems (Stewart et al. 2010). Duplication is not only costly but also inefficient. Laboratory tests and imaging can be time-consuming. If doctors are not aware that patients have had laboratory tests that the doctors needed, new laboratory tests must be ordered and physicians must wait till results come out. Second, duplicated laboratory records can cause unnecessary information processing burden for medical professionals. At a minimum, a doctor must read and understand more than one record, which is time consuming. Often, doctors also need to figure out a reason why another exact test was ordered. These are more or less a disruption of normal workflow and cause unnecessary delays for patient care. Third, in urgent situations, not having needed information readily available for critically ill patients can be lifethreatening for them. This is especially relevant in settings such as the ER. Cost benefits of HIE

The rising cost of US healthcare has made cost containment a priority of past administrations. A standardized national HIE has the potential to save billions of dollars a year by reducing duplicated testing, inpatient hospitalizations, and length-of-stay (LaBorde et al. 2011). The study by Walker et al. (2005) predicts that fully standardized and implemented HIE could yield a net value of $\$ 77.8$ billion per year annually, or US $\$ 3.76$ billion in laboratory tests and US\$8.04 billion in radiology tests.

HIE reduces cost and increases efficiency through a similar mechanism as it improves quality. Reduction of duplicated testing would result in cost savings. 
An ideal HIE would be able to eliminate duplication of testing at time of patient transfers. For example, Yaraghi (2015) studies financial effects of HIE in an emergency department (ED) in Western New York. The study finds that HIE usage was associated with, respectively, $52 \%$ and $36 \%$ reduction in the expected total number of laboratory tests and radiology examinations ordered per patient. Recent studies also show that HIE is effective in reducing imaging costs (Bailey et al. 2012; Bailey et al. 2013). HIE helps to achieve cost reduction also by more efficient utilization of hospital resources. Because most patients have only limited financial resources at their disposal, any unnecessary spending in duplicated tests invariably reduces available funds. It is worth noting that there are not yet many rigorous studies investigating the financial impacts of HIE, and scholars have doubts about whether HIE is effective in reducing cost at all (Rahurkar et al. 2015).

The disagreement of HIE's impact on cost reduction might result from the following reasons. First, HIE is a technology that is not matured (e.g. Rahurkar et al. 2015). Consequently, the implementation of the technology itself can be costly. The contemporary HIE systems might not be cost efficient, due to reasons such as a lack of a universal standard of HIE or low utilization of the technology. Cost analysis in essence is an accounting question. Studies tend to use various accounting metrics to calculate cost savings. Payne et al. (2013) argue that researchers do not have clear metrics to measure either cost or benefit. Furthermore, researchers cannot agree upon what type of costs should be 
measured. An actual determination of cost benefits would require longitudinal field research based data collection which are not a common practice.

HIE and Interoperability

A related concept that sometimes is used interchangeably with HIE is interoperability. Interoperability can be considered as a major goal of HIE. The Institute of Electrical and Electronics Engineers defines interoperability as the "ability of two or more components to exchange information and to use the information that has been exchanged (Garde et al. 2007). Heiler (1995) defines interoperability as the ability to exchange services and data with one another (among components of large-scale, distributed systems). He explains that interoperability is based on agreements between requesters and providers, such as message passing protocols, procedure names, error codes, and argument types.

The ONC, based on the description by Institute of Electrical and Electronics Engineers (IEEE), defines interoperability as "the ability of a system or a product to work with other systems or products without special effort on the part of the customer". For healthcare, it means that "people who need health information have it when they need it and have it in a way they can use it" (Jacob 2015b). With interoperability, "information about a patient's medications, diagnostic tests, allergies, or recent appointments can be pulled from an EHR or database at a physician's office, hospital, or laboratory and folded into the patient's EHR at another location" (Jacob 2015b, p.1214). 
There are different categorizations regarding the types of interoperability (Adebesin et al. 2013). To facilitate discussion and be relevant to our study, we identify three major types of interoperability, namely, structural, syntactic, and semantic. They are more nuanced categorizations, such as Wang et al. (2009)'s seven-level interoperability. The syntactic level and semantic level are in level two and three of Wang et al. (2009)'s model, respectively.

"Structural interoperability is an intermediate level that defines the structure or format of data exchange (i.e., the message format standards) where there is uniform movement of healthcare data from one system to another such that the clinical or operational purpose and meaning of the data is preserved and unaltered. Structural interoperability defines the syntax of the data exchange. It ensures that data exchanges between information technology systems can be interpreted at the data field level (HIMSS 2016)."

Syntactic interoperability is defined as the structure and provenance of information or knowledge that is understood by a system. This comprises all (machine-readable) aspects of data representation (Garde et al. 2007). Syntax can be considered as the grammar to convey semantics and structure (Veltman 2001).

Semantic interoperability provides interoperability at the highest level, which is the "ability of two or more systems or elements to exchange information and to use the information that has been exchanged" (HIMSS 2016). It takes advantage of both the structuring of the data exchange and the codification of the data so that the receiving end of the information systems can interpret the data. 
This level of interoperability supports exchange of patient summary information among caregivers and other authorized parties via potentially disparate EHR systems. It improves quality, safety, efficiency, and efficacy of healthcare delivery (HIMSS 2016).

The functions of structural interoperability and syntactic interoperability somewhat overlap. Structural and syntactic interoperabilities guarantee the "preservation of the clinical purpose of the data during transmission among healthcare systems, while semantic interoperability enables multiple systems to interpret the information that has been exchanged in a similar way through predefined shared meaning of concepts" (Adebesin et al. 2013, p. 56). In other words, structural and syntactic interoperabilities make sure that different systems can exchange information, whereas semantic interoperability ensures that these exchanges make sense - that the requester and the provider have a common understanding of the "meanings" of the requested services and data (Heiler 1995). Semantic interoperability is based on agreements on, for example, algorithms for computing requested values, the expected side effects of a requested procedure, or the source or accuracy of requested data elements (Heiler 1995).

One of the ways to accomplish semantic interoperability is to make semantics explicit in metadata. Doing so allows people to detect mismatched assumptions and create required mappings to overcome them (Heiler 1995). Using a repository technology which provides a shared database for metadata helps to eliminate ambiguity of semantical interpretation of the data. Although the 
theory is sound, its implementation in healthcare is complicated. For instance, one of the largest challenges of HIE is patient identification. A patient must be identified before the patient's information can be exchanged. To date there is not a nation-wide patient identification system (Hillestad et al. 2008). Our field interviews show that patients' misidentification (including both type one and type two errors) poses a serious threat to the viability of HIE.

\section{Research Motivation}

General MIS research applies to HIT

What differentiates research in HIE and other IS artifacts is that HIE functions in a domain different from other industry. Fottler (1981) believes that different management approaches are needed depending on an organization's for-profit status. For researchers, there may not be universal solutions for different organizations. We believe that this principle applies to IS research as well. Gawthorp (1971)'s study of environmental turbulence demonstrates the distinction between for-profit and not-for-profit organizations.

In a typical for-profit industry, environmental turbulence normally comes from the competitive pressure from other firms (Lichtenthaler 2009). In a typical not-for-profit industry, environmental turbulence can come from different sources such as government regulation changes. The healthcare industry is so unique that researchers sometimes argue that research in healthcare management should be published in context-specific outlets (Blair and Hunt 1986). Fottler 
(1987) noticed that the bulk of healthcare research indeed appears in context specific journals.

IS researchers voiced caution about drawing lessons mechanically from general MIS literature and applying them to healthcare. For example, Bozeman and Bretschneider (1986) note that the vast majority of MIS knowledge, both formal and "know how," has been developed from private sectors. This knowledge is useful to apply in private sectors, but it may not be applicable for not-for-profit sectors. Similarly, when comparing key IS issues between public and private sectors, Caudle et al. (1991) found that significant differences exist. Bretschneider (1990) discusses several differences between public and private information systems:

1. Public management information system (PMIS) managers must contend with larger levels of interdependence across organizational boundaries than their private counterparts do (Bretschneider 1990). The authority of public organizations derives in part from legal and constitutional norms. Embedded in those institutions are traditional concerns for checks and balances, exemplified by oversight groups or external organizational controls of personnel activity and financial resources. Consequently, public organizations exhibit greater interdependences across organizational boundaries than do private organizations.

2. PMIS must contend with higher levels of red tape than private MIS managers (Bretschneider 1990). PMIS red tape is often created for 
conformity (such as meeting particular standards imposed by the government) and legitimacy reasons (Meyer and Rowan 1977), which might have little to do with productivity.

3. PMIS planning is more concerned with extra-organizational linkages, while private MIS is more concerned with internal coordination (Bretschneider 1990).

4. PMIS tend to place the director lower in the organizational structure than private MIS (Bretschneider 1990).

Bretschneider (1990) concluded two differences between public and private IS. The first is that PMIS operates in a more constrained environment. This is due to higher levels of interdependency, constraints of accountability mechanisms, and red tape. The second point is that PMIS does not follow standard prescriptions provided in management literature. Rather than a failure of public managers, it was an adaptation of this type of organization to a more constrained management environment (Bretschneider 1990). Caudle et al. (1991) concludes that the public sector has multiple, conflicting, and often intangible goals. It produces "public goods" for problems that should be solved (like crime and poverty), even though these problems may have no known feasible solutions; and it is heavily impacted by politics and bureaucratic red tape. The public sector thus functions in a much different setting for IS management than the private sector (Caudle et al. 1991).

Dawes et al. (2004) discusses the unique risks faced by public sector IT including the following: (a) extreme risk aversion making PMIS hesitant to invest 
in risky unproven technologies; (b) divided authority over IT decisions due to legal, civil service, and political constraints that makes it difficult to manage IT projects; (c) multiple stakeholders with competing goals; (d) short budgeting cycles that make it difficult to plan long-term and adopt IT innovations; (e) highly regulated procurement using a competitive RFP process that makes it difficult to learn from experience; (f) too many links between programs and organizations making IT often dependent on external agencies such as through budgets and legal requirements. Making changes is thus challenging because doing so often affects other related agencies.

Many HIEs today operate in environments where a combination of both public and private, profit and not-for-profit organizations exist. To understand the complexity of these healthcare organizations is a prerequisite to understand the success of HIE.

\section{Research Question}

The lack of understanding of HIE makes this study both timely and meaningful. Although an exploration of HIE infrastructure started in the 1990s (Hammond 1994), researchers and practitioners still struggle to find an effective strategy to implement HIE (Hussain et al. 2015, Wilcox et al. 2006). In the meantime, this past decade has seen networks experimenting with different HIE solutions (e.g. Vest and Kash 2016), with many ending up with failures.

The past decade has seen the fastest growth of HIE adoption and use, with one major reason being governments' policy support. By $2014,76 \%$ of US 
hospitals had engaged in some forms of HIE (Hersh 2015). Researchers still contend that the use of HIE in the United States is in its infancy (Rahurkar et al. 2015). Most studies of HIE have focused on first-generation systems and some active HIEs experience low usage. In addition, many HIEs lacks a sustainable strategy. Typically, an HIE would start when outside funding comes in, but would fail whenever funding runs out (Lorenzi 2003). The HIE landscape is a mixed picture: some HIEs are starting, some are ending, some are successful and many are struggling. Many organizations have attempted HIE more than once with different degrees of successes and failures.

understanding of HIE adoption and implementation is inadequate. Given that a spectrum of HIE adaptors and users exists, this study simultaneously examines factors influencing providers' HIE's adoption and use. To address the above-mentioned issues and to gain a better understanding of HIE, this study tries to answer the following research questions:

1. What are the factors that contribute to HIE's adoption intentions?

2. What are the factors that contribute to HIE's continuance intentions?

\section{Expected Contributions}

Our study made the following contributions. First, although a plethora of studies about IS adoption exists, there is a paucity of empirical research investigating factors leading to HIE adoption. We developed a parsimonious model to examine critical factors leading to HIE's adoption and use. Second, realizing that research findings in the traditional IS domain might not be applicable to the 
healthcare industry, we included several healthcare specific factors in our research model. Moreover, we enriched some existing measures and developed several new measures that were healthcare specific. These constructs were conceptually developed and empirically tested in our research.

This research is highly relevant to the industry for both practitioners and policy makers alike. Healthcare is one of the largest industries in the United States and its share of GDP has been steadily growing. Findings relating to efficient use of HIT are therefore of great value. This is especially true for HIE because its adoption is one of the prominent objectives of contemporary healthcare policy. This study is likely to contribute to improvements of HIE implementation in the future. Even a small percentage of increase in HIE success still would lead to better patient outcomes and millions of cost savings.

\section{CHAPTER 2. LITERATURE REVIEW}

\section{HIT and HIE}

History of HIT

HIT is sometimes referred to as healthcare information system (HCIS), which includes a wide range of technologies. Wager et al. (2013) defines HCIS as an arrangement of information (data), processes, people, and information technology that interact to collect, process, and store information. To better understand the contemporary HIT, it is important to first examine the historical development of HIT. According to Staggers et al. (2001), in the 1950s, the emphasis of healthcare was on increasing the number and quality of facilities. 
The Hospital Survey and Construction Act (also known as the Hill-Burton Act) of 1946 provided funds for development of healthcare facilities. HCIS dates to 1960s when the first generation of computers were used for healthcare. Even back then, government policy had profoundly influenced the healthcare industry's use of information technology.

On July 30, 1965, President Lyndon B. Johnson signed the Social Security Amendment of 1965 into law. It created Medicare and Medicaid, which were two of America's most enduring social programs (Berkowitz 2008). Initially, both programs reimbursed hospitals for services using a cost-based reimbursement policy. Hospitals at the time were still benefiting from the funds available through the Hill-Burton Act, which allowed easy access to capital to build new facilities and expand their services (Brinker and Walker 1962, pp. 1948-1954). With a cost-based reimbursement system, the more services a hospital provided, the more revenue the hospital could generate. Healthcare executives realized that to capitalize on funds available, their organizations needed information systems that could automate patients' billing process and facilitate accurate cost reporting. Most early information systems in healthcare were therefore administrative applications driven almost exclusively by financial needs (Wager et al. 2013). Mainframe computers were supplied by major manufacturers such as IBM.

As technology advanced, mainframe computers were superseded by minicomputers in the 1970 s and then by microcomputers in the 1980s. As a computer's speed increased and its cost declined, more microcomputers and clinical applications began to be used in healthcare. During this period of time, 
healthcare costs were steadily rising, partially due to Medicare and Medicaid expenditures (Wager et al. 2013). By the mid-1980s, a variety of administrative and clinical applications was available for the healthcare industry, although they were often implemented piecemeal (Wager et al. 2013). Network technology (mostly LAN) allowed microcomputers to communicate with each other.

The 1990s saw a wide-spread implementation of managed care (Miller and Luft 1994). Physicians "were reimbursed on a capitated or fixed rate or some type of discounted rate... As physician payment relied increasingly on documentation substantiated in the patient's record and as computers became more affordable, physicians began to recognize the need for timely, accurate, and complete financial and clinical information" (Wager et al. 2013, p. 98). Before the 1990s, HIT ran on mainframe computers. The acquisition and maintenance of these computers nonetheless were cost prohibitive for small practices.

Consequently, HIT was mainly used by large hospitals. During the 1990s, the rapid decline of microcomputers costs made these new technologies widespread. For the first time, all sizes of medical practices were able to afford and use HIT.

Several major research reports appeared during the same period spurred HIT adoption. The Computer-Based Patient Record: An Essential Technology for Healthcare was published in 1991 (Dick et al. 1997) by IOM. This report brought international attention to problems inherent in paper-based medical records. It called for adoption of a computer-based patient record (CPR) by year 2001 (Wager et al. 2013). The second report, To Err Is Human, was published in 2000. This report has made significant impacts. It galvanized a dramatically expanded 
level of conversation and concern about patient injury in healthcare both in the United States and abroad. Patient safety, a topic little understood and less discussed in healthcare systems, became a frequent focus for journalists, healthcare leaders, and concerned citizens (Leape LL and Berwick DM 2005). This publication reported that as many as 98,000 people die annually as the result of medical errors. It called for a national effort to improve healthcare safety. A subsequent report by Committee on Data Standards for Patient Safety (Aspden et al. 2004) of IOM urged healthcare organizations to adopt information technology capable of collecting and sharing essential patient information (Wager et al. 2013).

\section{Major HIT technologies}

The major technologies that were first implemented included EMR, CPOE, and clinical DSS (Maslove et al. 2011). Wolfstadt et al. (2008) define CPOE as an electronic application used by physicians to order drugs and tests, and requests for consultations. CPOE not only improves productivity of medical professionals, it is also effective in reducing prescription errors. Analysis of medication errors suggests that prevention strategies targeting systems rather than individuals are most effective in reducing errors (Kohn et al. 2000). Clinical decision support systems (DSS) are built into almost all CPOE systems to varying degrees (Kaushal et al. 2003). CPOE and DSS are effective because they target the ordering stage of medications, introducing automation at the time of ordering, where most medication errors and preventable adverse drug events (ADEs) occur (Kaushal et al. 2003). CPOE improves patient safety in several 
ways. First, CPOEs are more legible than handwritten ones. Furthermore, CPOE can force physicians to "include dose, route of administration, and frequency in the order before authorizing the prescription, thus resulting in better structured and more complete medication prescriptions" (van Rosse et al. 2009, p.1184). Studies on CPOE have shown that it reduces incomplete and inappropriate prescriptions and adverse drug events. It also improves antibiotic ordering patterns and decreases length of stays and costs (Khajouei and Jaspers 2010).

Kawamoto et al. (2005) define DSS as "any electronic system designed to aid directly in clinical decision making, in which characteristics of individual patients are used to generate patient specific assessments or recommendations that are then presented to clinicians for consideration." According to Johnston et al. (1994), the first application of DSS in medicine dated back as early as 1974 . Classic DSS includes alerts, reminders, order sets, drug-dose calculations.

Kuperman et al. (2007) identifies two types of DSS - basic and advanced. Basic DSS includes drug-allergy checking, basic dosing guidance, formulary decision support, duplicate therapy checking, and drug-drug interaction checking. Advanced DSS includes dosing support for renal insufficiency and geriatric patients, guidance for medication-related laboratory testing, drugdisease contraindication checking, and drug-pregnancy checking. The past decade has seen more and more DSS integrating into other systems, such as CPOE (Ranji et al. 2013) . A knowledge-based DSS can assure that an order is safe and compliant with guidelines (Kuperman et al. 2007). CPOE and DSS can effectively tackle the essential issue of patient safety. 
Scholars have accumulated much evidence in the past two decades regarding the utility of HIT. There is a consensus that HIT is indispensable in healthcare and the use of HIT is vital for quality. For example, Buntin et al. (2011)'s review of HIT shows that of all articles that they had reviewed, 92 percent reached favorable conclusions of HIT's impact on quality, efficiency, and provider satisfaction. HIE, as a type of (advanced) HIT, although difficult to implement, promises great quality and cost improvements to healthcare.

History of HIE

To understand the HIE that we have today, it is important for us to first review the history of HIE and the major milestones of HIE developments in the past several decades.

Multi-hospital information systems (MHISs)

MHISs were probably one of the earliest technological developments in healthcare that bear resemblance to HIE. According to Collen (1995), MHISs were those that serviced three or more hospitals, with associated medical offices and clinical support services. By 1975 , about $25 \%$ of community hospitals belonged to MHISs (Collen, 1995). The major functions of many HMISs were administrative rather than clinical. Main MHIS functions included the following (Collen, 1995):

1. Providing centralized patient identification and file management;

2. Performing scheduling, order-entry, and results reporting for centralized services such as a regional laboratory; 
3. Tracking of pharmacy drug usage prescribed for patients by different physicians within multiple facilities.

In the 1980s, users exchanged not only data but also images and documents. Providers were using electronic mail for inter-facility consultations (Collen, 1995).

MHIS typically happened within a hospital system. MHIS was a solution for patient record sharing when hospitals and clinics merged. This is different from HIE because with an HIE, health information is exchanged among independent providers.

Prior to the advent of open architecture systems in the 1980s, technical specifications for an MHIS required uniform computer and communication standards for all hospitals and clinics in the system. This was to permit integration of data from the various databases (Collen, 1995). Because MHISs required a higher level of data integration, a single vendor was often needed to ensure that data handling procedures, file management, database organization, security, hardware, and software were all consistent and compatible (Collen, 1995).

A good example of MHIS is the US Department of Veterans Affairs (VA). President Lincoln established the National Asylum for Disabled Volunteer Soldiers, the direct antecedent for VA, in 1866. The National Asylum became the Veterans Administration in 1930 under President Hoover. In 1989, President Bush elevated it to cabinet level status (Brown et al. 2003). Collen (1995) reports that the VA operated 172 hospitals and 229 outpatient clinics in the 1980s. There 
were about 26 million veterans the United States, and the VA provided care to 1.5 million inpatients and furnished almost 20 million outpatient visits per year. The VA was the largest centrally coordinated civilian healthcare system in the United States. Since the 1950s, the VA has maintained a national centralized computer-based file for all VA patients that includes their identification data, claims, and social security numbers. A patient treatment file contained inpatient admission and discharge data that included diagnoses, surgical procedures, and patient disposition data. The VA initially used punch cards to manage all information (Collen, 1995). During the 1970s, a variety of clinical computer applications were developed in several VA hospitals. Historically, patient management software was often developed by individual providers, causing interoperability problems among different systems. Because of the dynamic nature of information technology, it was common that a hospital used multiple IT solutions. As time passed, more and more patients' records accumulated, making integration of different healthcare information systems increasingly difficult.

In February 1982, to provide centralized management, the VA administration developed a policy of support for decentralized computer operations and directed the establishment of six original Verification and Development Centers (VDCs). Their function was to assist the implementation of computer-based medical applications (Collen, 1995). The VA began to realize that the ability to integrate patient data entered and retrieved from various system models was crucial. Consequently, much effort was devoted to promote 
standardization. Although the VA has had some success pioneering HIE and is considered exemplar (e.g. Kern and Kaushal, 2007), other researchers argue that the VA still needs better integration of its patient healthcare information (Overhage 2007).

Fontaine et al. (2010) consider VA's unified EHR exemplifies an HIE within "closed" systems (Brailer 2005). An example of "open" systems are the community-based HIE initiatives such as Regional Health Information Organizations (RHIOs). It is generally considered that an open HIE system is more difficult to manage because of the complexity of coordination among participants. Coiera (2009) contends that building national scale health IT infrastructure is different from replicating a clinical system across different institutions, as what the VA had accomplished.

Different systems require different technical architectures. Rudin et al. (2009) distinguish three general architectural alternatives of HIE, namely fully centralized, peer to peer, and hybrid. These alternatives describe the physical storage location of clinical data and the way data are shared among members of an HIE network. In a fully centralized architecture, all clinical data are stored in a single central repository; no data are stored locally in physician offices. All clinical data stored in electronic health records would be shareable among community physicians. This architecture is essentially a fully integrated electronic health record system. The VA uses such an architecture (Rudin et al. 2009). By contrast, the peer-to-peer approach - often called a "federated" model - involves no centralized repository. Clinical data are stored at providers' local systems 
where they were originally generated. Data exchanges occur when an authorized healthcare provider sends a query for a particular patient and then receives responses from sites within the HIE network. This architecture requires providers to host and maintain data repositories as well as servers that can respond to queries (Rudin et al. 2009). A hybrid architecture combines aspects of fully centralized and peer-to-peer approaches. A centralized repository is used, but this repository is a copy of a portion of the data that are stored locally at each provider's sites. This architecture allows physicians to manage their own electronic health records as they do with the peer-to-peer approach. Each individual electronic health record "pushes" designated elements of new patient data to the centralized repository, which can then be retrieved by other providers in the network. Unlike the peer-to-peer approach, network-wide queries are unnecessary in the hybrid approach. Information retrieval is accomplished by direct access to the centralized repository from any site in the HIE network (Rudin et al. 2009). An open system falls into the category of peer-to-peer architecture, and a closed system uses a centralized architecture. A decentralized (or distributed) system in general is much more difficult to manage than a centralized system.

\section{Community Health Management Information Systems (CHMIS)}

The earlier attempts of HIE dated back to the 1990s. Healthcare professionals have been trying to exchange patient information since the appearance of electronic medical records. The Hartford Foundation initiated community health management information systems (CHMISs) through grants to 
seven states and cities in 1990 (Vest and Gamm 2010). In the 1980's and 1990 's, in response to the managed care movement, many hospitals began to merge into what became known as integrated delivery networks (Lorenzi 2003). Vest and Gamm (2010) describe CHMISs as a community and payer-centric means to healthcare management. A centralized data repository containing individual level demographic, clinical and eligibility information for a geographically defined community provided data to stakeholder organizations (e.g., local agencies, payers, employers, and researchers). A secondary function of CHMISs was a transaction system to facilitate billing in order to reduce cost. Regretfully, CHMISs were largely not successful. CHMISs occurred prior to the advent of cheap, reliable, high-speed internet access, which made CHMISs obsolete. Furthermore, a CHMIS required costly network connections, hardware, and software (Vest and Gamm, 2010). The novel idea of collecting personal health information into a single repository aroused security and privacy concerns from patients and providers (Vest and Gamm, 2010). CHMISs are one of the early major failed attempts of HIE.

\section{Community Health Information Networks (CHIN)}

According to Lorenzi (2003), CHMIS can be viewed as the precursor of the CHIN movement. The first recorded CHIN was not an electronic network, but an inter-library loan system (Gartenfeld 1978) in which hospitals could exchange information. Spurred by the development of EMRs, multiple CHINs were established in different states in the 1990s, such as the Wisconsin Health Information Network (Payton and Ginzberg 2001) and Greater Dayton Area 
Community Patient Health Information Network (Pouloudi 1999). Although CHIN was popular for several years, by 2000 nearly all CHIN efforts failed (Lorenzi 2003). Major reasons that contributed to CHIN's demise included conflicting missions of providers, an absence of trust among stakeholders, a lack of clear ownership over data, and unsustainable financing (Vest and Gamm, 2010).

National Health Information Infrastructure (NHII)

The NHII concept has evolved over several decades as medical informatics professionals implemented individual and enterprise-wide clinical information systems and explored implications of extending such systems throughout the entire healthcare continuum (Yasnoff et al. 2004). For example, Detmer (2003) reports that as early as 1986, a long-range planning panel of the National Library of Medicine (NLM) proposed a national computer network to be used by the entire biomedical community, including both clinical and research professionals. The 1991 IOM report on computer-based patient records included a vision of a "national healthcare information system" that would support data transfer for clinical purposes, reimbursement, and research. With appropriate confidentiality measures, it would bring knowledge resources to practitioners. The National Committee on Vital and Health Statistics (NCVHS), the statutory federal advisory committee to the Department of Health and Human Services (DHHS) for information policy and strategy, described a vision and plan for the NHII in its 2001 report, "Information for Health." It asserts that "implementation of the NHII will have a dramatic impact on the effectiveness, efficiency, and overall quality of health and healthcare in the United States" (HHS 2001). NHII as a 
long-term vision has not been accomplished. Researchers and practitioners are still focusing on making local HIEs successful, hoping that eventually all regional HIEs can be connected. Some examples of regional HIEs include CHMISs and RHIOs.

Legislative Impact on HIE

HIPAA (The Health Insurance Portability and Accountability Act)

The first major legislative act that had an important impact on HIE was HIPAA. The U.S. Congress passed HIPAA on August 21, 1996 (Dwyer III et al. 2004). HIPAA is important because HIPAA became law at a time when both the use of HIE (such as EMR or CPOE) and initial development of HIE were gaining momentum. On August 14, 2002, the DHHS published final modifications to the Privacy Rule, a set of regulations safeguarding the privacy of health information (Gunn et al. 2004). Compliance was required by April 14, 2003, and the regulations apply to both electronic and paper records (Annas 2003).

Dwyer III et al. (2004) explain the major components of HIPAA as follows. The first "A" in HIPAA is for "accountability" and implies accountability in insurance claims (combatting fraud). This is accomplished for the most part by utilizing computer software. The "IP" in HIPAA is for insurance portability. It limits exclusions that insurers can use, enables credits for past insurance, and attempts to enable individuals to purchase insurance. The privacy rule concerns policies regarding the flow of information, the right of patients to review and amend data in their medical records, and other administrative requirements. It 
applies to all individually identifiable information, including that contained in electronic, paper, and oral communications. HIPAA is important to HIE because it has more stringent regulatory requirements regarding how the flow of patient information should be handled.

Legislations since 2000

The early 2000s saw increased government involvements in HIT policy. In April 2004, President George W. Bush created the position of the Office of National Coordinator (ONC) through Executive Order (The White House n.d.). According to HealthIT.gov (n.d.), ONC for Health Information Technology is at the forefront of the administration's health IT efforts. It serves as a resource to the entire health system to support the adoption of health information technology and the promotion of nationwide health information exchange. ONC is organizationally located within the Office of the Secretary for the U.S. Department of Health and Human Services (HHS). ONC is the principal federal entity charged with coordination of nationwide efforts to implement and use the most advanced HIE (HealthIT.gov n.d.).

In 2005, the DHHS Secretary, Michael Leavitt, launched "the American Health Information Community - a multi-stakeholder, public-private sector body charged with advising the DHHS Secretary on health IT policy, that would spur the development of standards and the use of health IT" (Marchibroda 2007, p.S12). On August 22, 2006, President George W. Bush issued an Executive Order calling for federal sponsored healthcare programs to utilize HIT systems and products that meet recognized interoperability standards. Since 2004, the 
conversation within the federal government migrated from one which focused on "health IT adoption" to one that focused on "health IT interoperability" (Marchibroda 2007).

On February 17, 2009, President Barack Obama signed into law a $\$ 787$ billion economic stimulus package, the American Recovery and Reinvestment Act (ARRA). It directs about $\$ 150$ billion in new funds to healthcare, most of which would be spent within 2 years (Steinbrook 2009). The spending includes $\$ 87$ billion for Medicaid, $\$ 24.7$ billion for subsidies for private health insurance for people who lose or have lost their jobs, $\$ 19.2$ billion for HIT, and $\$ 10$ billion for the National Institutes of Health (NIH) (Steinbrook 2009). The HIT for Economic and Clinical Health (HITECH) Act, as part of the American Recovery and Reinvestment Act (Buntin et al. 2011), makes an estimated \$14-27 billion in incentive payments available to hospitals and health professionals to adopt certified electronic health records and use them effectively in the course of care (Buntin et al. 2011). The ONC for HIT is the main responsible body to guide physicians, hospitals, and other key entities as they adopt electronic health records and achieve so-called meaningful use, as spelled out in federal regulations (Buntin et al. 2011). The ARRA devotes approximately $\$ 19$ billion dollars to increasing participation in HIE, with the goal of creating RHIOs that will ultimately be linked to form a Nationwide Health Information Network (Fontaine et al. 2010). 
Types of HIE

The Office of the National Coordinator focuses on establishing the initial set of policies and standards (Williams et al. 2012). ONC describes three key forms of health information exchange: directed exchange, query-based exchange, and consumer mediated exchange. Directed Exchange is the ability to send and receive secure information electronically between care providers to support coordinated care. Query-based Exchange is the ability for providers to find and/or request information on a patient from other providers, which is often used for unplanned care. Consumer Mediated Exchange is the ability for patients to aggregate and control the use of their health information among providers (HealthlT.gov n.d.).

Directed exchange is used by providers to easily and securely send patient information - including laboratory orders and results, patient referrals, or discharge summaries - directly to another provider. This information is sent over the internet in an encrypted, secure, and reliable way amongst healthcare providers who already know and trust each other, and is commonly compared to sending a secured email. This form of information exchange enables coordinated care, benefitting both providers and patients (HealthIT.gov n.d.). An example of direct exchange is Direct Messaging Service (DMS) of Florida HIE (Tremblay and Deckard 2014). DMS is a "secure" service allowing exchange of paperless patient data. DMS is less sophisticated than Patient Look-Up (PLU). Consequently, it requires less upfront investment from participants. 
Query-based exchange is used by providers to search and discover accessible clinical sources on a patient. This type of exchange is often used when delivering unplanned care (HealthIT.gov n.d.). An example of direct exchange is PLU of Florida Health Information Exchange (Florida HIE, Tremblay and Deckard 2014). PLU is a searchable distributed database, a "network of networks" that allows participating healthcare organizations and affiliated users to query the medical records of other participating healthcare organizations for individual patient data (Florida-hie.net n.d.). All clinical data that moves across the Florida HIE is locally owned, stored, managed, and controlled. Queries can be based on a patient's name, date of birth, social security number, and/or other patient demographics. Each participating healthcare organization is vetted prior to joining the Florida HIE and assumes responsibility to ensure that their respective users are vetted.

Consumer-mediated exchange provides patients with access to their health information, allowing them to manage their healthcare online in a fashion similar to how consumers manage their finances through online banking. When in control of their own health information, patients can actively participate in their care coordination (HealthIT.gov n.d.).

For the purpose of our research, we include all types of exchanges to improve the generalizability of our research findings. For our research design, the distinction of different technologies is not essential because we broadly consider any provider's adoption or continuance intentions for HIE. In addition, because 
technology evolves fast, the inclusion of all types of technologies allows us to assess the current state of HIE adoption and use at the national level.

\section{Theoretical Underpinnings}

\section{SET}

\section{Early work of SET}

Social exchange has its deep roots in sociology and psychology (Emerson 1976; Homans 1958; L'Abate 1979). According to Das and Teng (2002), SET was initially developed to examine interpersonal exchanges that are not purely economic. In an earlier literature review of SET, Emerson (1976) identified four founders of SET, namely, George Homans, John Thibaut, Harold Kelley, and Peter Blau. The theory views people's social behavior in terms of exchanges of resources (Das and Teng 2002). The need for social exchange is created by a scarcity of resources, prompting actors to engage one another to obtain valuable inputs (Levine and White 1961). We start our discussion of SET by briefly reviewing major developments of the theory.

In general, researchers consider Homans (1958) as the first scholar who systematically developed the concept of SET (Blau 1968; Lambe et al. 2001). Based on reinforcement theory, Homans (1958) initially drew on exchange behaviors from experimental animals such as pigeons. He then proceeded to discuss exchange situations among human beings. He developed important taxonomies such as values and practical equilibrium, some of which became key components of SET. While examining the (social) influence process and the 
formation of social structure in social exchange, Homans (1958) explored different aspects of social exchange, such as profit, social control, and distributive justice. He concluded that, "Social behavior is an exchange of goods, material goods but also non-material ones. Persons that give much to others try to get much from them, and persons that get much from others are under pressure to give much to them. This process of influence tends to work out at equilibrium to a balance in the exchanges."

Building upon his earlier work, Homans developed his theory in a follow up thesis, "Social Behaviour: Its Elementary Forms (Homans 1961)," in order to "to make it more lucid and logical (Zeitlin 1975)." Similar to his previous book, the primary research technique that Homans used were observations of informal human interactions in industry (Turner 1961). Clearly based on social economics analysis (T. and Gullahorn 1962), he examined how valuations of cost and profit influence human exchange. Homans viewed social exchange as reciprocal rewards and costs in human interaction. In his terms, social exchange is simply a trade between or among participating parties: each participant benefits, but each must pay a price for the exchange. Homans also further discussed several distinctive behaviors in social exchange, such as the formation and impacts of distributive justice, and different types of "currency" used in social exchange, namely rewards and costs.

Thibaut and Kelley's work traces back to an earlier book "The Social Psychology of Groups" (Thibaut and Kelley 1959), where the authors discussed some concepts similar to what Homans mentioned later, such as social control, 
positive components (rewards), and negative components (costs). Kelley and Thibaut's major contribution to SET was that they expounded how parties in an exchange weigh costs and benefits to determine their relationship commitment (Lambe et al. 2001). From a different angle, Emerson (1962) enriched SET from the aspect of power and dependence. By clarifying different concepts of power, authority, legitimacy and power structures, Emerson (1962) brought these terms "together in a coherent scheme" (p. 31). A strong flavor of economics based analysis can be observed because a social exchange relationship is studied "with little or no regard for particular features of the persons or groups." Power became the anchor of Emerson's discussion. Surrounding power, Emerson discussed the balance and imbalance of power and how equilibrium is reached, and in the process, how legitimation, norms, and role-prescriptions are formed (Emerson 1962). Emerson's later work (e.g. Emerson 1976) continued to bring together different streams of research which helped SET become a mature theory.

Blau (1964)'s work is similar to Emerson's (1962) in several ways. For example, Blau emphasized power in exchange relationships and inspected the important roles of norms. He went further to proclaim the ubiquitousness of the relationship of social exchange. Although some authors criticized this as an overstatement (Bierstedt 1965), it indeed helped SET gain wide recognition as a systematic, independent theory. Indeed, scholars stated that "Blau (1964) may have been the first to use the term "theory of social exchange" to describe his conceptualization "of social interaction as an exchange process (Lambe et al. 2001)." 
While the theory was developed, more scholars enriched the theory by exploring its different aspects. Important contributors included Chadwick-Jones (1976), Cook (1977), Kelley and Thibaut (1978), and Levine and White (1961), to name a few. It is also worth noting that SET is invariably intertwined with other theories. Seminal pieces of SET are also regarded as foundational work for several other theories that appeared later, such as the resource dependence theory (Davis and Cobb 2010; Pfeffer and Salancik 1978).

\section{Major assumptions of SET}

SET operates under several premises (e.g. Narasimhan et al. 2009). The first crucial assumption is that individuals engaging in social exchange are rational beings who seek self-interest maximization. Such self-interest seeking is the driver to determine people's behaviors in social exchange. Humans as rational beings are goal oriented and they calculate the best possible means to engage in interaction and seek to maximize profits and returns (Tanskanen 2015). As such, each party in the exchange relationship seeks "mutual benefit," without consideration of individual differences and emotions. Such a simplified assumption was characteristic when the theory initially appeared. As the theory evolved, different interpretations reshaped it, while in the meantime adding granularity and enriching it. For example, Homans' work was first criticized as a vehicle for "exploitation (Zeitlin 1975)" (p. 475). Criticism as such later gradually declined as the theory became more coherent and its boundaries clearly defined.

Second, individuals have access to information about social, economic, and psychological dimensions that allow them to assess alternative, more 
profitable situations relative to their present condition. Thus, individuals are constrained by bounded rationality. Although profit maximization is exercised, it is not necessarily achieved. Third, exchanges are voluntary; and consequently, satisfaction of individuals thus becomes vital. Any party who is dissatisfied from the exchange can opt to exit at any time. Social exchange relationships can be construed as a type of "governance mechanism (Lambe et al. 2001)", where the market and hierarchy types of governance are absent (Ouchi 1980). In this type of governance, people's interactions are two-sided, mutually contingent, and mutually rewarding, which involves "transactions" or simply "exchange (Emerson 1976)." Because fiat governance is lacking, exchange actors' satisfaction with the relationship is critically important (Molm 1991).

Fourth, SET operates within the confines of a cultural context (i.e., norms and behaviors being defined by others) (Narasimhan et al. 2009). Meaningful interpretations, such as fairness and justice, are only possible when the social context is taken into consideration. Fifth, an ongoing social exchange relationship is governed by rewards or punishments carried out by exchange parties. Lambe et al. (2001, p.3) summarized that the core explanatory mechanism of SET is the "relational interdependence, or relational contract, that develops over time through the interactions of the exchange partners. (p.3)" This is accomplished by the actions of one person's providing rewards or punishments for the actions of another person and vice versa in repeated interactions (Muthusamy and White 2005). 


\section{Restricted and generalized exchanges}

Social exchange theorists distinguish restricted and generalized exchanges (Blau 1964; Ekeh 1974; Yamagishi and Cook 1993). According to Das and Teng (2002), restricted social exchange (a.k.a. dyadic or mutual exchange) occurs when two parties directly exchange with each other. In restricted exchanges, the resources that one actor gives are directly contingent on the resources that the other gives in return (Takahashi 2000). In contrast, generalized social exchanges take place among a group of at least three parties, where direct reciprocity is sometimes absent. Generalized exchange is characterized by unilateral resource giving because one's giving is reciprocated not by the recipient, but by a third party (Molm and Cook 1995).

Social exchange theorists had noticed the differences between restricted and generalized exchanges when SET was initially developed. Although the term of generalized exchange had not been coined, both Blau (1964) and Thibaut and Kelley (1959) had extensive discussions about social exchange where more than two people are involved. On the contrary, Ekeh (1974) noted that Homans' work considered only exchange between two persons. Ekeh (1974) described Homans' theory as 'limited to restricted exchange between two individuals both in time and space: 'Here social behavior is elementary in the sense that the twomen are in face to face contact, and each is rewarding the other directly and immediately"' (p. 124). Ekeh went on to argue that generalized exchange was just as common as restricted exchange: "If $A$ gives to $B, B$ gives to $C$, and $C$ gives A, we have generalized exchange" (Ekeh 1974, p. 125). Ekeh listed 
examples for generalized exchanges such as the cooperative arrangements that farmers make to help each other out with harvesting chores or the library consortia organized by local universities. The absence of one-to-one correspondence between the giver and receiver is a defining feature distinguishing restricted and generalized exchange (Das and Teng, 2002).

Generalized exchanges are inherently more complex. Early research studying SET tends to focus more on exchanges between a dyad. Consequently, empirical knowledge about generalized exchanges is limited. Das and Teng (2002) reason that restricted exchanges entail direct reciprocity between two parties. As such, accountability is relatively high because the monitoring of agency problems is relatively easy (e.g. free riding relatively easy to detect and remedy). By comparison, in generalized exchanges, rewards that an actor receives are usually not directly contingent on the resources provided by that actor (Yamagishi and Cook 1993). Any member of the exchange system can free ride and there is no guarantee of reciprocity (Takahashi 2000).

It is important to note that HIE is clearly a generalized exchange because typically an HIE has multiple participants (more than two). Indeed, The first recorded CHIN (an early form of HIE) was an inter-library loan system (Gartenfeld 1978) where hospitals exchanged information. Our research thus not only empirically examined factors that lead to successful HIE adoption but also helped improve the understanding of generalized exchange in SET. 


\section{SET's application in macro research}

SET has been widely used in different disciplines since its appearance. For example, Emerson (1976) noted that SET had been utilized in the areas of inter-organizational relations, urban studies, and political science. Later on, other fields such as marketing also adopted SET as the theoretical lens (Morgan 1991). The applications of SET in different fields, albeit broad, have concentrated mostly in psychology (e.g. industrial psychology or consumer behavior). This is partly due to SET's natural affinity for psychological constructs that developed along with the theory, such as trust and justice (Cropanzano and Mitchell 2005; Homans 1961). As a result, in the past two decades SET has been mainly applied to organizational behavior research. In contrast, macro research also has a long tradition of using SET, although its use was not as broad. As early as 1976, Emerson indicated the application of SET in inter-organizational relations. Examples of using SET at the organizational level analysis include works by Anderson and Narus (1984), Anderson and Narus (1990), and Steensma and Lyles (2000), to name a few.

One stream of research using SET in inter-organizational relations is for the study of supply chain, such as the relationship between distributors and manufacturers (Anderson and Narus 1984; Anderson and Narus 1990), or simply between buyers and sellers (Dwyer et al. 1987). Originating from marketing, researchers in this field contend that business relationships should be considered as ongoing exchange processes (Hallén et al. 1991). SET thus offers a perfect theoretical lens to study business transactions. 
It is interesting that while the same theory of SET was used to study interorganizational relationships, the context of research has been evolving as technology changed. Earlier works using SET (e.g. Anderson and Narus 1984) simply examined how buyers and sellers cooperated without giving much consideration of technology. Many later studies tended to focus on particular technological artifacts or solutions, such as inter-organizational information systems (IOS), Electronic Data Interchange (EDI) (e.g. Son 2001; Son et al. 2005) and e-commerce (Bunduchi 2008).

Diffusion of innovations theory

The theory of diffusion of innovations was developed by Rogers (Rogers 1962, Rogers 1983, Rogers 1995, Rogers 2003). Rogers defines innovation as a type of uncertainty, "idea, practice, or object that is perceived as new" (Mishra 1996, p.249). Diffusion, on the other hand, is defined by Rogers as the adoption of an innovation "over time among the members of a social system".

Rogers considers innovation diffusion as a "social process" (Czepiel 1974, p. 172). DOI has long appealed to those interested in "industrial innovation diffusion research" (Czepiel 1974, p. 172). Undoubtedly, HIE is an innovation that is diffused in the healthcare industry. For Rogers (2003), the innovation-decision process involves several steps: (1) knowledge (or awareness), (2) persuasion, (3) decision, (4) implementation, and (5) confirmation (Sahin and Thompson 2006). Rogers further categorizes innovation adopters into several groups: innovators, early adopters, early majority, late majority, and laggards (Mahajan et al. 1990). Moreover, the theory considers several factors that impact the innovation diffusion 
process, which includes relative advantage, compatibility, complexity, trialability, and observability (Czepiel 1974).

Diffusion of innovations theory looks at both the adoption and the diffusion of an innovation (Sahin and Thompson 2006). In concert with it, our study examines both the adoption and the implementation of HIE. We however noticed several healthcare specific characteristics, which makes this study unique and worthwhile. First, despite the long history of diffusion of innovations research, the application of the theory to the diffusion of HIE technology seems to be problematic. To be sure, given the difficulties and challenges for HIE adoption and implementation, researchers seem to have limited grasp of the drivers for the diffusion of $\mathrm{HIE}$, which does not seem to follow other technology innovation diffusion patterns. We reason that HIE is a different type of innovation because users of HIEs are often mutually reliant to make the HIE technology work while in the meantime each party maintains its independence. For instance, in a single HIE transaction, a healthcare provider needs to rely on other providers' goodwill to obtain needed patient information. Such a relationship is best described as a social exchange relationship. We thus propose that using diffusion of innovations theory in isolation does not satisfactorily explain the diffusion of HIE. Rather, the social exchange context must be taken into consideration.

\section{Prior Research on Inter-Organizational Relationships}

HIE is in essence an inter-organizational information system in healthcare. Although few studies existed for HIE, research in inter-organizational IS has a long tradition. Because IT evolves at a very fast pace, the past three decades have 
witnessed several major types of inter-organizational IS's appearance and industrial application. Research in inter-organizational IS usually falls into the category of inter-organizational systems (IOS) (e.g. Chatfield and Bjørn-Andersen 1997; Vitale and Johnson 1988). Among different types of technology, what resembles HIE the most is Electronic Data Interchange (EDI) (lacovou et al. 1995, Mukhopadhyay et al. 1995). EDI is explained by Hansen and Hill (1989) as "the movement of information electronically between a buyer and seller for purposes of facilitating a business transaction." EDI allows suppliers and users to exchange different kinds of information (such as sales or manufacturing) which leads to lower costs and higher responsiveness in operations. Many scholars (e.g. Mukhopadhyay et al. 1995) have observed and discussed the benefits of EDI. EDI is the precursor of many other more sophisticated technologies such as just-intime (JIT) (Srinivasan et al. 1994) and vendor managed inventory (VMI) (Claassen et al. 2008). In fact, EDI is still in wide use today.

The rich research in EDI provides us with a solid research foundation for the study of HIE. Indeed, research in EDI has examined factors at individual, organizational level and inter-organizational levels. Based on this earlier research, we critically identify factors that are important and unique to the healthcare industry, and try to use them to explain HIE success. 


\title{
CHAPTER 3. RESEARCH MODEL AND HYPOTHESES DEVELOPMENT
}

\author{
Factors impacting HIE's adoption and use
}

Given the complexity of HIE, it is necessary to examine HIE from a holistic perspective. We believe that the following factors play important roles in influencing the success of HIE. These factors include intra-organizational factors, inter-organizational factors, environmental factors, and characteristics of HIE as an innovation. They exert influences on organizations' risk and relative advantage perceptions, which in turn impacts HIE's adoption and use intentions.

Intra-organizational Factors

Intra-organizational factors are crucial to technology adoption and use within an organization. There is a myriad of these types of factors that have been examined in the IS literature. We identified two essential factors that are instrumental to HIE's adoption and use: 1). top management support, and 2). absorptive capacity.

\section{Top management support}

Top management support is probably indispensable for any new projects to succeed for a company. This is especially the case for information technology initiatives because of their inherent complexity.

As Rai and Patnayakuni (1996) indicated, the importance of topmanagement support for successful implementation of innovations was well accepted. As they argued, implementing a new technology invariably requires 
resources that will be forthcoming only with the active support of top management. Furthermore, strong leadership helps overcome behavioral and technical inertia that accompanies significant changes in everyday job practices and job roles (Rai and Patnayakuni 1996).

Literature in health information technology also shows that top management's support is important. For example, a recent study (Van Laere and Aggestam 2016) shows that the commitment from top management to support a healthcare information system was crucial for its success. Another qualitative study for a healthcare IS implementation at Sentara Healthcare particularly emphasized that the comprehensiveness of the implementation required greater commitment from both the executive leadership and top management support. Yet another study (Payton and Ginzberg 2001) investigating the implementation of interorganizational healthcare systems (an early attempt of HIE implementation) vividly described the roles that top management played: "They (hospital top management) have been the key to gaining Wisconsin Health Information Network (WHIN) support. One is a visionary (CEO); one signs the check (CFO), and one is responsible for delivery (CIO)" (Payton and Ginzberg 2001, p. 9).

\section{Absorptive capacity}

The concept of absorptive capacity was proposed around 1990 by Cohen and Levinthal (1990). Cohen and Levinthal (1989) define absorptive capacity as the ability to learn from external knowledge through processes of knowledge identification, assimilation and exploitation (Camisón and Forés 2010). They argue that the ability of a firm to recognize the value of new, external information, 
assimilate it, and apply it to commercial ends is critical to its innovative capabilities (Cohen and Levinthal 1990). Another review paper (Zahra and George 2002) considers that absorptive capacity includes dimensions of acquisition, assimilation, transformation and exploitation.

The importance of absorptive capacity in IT adoption is well established. For example, a recent study (Spanos 2012) found that absorptive capacity influences firms' intentions to adopt computer integrated manufacturing (CIM) systems. The adoption and the use of HIE can also be influenced by absorptive capacity. Firms with higher levels of absorptive capacity have higher levels of acquisition, assimilation, transformation and exploitation capabilities. It is thus easier for healthcare providers with higher levels of absorptive capacities to adopt and implement HIE.

Inter-organizational factors

\section{Trust}

\section{Trust in SET}

Trust is arguably one of the most important constructs in SET (Lee and Kim 1999). Chadwick-Jones (1976) even proclaims that "If there is no trust, then neither is there social exchange" (p. 342). In explaining the role of trust in social exchange, Blau (1964) states that "since there is no way to assure an appropriate return for a favor, social exchange requires trusting others to discharge their obligations... By discharging their obligations for services rendered, if only to provide inducements for the supply of more assistance, individuals demonstrate their 
trustworthiness, and the gradual expansion of mutual service is accompanied by parallel growth of mutual trust ..." (p. 94). Blau (1964) continues to argue that "only social exchange tends to engender feelings of personal obligation, gratitude, and trust; purely economic exchange as such does not" (p.94). He distinguishes social exchange and economic exchange. According to him, "the basic and most crucial distinction is that social exchange entails unspecified obligations. The prototype of an economic transaction rests on a formal contract that stipulates the exact quantities to be exchanged." (p.93) For an economics exchange, whether a transaction is "consummated at a given time, in which case the contract may never be written, or not, all the transfers to be made now or in the future are agreed-upon at the time of sale (p.93)." For economic exchanges, all costs and risks in each transaction have been "duly taken into account in and fully repaid" (Blau, 1964, p. 94).

Social exchange, in contrast, involves the principal that one person does another a favor, and while there is a general expectation of some future return, its exact nature is definitely not stipulated in advance" (p. 93). "In contrast to economic commodities, the benefits involved in social exchange do not have an exact prize in terms of a single quantitative medium of exchange, which is another reason why social obligations are unspecific... The actors themselves cannot precisely specify the worth of approval or of help in the absence of a money price." (Blau, 1964). Social exchange "involves favors that create diffuse future obligations, not precisely specified ones, and the nature of the return cannot be bargained about but must be left to the discretion of the one who makes it (p. 93)." "Trust is of the 
essence of a social exchange and as mutual trust flourishes so does the extent and commitment to the exchange... it becomes all the more obvious that if the return in a social exchange cannot be precisely specified (or if it cannot be bargained about), these are conditions which are entirely different from an economic exchange " (Chadwick-Jones 1976, p. 294-295). Stephane Bignoux (2006) also argues that in contrast to pure economic exchanges, the benefits from social exchange is voluntary for parties to provide benefits. Thus, SET focuses on "the social relations and personal ties among the actors that shape the exchange of resources and benefits. Personal ties are the bonds that result from successful, mutually rewarding interactions over time. They are founded upon trust, reciprocation and reward." (p. 618).

Blau (1964) also emphasizes that the development of trust is a gradual process. In contrast, time plays no role in economic exchanges—-the arm's length transactions are the same the first time or many times later. According to Blau (1964), social exchange often starts with some friendly and small exchanges whose rewards are often of extrinsic in nature. The "gradual development of an exchange permits the test of trustworthiness during the initial stages of a relationship where there is little commitment. As mutual trust grows the content of exchange becomes more varied and as it begins to include device, help, social support, or companionship, these transactions will produce some intrinsic significance for the relationship - at this point, the differences between economic and social exchange are at their greatest." (Chadwick-Jones 1976, p. 328). 
Despite trust's importance, among the social exchange theorists, only Blau (1964) discussed the role of trust in-depth. Other scholars, such as Homans (1958), Thibaut and Kelley (1959), almost mentioned none of the roles that trust played in social exchange. The reason is that these authors have not given much thought about the impacts of "information scarcity" (Chadwick-Jones 1976, p. 111) for the social exchange actors. The early work of these authors, except for Blau (1964), implies that actors would automatically notice any unfair treatment in exchange and make consequent adjustment to it. Blau (1964) on the other hand has noticed the intricacies of trust and thus has conducted in length discussion of many aspects of it. For example, Blau (1964) contends that although future obligations are not specified, exchange parties have fairly precise expectations regarding how much each has contributed to the exchange and consequently, how much the other party should repay one's favor. If actor A considers that act B has violated his trust, the consequences are not only withdrawn behavior or power shift (as discussed by other researchers) but also resentments (such as anger) and possible aggressive behavior (retaliation). Chadwick-Jones (1976, p. 295) identifies a crucial difference between Blau (1964) and Thibaut and Kelley (1959)'s work: Blau (1964), suggests that "much of social exchange does not lend itself to a payoff treatment with quantified outcomes." The game theory matrix that Thibaut and Kelley (1959) developed, on the other hand, treats social exchange "only with quantified outcomes within the control of laboratory designs, so that experimenters can allocate points or money to the alternative outcomes (see Chapter 3, p.33)" (p. 295). 


\section{Trust in organizational theories}

Scholars later have extensively studied the role of trust in social interactions. For example, trust plays important roles in both agency theory (Jensen and Meckling 1976) and transactional cost economics (TCE) (e.g. Coase 1937; Williamson 1975; Williamson 1979). We mention these theories because they are both very relevant to social exchange and these theories later have been developed for the study of inter-organizational relationships. Agency theory is concerned with resolving two problems that can occur in agency relationships (Eisenhardt, 1989). According to Eisenhardt (1989), agency problems arise when "(a) the desires or goals of the principal and agent conflict and (b) it is difficult or expensive for the principal to verify what the agent is actually doing" (p. 58). Social exchange relationship can be viewed as a multi-agent interaction. Although in social exchange, no specific terms are stipulated, each actor has his or her expectations of what the other party should perform reciprocally. These expectations are governed by complex functions of a society such as norms (Blau, 1964). In inter-organizational relationships, one party often needs to fulfill its responsibility without the possible monitoring of the other party and thus agency problem arises. This problem however can be effectively mitigated if enough trust exists between exchange parties (Chadwick-Jones 1976).

Trust is also important in TCE because it is one of the fundamental factors that distinguishes different governing mechanisms. TCE posits that there are different governing mechanisms to reduce transaction costs. TCE theorists first identify two major types of governing mechanisms, market and hierarchy (e.g. 
Coase 1937; Williamson 1975). In these two types of mechanisms, trust can be largely absent (especially in the market mechanism). Scholars also noticed another type of governing mechanism that was different from the aforementioned types. Rather, this third type seems to reside in between market and hierarchy. Realizing the limitations of these governing mechanisms, researchers began to explore alternative explanations (e.g. Granovetter 1985, Coleman 1988, Uzzi 1997). Ouchi (1980) proposes a taxonomy categorizing three basic mechanisms of mediation or control: markets are efficient when performance ambiguity is low and goal incongruence is high; bureaucracies are efficient when both goal incongruence and performance ambiguity are moderately high; and clans are efficient when goal incongruence is low and performance ambiguity is high. This new type of governing mechanism manifests in such concepts as organizational networks (e.g. Tsai 2001) and researchers have developed theories such as the relational view of the firm (Dyer and Singh 1998) to explain its functions.

Social exchange between organizations exhibit almost identical characteristics to the social exchange between individuals. Das and Teng (2001) contend that social exchanges may or may not involve extrinsic benefits with objective economic value. In contrast to economic exchanges, the benefits from social exchanges often are not contracted explicitly, and it is voluntary for a party to provide benefits for another. As a result, exchange partners are uncertain whether they will receive benefits. Once again, when traditional governance system is absent and the action of the other party is uncertain, trust is indispensable in maintaining the ongoing exchange relationship. 
The lack of formal governing mechanism makes self-enforcement indispensable in a voluntary participation based inter-organizational networks. In developing the relational view of the firm, Dyer and Singh (1998) discuss the important role of trust. According to these authors, governance "plays a key role in the creation of relational rents because it influences transaction costs, as well as the willingness of alliance partners to engage in value-creation initiatives... informal social controls supplement and often supplant formal controls" (p. 669). Dyer and Singh (1998) continue to argue that "informal self-enforcing agreements may rely on personal trust relations (direct experience) or reputation (indirect experience) as governance mechanisms. A number of scholars have suggested that informal safeguards (e.g., goodwill trust) are the most effective and least costly means of safeguarding specialized investments and facilitating complex exchanges (Dyer and Singh 1998, Hill 1995, Uzzi 1997).

\section{Environmental factors}

\section{Environmental Uncertainty}

Uncertainty is a construct that is commonly seen in strategy (Waldman et al. 2001). Much discussion about uncertainty is concerned with environmental uncertainty. This construct is important because it exerts influence on decisionmaking-people would make different decisions under different levels of uncertainty.

We argue two types of uncertainty are especially salient in HIE. First, there is government policy uncertainty. Compared to other industries, healthcare is 
strongly influenced by government policy. For instance, the meaningful use stage III criteria from the HiTech Act (HealthIT n.d.) have explicit incentives or sanctions for organizations who meet or do not meet government requirements by certain deadlines. In addition, given the complexity of healthcare and the scope of coverage, certain healthcare policies are not clearly spelled out, which causes uncertainty as well.

Another source of government policy uncertainty originates from the inconsistent healthcare policy (Jin et al. 2009), due to factors such as transitions between different administrations. Because HIE involves significant upfront investment, providers will be unwilling to join HIEs when there is a possibility that HIE might lose policy support.

\section{Adoption pressures}

One dimension of diffusion of innovations is voluntariness. Voluntariness is defined as "the degree to which use of the innovation is perceived as being voluntary, or of free will" (Moore and Benbasat 1991, p.195). We postulate that voluntariness is an important environmental factor in HIE adoption for the following reasons. First, as generally accepted in the theory, when examining the diffusion of innovations, consideration must be also given to whether individuals are free to implement personal adoption or rejection decisions (Moore and Benbasat 1991). The institutional adoption/use behavior of HIE is sometimes beyond the control of the institution. For example, Stage III meaningful use requires healthcare providers to use HIE. Such policies directly affect healthcare providers' HIE adoption/use behavior and thus cannot be overlooked. Second, voluntariness is influenced by 
the social exchange relationship. SET emphasizes voluntary participation. Indeed, no social exchange relationship would exist if one party is not motivated enough to join and stay in. Researchers (Thibaut and Kelley 1959) also argue that social exchange happens only when both actors receive benefits higher than "comparison level alternatives" (p.21), the threshold to stay in an exchange relationship.

Adding healthcare contextual factors, we expanded the construct voluntariness by developing a construct of HIE adoption pressure. In addition to components of voluntariness, the measure also captures pressure originating from government policy and patients' expectations.

HIE characteristics as an innovation

Theorists (Moore and Benbasat 1991) consider that perceived characteristics of using an innovation, as opposed to the primary characteristics of innovations, should be used to measure the utility of an innovation. The reason is that different adopters perceive primary characteristics in different ways, and thus their adoption behaviors may differ (Moore and Benbasat 1991). Rogers (1983) identified five general attributes of innovations that would influence adoption. Based on Rogers' work, Moore and Benbasat (1991) used the following definitions for these characteristics:

- Relative Advantage: the degree to which an innovation is perceived as being better than its precursor; 
- Compatibility: the degree to which an innovation is perceived as being consistent with the existing values, needs, and past experiences of potential adopters;

- Complexity: the degree to which an innovation is perceived as being difficult to use;

- Observability: the degree to which the results of an innovation are observable to others; and

- Trialability: the degree to which an innovation may be experimented with before adoption.

Moore and Benbasat (1991)'s study found that observability, as originally defined by Rogers, seemed to tap into two distinctive constructs: result demonstrability and visibility. Result demonstrability is tangibility of result, including observability and communicability. Visibility is the degree to which the results of an innovation are visible to others (Van Slyke et al. 2004).

These qualities are important for HIE adoption/use as an innovation. Researchers have repeatedly mentioned the importance of compatibility of HIE to the existing system. Rudin et al. (2014) cited that workflow and compatibility are significant barriers of HIE. They also concluded that the complexity of integrating current systems with an HIE is a sustainable challenge. Result demonstrability in HIE refers to how non-HIE adopters view the impact of HIE by its users. HIEs often cluster in a confined geographic area due to the ease of local information exchange. Healthcare providers usually are keenly aware of the results of HIE usage. Rogers and Kincaid (1981) observed that opinion leaders' adoption of 
innovations can have a significant effect on other peers in the network (Yaraghi et al. 2014). Our experience with Florida HIE also shows that early adopters were usually large, resource abundant hospitals. Other providers tend to adopt if they see positive results with from early adopters.

Similar to result demonstrability, if an HIE is more visible, it is more conducive to the diffusion of the technology. Researchers (Agarwal and Prasad 1997) argue that visibility is important to adoption intention but not continuous intentions. Their study result suggests that while the omnipresence of a technology may compel potential adopters to utilize it in the near term, such an effect may not be sustained after initial usage. Lastly, trialability also contributes to adoption/continuous intentions although the effect should be technology context specific.

Mediators

\section{Relative advantages}

Relative advantage is a concept in the theory of diffusion of innovations. Introduced by Rogers (1962), relative advantage refers to benefits that people gain by adopting a new technology as compared to its predecessor. Rogers defines relative advantage as the degree to which using an innovation is perceived as being better than using the practice it supersedes (Choudhury and Karahanna 2008, Rogers 1995).

Moore and Benbasat (1991)'s work was one of the earlier explorations to empirically examine relative advantage. For these authors, relative advantage 
covers quality, efficiency, effectiveness, and productivity gains by using an innovation. We believe that relative advantage explains healthcare providers' motivations to adopt and implement HIE. Furthermore, we also consider healthcare specific relative advantage. We conceptualize that there are three types of relative advantage: financial, operational, and technological. In addition, the roles that healthcare specific relative advantage plays in HIE diffusion must be emphasized. First, financially, healthcare providers can greatly benefit from government incentives related to HIE. For instance, HITECH act (Blumenthal 2010) has stipulations regarding financial incentives. Healthcare providers that meet meaningful use Stage III criteria by certain deadlines would receive financial compensation. Similarly, financial incentives also come from other levels of governments, some through federal grants (Lorenzi 2003). Second, some of the relative advantages of HIE reside in the social exchange relationship. When patients' records are exchanged, healthcare providers are more likely to improve their healthcare efficiency and quality (Daniel and Mensah 2015).

\section{Risks}

Webster dictionary defines risk as the possibility that something bad or unpleasant (such as an injury or a loss) will happen. We extend the diffusion of innovations theory and propose that risk is a dimension that researchers should consider. Indeed, in many cases, risk is the opposite of relative advantage. Adding risk to the theory not only makes the theory richer but also enables scholars to empirically test it. 
Similar to relative advantage, we conceptualize that there are three aspects of risks to be considered for HIE adoption: financial, operational, and technological. Of the three aspects of risks, there can be either a general kind of risk or healthcare context specific risk. For example, a general type of financial risk can be risk related to IT investment, such as the failure to recuperate an HIE investment. A general type of operational risk can be workflow interruptions, which commonly happen during HIT implementation (Cochran et al. 2015). Healthcare specific types of risk include concerns such as losing patients and consequently losing revenue. This happens because patients' medical records are shared among different providers, which gives patients a higher degree of mobility in choosing/switching healthcare providers. Risk can also be understood through the lens of SET. For example, losing patients due to sharing of patient information among providers is an inherent type of risk originating from social exchange (Blau 1964).

The dependent variables-HIE adoption and continuance intentions

IS literature distinguishes two types of user intentions - IS pre-adoption and IS post-adoption. This study simultaneously examines both variables: healthcare providers' intention to adopt HIE and healthcare providers intention to continuously use HIE.

\section{Adoption intentions for IS pre-adoption}

IS usage can be viewed as a temporal process with at least two critical stages_-pre-adoption and post-adoption (e.g. Ahuja and Thatcher 2005; 
Karahanna et al. 1999). For example, the research of Davis (1989) shows that use intentions precedes actual use. Possibly, due to the fast development of information technology, research on adoption has been largely focusing on preadoption until the late 1990s. As Karahanna et al. (1999, p.184) lamented, "the temporal dimension of the adoption process - i.e., the sequence of activities that lead to the initial adoption and subsequent continued usage of an IT innovation ...-has been ignored".

Understanding HIE's adoption intention (use intention) is undoubtedly important. Any innovation or technology must be first tried out before its continuous use. The enablers or barriers for healthcare providers to join an HIE must be first understood. To date, we are not aware of any similar studies which empirically and holistically examine factors that influence healthcare providers' intentions to adopt HIE. Existing IS adoption literature, although useful, might not provide enough guidance for both academics and industry because after two decades of continued efforts, HIE's adoption and use still face a multitude of challenges.

\section{Continuance intentions for IS post-adoption}

The result of adapting an innovation is its subsequent use. For some information systems, continuous use is an automatic result of adoption. For HIE, on the other hand, it is not necessarily the case. Repeated efforts of healthcare organizations to adopt HIE in the past decade are good indications of strong HIE adoption intentions. 
Very often, even if the initial HIE implementation seems to be successful, HIE still does not have long-term viability. For example, the Santa Barbara county care data exchange was once considered one of the most ambitious and best-publicized health information exchange (HIE) efforts in the United States and a model for emerging regional health information organizations (RHIOs) elsewhere (Miller and Miller 2007). The project has been credited with several innovative approaches, including certification of health information technology vendors, a communitywide governance model, and deployment of a peer-to-peer technical model (Frohlich et al. 2007). Despite its promising outcome, the project ended in December 2006. Indeed, many other HIE projects met similar fates, terminating after several years of existence (HIMSS 2013).

Research has shown that post-adoption behaviors are particularly important in certain industries. For instance, Parthasarathy and Bhattacherjee (1998, p. 362) discuss that continuance of post adoption is of "primary concern" for online service firms for three reasons. First, Rust and Zahorik (1993) argue that effective subscriber base, and hence their market share and revenues, are determined by the net difference between the number of new subscriptions (initial adoption) and number of discontinuers in that period. Second, negative interpersonal influence of service discontinuers is generally more persuasive than positive interpersonal influence. This could trigger further discontinuance by other subscribers while preventing new adopters from subscribing, despite positive influences from other sources (Parthasarathy and Bhattacherjee, 1998). Third, acquiring new customers is more expensive for online service firms than 
retaining existing customers. Reasons include the search costs associated with identifying new customers, start-up costs involved in setting up new accounts, and time spent by customer service and technical support personnel in initiating new customers to the service (Parthasarathy and Bhattacherjee, 1998).

HIE is different from the online service example mentioned above. In terms of post-adoption behavior, however, HIE bears strong resemblance. First, HIE users, like online service customers, do not normally develop HIE infrastructures in-house. Rather, HIE users usually use services developed by a third-party (Florida-hie.net n.d.). Second, providers often subscribe HIE services, which is similar to online services in terms of subscription. For example, as of July 1, 2014, all three major types of Florida HIEs have subscription services as its marketing strategy, with both PLU and ENS requiring a base annual fee (Florida-hie.net n.d.). Many HIEs infrastructures are set up through government grants and healthcare providers are the only users of the HIE service.

Parthasarathy and Bhattacherjee (1998) contend that a major difference between subscription-based IT services and conventional IT services is their cost structure. According to these authors, subscription-based IT service requires minimal initial setting up from users' end and adopters pay a flat charge or a usage-based fee for using the service. In comparison, for conventional IT services, adopters incur a large initial cost in acquiring the product or service and have minimal operating costs thereafter. Adoption of conventional IT services products or services is thus risky because it tends to lock-in adopters once the initial adoption decision is made. Discontinuance of a service might involve 
considerable sunk costs (initial purchase price for products and termination fee for services). In contrast, subscription-based services are less risky in that they do not require a large initial investment and they can be discontinued at any time without significant sunk costs (Parthasarathy and Bhattacherjee, 1998). While an initial adoption decision is very important in the case of IT products and conventional services, post-adoption behavior (continued adoption or discontinuance) assumes greater importance for subscription-based IT services (Parthasarathy and Bhattacherjee, 1998). Post adoption behavior for HIE is thus instrumental for HIE's long-term success.

Despite the similarities between subscription-based IT service and HIE technology, there are also important differences. For example, research about continuance has primarily focused on individual's adoption behaviors (Spiller et al. 2007). In contrast, studies examining post-adoption behavior for organizational users has been scarce (Spiller et al. 2007). Furthermore, IS research of post-adoption behavior in healthcare organizations is even more scant. We stress this point because healthcare is fundamentally different from other industries, and thus post-adoption behaviors are likely to be influenced by factors that are unique to the industry. One factor is government incentives. For HIE projects, it is very common that governments would first spend sizable amounts of money setting up an HIE infrastructure and then encourage providers to join. For example, the Santa Barbara County Care Data Exchange was funded by a $\$ 10$ million, three-year grant by the California HealthCare Foundation(CHCF) (Miller and Miller 2007). The project eventually failed eight 
years later, which apparently was not caused by pre-adoption factors. It is uncommon for other industries to receive large amount of government incentives to encourage IT adoption. Outside funding creates an "artificial market demand" for both pre- and post-adoption of HIE. Research shows that many HIE can be "sustained" only when outside funding continues to exist (Vest et al. 2013). Indeed, research by Adler-Milstein et al. (2013) found that grants and contracts, albeit artificial, were the most substantial source of HIE support, with 52 percent of existing, operational HIEs relying on them. In comparison, less than a quarter of HIEs were able to cover operating costs using revenue generated from customers (Adler-Milstein et al., 2013). As such, the mere investigation of adoption intentions is insufficient. Indeed, the high failure rate of HIE projects has shown that strong adoption intentions and consequent use do not readily translate to HIE success. The success of HIE depends on sustained use rather than merely initial adoption intentions. If an HIE is not sustainable, it will not be successful no matter how strong the initial adoption intentions. The repeated failures of HIE initiatives are extremely detrimental because not only investments are wasted, they also erode confidence of stakeholders. In the meantime, patients suffer because they cannot benefit from the cost and quality improvements offered by an HIE.

In an executive overview, Weber (2001) emphasizes the importance of continuance: "For many information systems, individuals have a choice whether to use the system in the first place. If they decide to use the system, they then have a choice whether to continue to use it. For example, many financial 
institutions offer online banking facilities to their customers. Not only is use of these facilities optional, but customers also have a choice of discontinuing their use of them later. How can firms ensure individual users will continue to use their system over the long term? Just because users have adopted the system initially does not mean they will persist in using it. This issue is important because continuance determines the long-term success of information systems in general" (Weber, 2001, p. 351).

We believe that continuance is an equally important factor to consider for HIE success. SET emphasizes ongoing interaction and gradual building up trust. Most of the important factors governing social exchange are not static in nature; rather they must be developed over time (e.g. Blau 1964). Social exchange starts with initial attraction (Blau 1964) and the relationship is dynamic. This is because both exchange parties are constantly contributing to, and at the same time, benefiting from the exchange, and each party consciously or subconsciously evaluates whether the exchange is worth continuing. For Blau (1964), the evaluation criteria are the rewards that a party derived from the exchange. For Thibaut and Kelley (1959), the evaluation is from comparison between the current exchange and other alternatives. Exchange can move in different directions at any time-a party may be satisfied with the exchange and thus continue, or feel exploited and decide to stop.

The formation and perpetuation of HIE goes through a similar process, and can be explained by SET. For example, the formation of HIE requires initial attraction. Healthcare providers join HIE for potential benefits that HIE promises 
when all participants exchange patient information for mutual benefit. This process is similar to how social groups attract new members mentioned by Blau (1964). Once a provider joins HIE, the provider contributes to and benefits from HIE the same way that a member engages exchange within a social group. Satisfaction derived from exchanges over time determines whether a member will stay or leave the group. Similarly, satisfaction derived from HIE will determine whether users will stay in and use HIE. After all, a voluntary user will continue to be a member only when it perceives that the benefit derived from being a member in an HIE is greater than other alternatives.

The success of HIE largely depends on its continuous use. Many cost controls and quality benefits can be achieved only through the use of an HIE. Given the voluntary nature of HIE participation, a healthcare provider's continuous use is a vital factor for HIE's success. As such, the initial adoption intentions of providers are necessary but not sufficient for HIE success. After all, an HIE will not be successful if users join first and leave later. The mixed success of HIE initiatives for the past decade show that our understanding of factors influencing its continuous use is still limited. The purpose of this study is to consider both the adoption and continuance pieces of the puzzle and to answer a question: what are the factors that lead to HIE success? 


\section{Hypothesis development}

Top management support

There is an abundant of literature and empirical evidence showing that top management support is a crucial factor for IS success. We argue that top management support affects HIE success through an organization's perceptions of risk and relative advantage. Researchers (Kwon and Zmud 1987) assert that successful IS implementation occurs when sufficient organizational resources are directed toward motivating and sustaining an implementation effort (Thong et al. 1996). These resources include sufficient funding, technical skills, etc. (Thong et al. 1996). Because both risk and relative advantage have financial and technical dimensions, it is conceivable that a positive relationship between top management support and IS implementation success is mediated by reduced risk and increased relative advantage. A healthcare provider with stronger top management support is likely to allocate more technical resources to its HIE project. More technical resources, in turn, are more likely to successfully implement an HIE system with higher quality. Healthcare literature shows that successful information technology adoption and implementation occur when strong top management support presents (McFadden et al. 2009). Because HIE is a type of HIT, it is reasonable to expect that top management support is instrumental to HIE success as well. We thus hypothesize the following:

H1: Top management support negatively affects Risk.

H2: Top management support positively affects relative advantage. 
Absorptive capacity

Absorptive capacity is a firm's ability to identify, assimilate, transform, and apply valuable external knowledge (Roberts et al. 2012). A seminal paper by Cohen and Levinthal (1990) particularly focuses on learning and innovation. Because HIE is a type of innovation, we propose that it is influenced by absorptive capacity. Roberts et al. (2012) undertook a thematic analysis to assess the role of absorptive capacity in the IS literature. Their findings showed that absorptive capacity impacts operational efficiency, which is a dimension of risk and relative advantage. They also found that absorptive capacity influences IT-based outcomes as well as organizational effectiveness, which are also components of risk and relative advantage. Healthcare providers with higher levels of absorptive capacity are more likely to adopt and effectively use HIE because they possess higher levels of capabilities. We thus propose the following:

H3: Absorptive capacity positively affects relative advantage.

H4: Absorptive capacity negatively affects Risk.

Trust

Lee and Kim (1999) define trust in an inter-organizational relationship context as "the firm's belief that the other company will perform actions that will result in positive outcomes of the firm, and will not take unexpected actions that would result in negative outcomes for the firm." Literature using SET studying inter-organizational IS has shown that trust is indeed indispensable in inter-firm 
relationships (e.g. Allen et al. 2000). For example, Muthusamy and White (2005) examined learning and knowledge transfer in strategic alliances and found that social exchanges such as reciprocal commitment, trust, and mutual influence between partners had a positive impact. They argue that since the relationship in SET is voluntary and there is no way to assure an equivalent return of a favor for a party, social exchange requires trusting others to discharge their obligations. Research by Son et al. (2005) shows that the relationship between trust and EDI usage is positive.

We believe that trust used at the organizational level of research fits the context of HIE. Literature usually considers trust having three dimensions: ability, benevolence, and integrity (Venkatesh and Bala 2012). First, for an HIE, ability is important because a participating healthcare provider of HIE needs to know that other providers (as well as the whole HIE system) are capable of providing them with information they need in a timely manner. Second, in terms of benevolence, a provider needs to know that if it requires patients' information, other HIE members would be willing to provide assistance. Third, a provider should have faith that other providers are honest with them (such as observing the common norms of the profession-Narasimhan et al. 2009) and are responsible (such as providing accurate information).

Despite the above-mentioned similarities between traditional IS research and HIE, the unique characteristics of HIE still make it different from general IT. One critical difference is that traditional IS research usually examines the dyad of relationships between social exchange partners, whereas HIE involves multiple 
actors. Although multiple actors' social exchanges have been discussed in literature since the first appearance of SET (e.g. Thibaut and Kelley 1959), there is a dearth of empirical research studying such relationships, especially in healthcare settings. Indeed, as Das and Teng (2001) lamented, developing trust among multiple partners is particularly problematic in constellations, and this happens when the need for trust is especially high in generalized social exchanges. Trust not only reduces transaction cost but also encourages exchange parties to adhere to the cooperative spirit and go beyond the contract when facing uncertainties and ambiguities.

We further propose that trust influences healthcare providers' intentions through risk and relative advantage. We measure two types of trust: trust among HIE participants and trust in the broad HIE system. When a healthcare provider has a higher level of trust to other HIE participants and an HIE system, it is more likely to join an HIE. For the existing HIE users, a higher level of trust makes cooperation and coordination among healthcare providers easier. It is well established that in inter-organizational relationships, trust reduces transaction cost (Bromiley and Cummings 1995) and increases relational rent (Dyer and Singh 1998), which is a source of competitive advantage. Better cooperation is thus likely to reduce the financial and operational aspects of risk and in the meantime improve relative advantage. The following is thus proposed:

H5: The greater a provider's trust, the greater relative advantage.

H6: The greater a provider's trust, the lesser risk. 


\section{Environmental uncertainty}

Thompson (1967) views uncertainty as a negative environment factor that needs to be controlled. In fact, he suggests that one of the major goals of any organization is to control the environment and reduce uncertainty. Other research (e.g. Sia et al. 2004) states that uncertainty affects organizational change and innovation. In a study about enterprise systems adoption, Hwang (2005) found that uncertainty avoidance positively impacts perceived ease of use. Although the uncertainty avoidance that Hwang (2005) measured related to individual perceptions of job characteristics, which is different from the focus of this study, the consequences of the measures are similar, one being HIE adoption and the other being ERP adoption. The construct of perceived ease of use overlaps with relative advantage. It is thus reasonable to postulate that uncertainty impacts relative advantage. Because uncertainty refers to the lack of assurance about future success, it relates to possible negative outcomes. Therefore, a higher level of uncertainty would be associated with a higher level of perceived risk.

In another study, Sia et al. (2004) investigated how environmental uncertainty shapes organizational attitudes toward adopting innovative work practices such as Distributed Work Arrangements. They found that uncertainty is negatively related to relative advantage. Empirical evidence seems to support such a notion. For example, Adler-Milstein and Jha (2012) conclude that uncertainty about the legal ramifications of a data breach or unauthorized access through HIE is a barrier to HIE adoption. The implied meaning is that uncertainty increases risk and reduces relative advantage. We thus propose the following: 
H7: The greater the environmental uncertainty, the lower the perceived relative advantage.

H8: The greater the environmental uncertainty, the greater the perceived risk.

Adoption pressure

The measure of adoption pressure was based on the construct of voluntariness (Moore and Benbasat 1991, Van Slyke et al. 2004), and we added a policy dimension that we developed. One component of adoption pressure is patients' expectations. Patients are the customer of providers so healthcare organizations must be sensitive to their needs. Detmer (2003) reported that meeting patients' expectations for efficient access to health information is a motivator for clinicians to adopt HIE. The author also lists this factor as improvement goals for "patient experience" (p. 260). Patient experience is one of the components of relative advantage of HIE. We also argue that when patients' expectations for HIE are high, certain risks (such as operational risks) are reduced because HIE implementers (providers) know that HIE would satisfy customers' needs.

Adoption pressure includes government policy pressure for HIE adoption. The past decade has seen strong financial and policy support for HIE. When government policy pressure is high, policy support tends to be high as well, such as Meaningful Use incentive programs. The following are thus proposed:

H9: The greater adoption pressures, the greater relative advantage.

H10: The greater adoption pressures, the lesser risk. 
HIE Characteristics as an innovation

HIE characteristics capture innovation characteristics in the healthcare context (Moore and Benbasat 1991, Rogers 1983). This measure is developed based on the operationalization by Van Slyke et al. (2004). It includes five components: compatibility, complexity, result demonstrability, visibility and trialability. Many studies have examined the relationship between innovation characteristics and adoption/use intentions. For example, Van Slyke et al. (2004) investigated perceived innovation characteristics on intention to use groupware. They found that compatibility positively relates to use intention and that complexity negatively relates to use intention. We argue that innovation characteristics as a whole impact adoption/use intentions but through risk and relative advantage. It is conceivable that if an HIE is perceived as complex, it is likely to be perceived to be expensive and difficult to implement, because such technologies tend to cause higher technological, financial and operational risk. On the other hand, HIE perceived to be compatible, visible, result demonstrable and triable tend to remove user barriers for adoption. We thus propose the following:

H11: The greater HIE characteristics as an innovation, the greater the perceived relative advantage.

H12: The greater HIE characteristics as an innovation, the lower the perceived risk. 
Mediating roles of relative advantage and risk

Studies on innovation generally consider that there is a positive relationship between relative advantage and IS adoption. For example, Van Slyke et al. (2004) found that relative advantage positively leads to use intention. Another study (Sia et al. 2004) found the same result. Relative advantage and risk in our study include both financial, technical, and operational dimensions. Relative advantage and risk have opposite effects on HIE adoption and continuous use. An HIE that has a higher level of relative advantage and a lower level of risk in these three dimensions should lead to both higher HIE adoption and continuance intensions. Thus, we propose the following:

H13: The greater the relative advantage, the greater the adoption/continuance intentions.

$\mathrm{H} 14$ : The greater the risk, the lower the adoption/continuance intentions.

\section{CHAPTER 4. RESEARCH METHODOLOGY}

Conceptual development

This research starts with extensive prior qualitative research about HIE. The author was a co-investigator for a 3-year Florida HIE evaluation grant, which provided him with many opportunities to understand multiple challenges healthcare providers had with HIE adoption and implementation. For example, the author participated in both technical and non-technical Florida HIE monthly meetings which dealt with both technical and managerial issues. 
Based on intimate practical knowledge, we started the conceptual development with a comprehensive literature review. Emphasis was placed upon both qualitative and quantitative research papers that were relevant to HIE adoption and implementation. The scope of the literature review was comprehensive. It encompassed multiple domains where HIE was a topic of interest. Literature covered included disciplines such as management information systems, healthcare, healthcare policy, and sociology, to name a few. The literature review helped identify prominent, novel issues related to HIE adoption and implementation, which narrowed down the scope of this research to factors that were both important and understudied.

Interviews with subject matter experts were conducted to develop a deeper understanding of the nature of problems under investigation. All subject matter experts who participated in the interviews had extensive exposure and knowledge about HIE. Typical participants included healthcare organization top management personnel (such as CEOs or CIOs), government agency employees, physicians, and provider technology lead individuals.

Interviews were conducted iteratively. The first round of interviews, a less formal type, were conducted during the initial research model conceptualization phase. Some were conducted by the author. Secondary qualitative data were collected based on interviews by the authors' advisors and colleagues. All secondary interview data were either audio recordings or transcriptions of audio recordings. The second round of interviews were conducted throughout the conceptual model development phase and measure development. 


\section{Scale development}

The scale development of this study is based on procedures outlined by Moore and Benbasat (1991). Once the research model was finalized, a comprehensive literature review was conducted as the basis for scale development. There are two types of measures in our research model.

We used literature review to identify any existing operationalizations for all constructs, which was the starting point for construct development and measure refinement. Constructs adopted from existing literature include top management support, absorptive capacity, trust, HIE innovation characteristics (measures based on the dimensions of Rogers' ( 2003) diffusion of innovations.)

We also developed the following constructs which were both novel and healthcare specific: environmental uncertainty, adoption pressures and risk. Another construct, relative advantage, was developed based on an existing measure but was greatly modified to be suitable for the HIE context. We first reviewed relevant literature and definitions of these constructs. Combined with subject expert interviews, we developed, selected, and purified items based on construct validity criteria (Nunnally and Bernstein 1994). Items that failed to satisfy various validity criteria (e.g. poor content validity) were dropped. Item purifications were done through a $\mathrm{Q}$ sorting procedure as discussed below.

Q sorting

We followed the procedures suggested by Moore and Benbasat (1991). According to the authors, $Q$ sorting is useful to determine if (1) all facets of a 
construct are measured (i.e., content validity) and (2) the measures for a construct belong together (i.e., convergent validity) and are distinguishable from the measures of other constructs (i.e., discriminant validity) (Rai and Tang 2010). Q sorting was carried out iteratively by using seven information system $\mathrm{PhD}$ students as judges. At each round of $Q$ sorting, a judge was presented with the operational definitions of all constructs and corresponding items created through scale development. Each judge was asked to place items into different categories (constructs). Items that were not correctly placed were discussed, modified, or discarded. Toward the end of the $Q$ sorting, a convergence in the sorting results were observed. We achieved $85 \%$ of correctness with the last round of $Q$ sorting and we did not observe marked improvements with the last three rounds of $Q$ sorting (fifth, sixth and seventh). The final pool of items retained through $Q$ sorting were used for data collection. Table 1 presents operational definitions for all constructs (including dimensions). For the complete list of items used in the questionnaire surveys, refer to Appendix A1.

\begin{tabular}{|l|l|l|}
\hline Constructs & Operational definitions & Key references \\
\hline $\begin{array}{l}\text { HIE adoption } \\
\text { intention }\end{array}$ & $\begin{array}{l}\text { HIE adoption intention is your } \\
\text { organization's willingness to adopt HIE. }\end{array}$ & $\begin{array}{l}\text { (Lee and Kozar } \\
\text { 2008) }\end{array}$ \\
\hline $\begin{array}{l}\text { HIE continuous } \\
\text { intention }\end{array}$ & $\begin{array}{l}\text { Your organization's } \\
\text { willingness/commitment to continue using } \\
\text { the current HIE that your organization } \\
\text { uses. }\end{array}$ & $\begin{array}{l}\text { (Bhattacherjee et al. } \\
\text { 2008) }\end{array}$ \\
\hline $\begin{array}{l}\text { Absorptive } \\
\text { capacity }\end{array}$ & $\begin{array}{l}\text { Your organization's ability to learn and } \\
\text { assimilate new knowledge. }\end{array}$ & $\begin{array}{l}\text { (Cohen and } \\
\text { Levinthal 1989) }\end{array}$ \\
\hline $\begin{array}{l}\text { Top } \\
\text { management } \\
\text { support }\end{array}$ & $\begin{array}{l}\text { The commitment and support for HIE from } \\
\text { your organization's top management. }\end{array}$ & $\begin{array}{l}\text { (Rai and } \\
\text { Patnayakuni 1996) }\end{array}$ \\
\hline Trust & $\begin{array}{l}\text { Your organization's beliefs in, and } \\
\text { willingness to depend on, other healthcare } \\
\text { providers or the HIE systems in exchange } \\
\text { patient information. }\end{array}$ & $\begin{array}{l}\text { (Mayer et al. 1995) } \\
\text { (McKnight et al. } \\
\text { 1998) }\end{array}$ \\
\hline
\end{tabular}




\begin{tabular}{|c|c|c|}
\hline $\begin{array}{l}\text { Trust in HIE } \\
\text { partner's ability }\end{array}$ & $\begin{array}{l}\text { Your belief and trust in other HIE partners' } \\
\text { ability to do what needs to be done for } \\
\text { exchanging patient information. }\end{array}$ & $\begin{array}{l}\text { (Venkatesh and Bala } \\
\text { 2012) } \\
\text { (Muthusamy and } \\
\text { White 2005) }\end{array}$ \\
\hline $\begin{array}{l}\text { Trust in HIE } \\
\text { partner's } \\
\text { benevolence }\end{array}$ & $\begin{array}{l}\text { Your belief and trust in other HIE partners' } \\
\text { care, kindness and generosity in working } \\
\text { together in exchanging patient } \\
\text { information. }\end{array}$ & $\begin{array}{l}\text { (Venkatesh and Bala } \\
\text { 2012) } \\
\text { (Muthusamy and } \\
\text { White 2005) }\end{array}$ \\
\hline $\begin{array}{l}\text { Trust in HIE } \\
\text { partner's } \\
\text { integrity }\end{array}$ & $\begin{array}{l}\text { Your beliefs and trust in other HIE } \\
\text { partners' adherence to moral principles in } \\
\text { working together in exchanging patient } \\
\text { information. }\end{array}$ & $\begin{array}{l}\text { (Venkatesh and Bala } \\
\text { 2012) } \\
\text { (Muthusamy and } \\
\text { White 2005) }\end{array}$ \\
\hline $\begin{array}{l}\text { Trust in the } \\
\text { broad HIE } \\
\text { platform }\end{array}$ & $\begin{array}{l}\text { Your belief and trust in HIE system and } \\
\text { policies. }\end{array}$ & Self-developed \\
\hline $\begin{array}{l}\text { Environmental } \\
\text { Uncertainty }\end{array}$ & $\begin{array}{l}\text { The level of unpredictability in all aspects } \\
\text { relating to HIE, including government } \\
\text { policies, technologies, business } \\
\text { environments and relations. }\end{array}$ & $\begin{array}{l}\text { (Newkirk and } \\
\text { Lederer 2006) }\end{array}$ \\
\hline $\begin{array}{l}\text { Government } \\
\text { policy } \\
\text { uncertainty }\end{array}$ & $\begin{array}{l}\text { The level of unpredictability relating to HIE } \\
\text { in aspects of policy. }\end{array}$ & $\begin{array}{l}\text { (Waldman et al. } \\
\text { 2001) }\end{array}$ \\
\hline $\begin{array}{l}\text { Environmental } \\
\text { technology } \\
\text { uncertainty }\end{array}$ & $\begin{array}{l}\text { The level of unpredictability relating to HIE } \\
\text { in aspects of technology. }\end{array}$ & $\begin{array}{l}\text { (Newkirk and } \\
\text { Lederer 2006) }\end{array}$ \\
\hline $\begin{array}{l}\text { Adoption } \\
\text { pressures }\end{array}$ & $\begin{array}{l}\text { The extent of pressure or voluntariness } \\
\text { that your organization faces in HIE } \\
\text { adoption. }\end{array}$ & $\begin{array}{l}\text { (Moore and } \\
\text { Benbasat 1991) } \\
\text { (Van Slyke et al. } \\
\text { 2004) }\end{array}$ \\
\hline $\begin{array}{l}\text { HIE } \\
\text { characteristics } \\
\text { as an innovation }\end{array}$ & $\begin{array}{l}\text { As a new innovation, how HIE's } \\
\text { characteristics (compatibility, complexity, } \\
\text { result demostrability, visibility, and } \\
\text { triability) compare to an existing } \\
\text { technology. }\end{array}$ & (Rogers 1962) \\
\hline $\begin{array}{l}\text { Risk of the } \\
\text { organization }\end{array}$ & $\begin{array}{l}\text { The possibility of incurring a financial, } \\
\text { operational or technological loss because } \\
\text { of joining/using HIE. }\end{array}$ & Self-developed \\
\hline $\begin{array}{l}\text { Risk of the } \\
\text { organization- } \\
\text { financial aspect }\end{array}$ & $\begin{array}{l}\text { Financial risks that might arise from your } \\
\text { joining/using HIE }\end{array}$ & (Vest et al. 2013) \\
\hline $\begin{array}{l}\text { Risk of the } \\
\text { organization - } \\
\text { operational } \\
\text { aspect }\end{array}$ & $\begin{array}{l}\text { Operations aspects of risks that might } \\
\text { arise by joining/using HIE, which includes } \\
\text { all aspects/activities related to the } \\
\text { production of services, including business } \\
\text { functions/processes/relations. }\end{array}$ & $\begin{array}{l}\text { (Iroju et al. 2013) } \\
\text { (Lorenzi 2003) }\end{array}$ \\
\hline $\begin{array}{l}\text { Risk of the } \\
\text { organization- } \\
\text { technological } \\
\text { aspect }\end{array}$ & $\begin{array}{l}\text { Technological risks that might arise from } \\
\text { your joining/using HIE }\end{array}$ & $\begin{array}{l}\text { (Detmer 2003) } \\
\text { (Iroju et al. 2013) } \\
\text { (Rudin et al. 2014) }\end{array}$ \\
\hline
\end{tabular}




\begin{tabular}{|l|l|l|}
\hline $\begin{array}{l}\text { Relative } \\
\text { Advantage }\end{array}$ & $\begin{array}{l}\text { The degree to which using HIE is } \\
\text { perceived to be better than other } \\
\text { alternatives for exchanging patient } \\
\text { information. }\end{array}$ & $\begin{array}{l}\text { (Moore and } \\
\text { Benbasat 1991) } \\
\text { (Choudhury and } \\
\text { Karahanna 2008) }\end{array}$ \\
\hline $\begin{array}{l}\text { Relative } \\
\text { advantage - } \\
\text { financial aspect }\end{array}$ & $\begin{array}{l}\text { Financial advantage that might arise with } \\
\text { your joining/using HIE }\end{array}$ & $\begin{array}{l}\text { (Moore and } \\
\text { Benbasat 1991) }\end{array}$ \\
\hline $\begin{array}{l}\text { Relative } \\
\text { advantage - } \\
\text { operational } \\
\text { aspect }\end{array}$ & $\begin{array}{l}\text { refers to operations aspects of relative } \\
\text { advantage that might arise by } \\
\text { joining/using HIE, which includes all } \\
\text { aspects/activities related to the production } \\
\text { of services, including business } \\
\text { functions/processes/relations. }\end{array}$ & $\begin{array}{l}\text { (Moore and } \\
\text { Benbasat 1991) } \\
\text { (Kuperman and } \\
\text { McGowan 2013) }\end{array}$ \\
\hline $\begin{array}{l}\text { Relative } \\
\text { advantage - } \\
\text { technological } \\
\text { aspect }\end{array}$ & $\begin{array}{l}\text { Technological advantage that might arise } \\
\text { with your joining/using HIE }\end{array}$ & $\begin{array}{l}\text { (Jaworski and Kohli } \\
\text { 1993) }\end{array}$ \\
\hline
\end{tabular}

Table 1: Operational definitions for all constructs

\section{Sample Selection and Data Collection}

We used web-based online surveys (Qualtrics) to collect data. The items were randomly ordered to minimize any bias from the survey method (Xia and Lee 2005). Seven-point Likert scales were used to measure all items.

Qualified respondents were upper management level executives and professionals who are familiar with his/her organizations' HIE efforts. Job titles of typical respondents included $\mathrm{CIO}$, CEO, IT director, and IT manager. Multiple sources were used for the survey to improve the generalizability of the study results. We sent out survey invitations through professional contacts in Florida using email distribution lists. These contacts included the Healthcare Information and Management Systems Society (HIMSS) local chapters and Agency for Healthcare Administration (AHCA). The second source of data collection was the Lexis-Nexis database. CIOs and CEOs who met our selection criteria with valid 
email addresses were invited to participate in our surrey. The third source was Qualtrics Panels. Qualtrics has a data collection service and we used the same respondent selection criteria to collect data.

All potential respondents received a solicitation email describing the purpose of the study with a survey link and a copy of the survey attached to the email. Data collection started in February 2017 and ended in June 2017. Out of a total of 163 responses, 117 surveys were completed and were used for data analysis.

\section{CHAPTER 5. DATA ANALYSIS}

This study uses structural equation modeling (SEM) (Anderson and Gerbing 1988, Kline 2010). SEM is generally viewed as a confirmatory analysis tool (Anderson and Gerbing 1988). By confirmatory, we mean that data is run against the hypothesized theory model and the purpose of analysis is to see whether the data-implied model fits the theory-implied model (Kline 2010). SEM can evaluate both measurement and structural models. According to Anderson and Gerbing (1988), a confirmatory measurement, or factor analysis, model specifies relationships of observed measures to their posited underlying constructs, while the constructs are allowed to inter-correlate freely. A confirmatory structural model then specifies the causal relations of the constructs to one another, as posited by theory.

Considering that formative measures were used for the study, we use partial least squares SEM (PLS-SEM) to analyze the data. Some researchers believe that 
PLS-SEM is especially suitable for developing theories in exploratory research (Hair Jr and Hult 2016). In addition, PLS-SEM can easily handle reflective and formative measurement models, as well as single-item constructs, with no identification problems (Hair Jr and Hult 2016).

\section{Descriptive Analysis}

Out of a total of 163 responses, 117 surveys were completed surveys without missing values. These surveys were retained for data analysis. We first perform a descriptive analysis which is shown below. The majority of respondents held titles such as IT director and $\mathrm{CIO}$, a good indication that the study correctly surveyed perceptions from the desired respondents (Table 2). For the complete list of descriptive statistics of all variables, please refer to Appendix Table B1.

\begin{tabular}{|l|r|r|}
\hline & Frequency & Percent \\
\hline No answer & 2 & 1.7 \\
\hline CEO & 9 & 7.7 \\
\hline CFO & 3 & 2.6 \\
\hline CIO & 26 & 22.2 \\
\hline CMIO & 8 & 6.8 \\
\hline CTO & 4 & 3.4 \\
\hline Director & 6 & 5.1 \\
\hline IT Director & 32 & 27.4 \\
\hline Manager & 9 & 7.7 \\
\hline MD & 9 & 7.7 \\
\hline Other & 9 & 7.7 \\
\hline Total & 117 & 100.0 \\
\hline
\end{tabular}

Table 2: Respondents by job title 


\begin{tabular}{|c|c|c|c|c|c|}
\hline Category & Data type & & & Missing & Total \\
\hline \multicolumn{2}{|c|}{ Ownership } & Public & Private & & \\
\hline & Frequency & 35 & 81 & 1 & 117 \\
\hline & Percent & 29.9 & 69.2 & .9 & 100.0 \\
\hline \multicolumn{2}{|c|}{ Profit status } & For profit & Not-for-profit & & \\
\hline & Frequency & 41 & 76 & & 117 \\
\hline & Percent & 35.0 & 65.0 & & 100.0 \\
\hline \multicolumn{2}{|c|}{ Teaching status } & Teaching & Not teaching & & \\
\hline & Frequency & 58 & 58 & 1 & 117 \\
\hline & Percent & 49.6 & 49.6 & .9 & 100.0 \\
\hline \multicolumn{2}{|l|}{ Location } & Urban & Rural & & \\
\hline & Frequency & 84 & 33 & & 117 \\
\hline & Percent & 71.8 & 28.2 & & 100.0 \\
\hline
\end{tabular}

Table 3: Demographics data of healthcare providers

Test of the Measurement Model

Reflective and formative constructs

There are two broad types of measurement specification: reflective and formative measurement models (Hair Jr and Hult 2016; Hulland 1999). According to Bollen (2007), Hubert M. Blalock was the first social scientist to give systematic attention to the distinction between what he called effect and cause indicators (Blalock 1971). Cause indicators (for formative constructs) are ones in which the indicator affects the latent variable. Effect indicators (for reflective constructs) are the more typical type of indicators that depend on a latent variable (Bollen 2007). 
The reflective measurement model has a long tradition in the social sciences and is directly based on classical test theory (Hair Jr and Hult 2016, Nunnally and Bernstein 1994). Reflective indicators are believed to reflect the unobserved, underlying construct, with the construct giving rise to the observed measures (Hulland 1999). They can be viewed as a representative sample of all possible items available within the conceptual domain of the construct (Nunnally \& Bernstein, 1994). Because these indicators are "reflections" of the same conceptual domain of the construct, they are supposed to be highly correlated. In addition, replacing one indicator by another or omitting one is permissible sometimes because doing so will not change the conceptual domain.

Formative measurement models are based on the assumption that causal indicators form the construct by means of linear combinations (Hair Jr and Hult 2016). Each indicator for a formative construct uniquely and collectively captures a specific aspect of the construct's domain (Hair Jr and Hult 2016). Consequently, omitting one indicator would cause the exclusion of an essential part of a construct domain, which damages the content validity. It is thus of great importance that all indicators must be present to operationalize a formative construct (Diamantopoulos and Winklhofer 2001).

\section{Determination of formative and reflective constructs}

Constructs are not inherently formative or reflective (Bollen 2007). Rather, the specification depends on the construct conceptualization and the objective of the study (Hair Jr and Hult 2016). It is generally agreed upon that the decision whether or not indicators should be modeled in a formative mode relies on 
considerations of theory/substantive knowledge, research objective, and empirical conditions (Chin 1998a). According to Gefen et al. (2000), formative constructs are more appropriate for theory building rather than theory testing. Considering the explorative nature of the study and limited understanding of some new constructs, using formative measurement would be suitable. Fornell et al. (1990) argue that if the indicators are seen as the quantified aspects of a theoretical concept, the indicators are reflective. If, on the other hand, the theoretical variable is a categorization and measurement device for a complex phenomenon in the real world, the indicators are formative.

We followed four guidelines proposed by Jarvis et al. (2003) to determine if constructs used in this study should be formative or reflective. The first guideline relates to the direction of causality between the construct and its indicators. For formative measurement models, the direction of causality flows from the measures to the construct; and for reflective measurement models, it flows from the construct to the measures. The second guideline relates to the interchangeability of the indicators. The indicators need not be interchangeable for formative measurement models but should be for reflective measurement models. The third criterion relates to the issue of whether the indicators should co-vary with each other. Covariation among the indicators is not necessary or implied by formative indicator models, but covariation among the indicators is a necessary condition for reflective indicator models. Finally, the fourth criterion relates to whether all of the measures are required to have the same antecedents and consequences. For the reflective indicator model, since all of 
the indicators reflect the same underlying construct and are assumed to be interchangeable, they should all have the same antecedents and consequences.

Jarvis et al. (2003) further suggested more specific guidelines and suggested that a construct should be modeled as having formative indicators if the following conditions prevail: (a) the indicators are viewed as defining characteristics of the construct, (b) changes in the indicators are expected to cause changes in the construct, (c) changes in the construct are not expected to cause changes in the indicators, (d) the indicators do not necessarily share a common theme, (e) eliminating an indicator may alter the conceptual domain of the construct, ( $f$ ) a change in the value of one of the indicators is not necessarily expected to be associated with a change in all of the other indicators, and (g) the indicators are not expected to have the same antecedents and consequences. On the other hand, a construct should be modeled as having reflective indicators if the opposite is true and the conditions shown in the last column in the table are satisfied.

Researchers also suggest that "actionable indicators" should be used for formative constructs, such as research in success factor study in marketing (Albers 2010, Vinzi et al. 2010). Success factor modeling investigates factors that likely contribute to success in marketing (e.g. retention of customers). As the authors argued, with respect to success factor studies, researchers are not so much interested in supporting hypotheses of the type that a construct such as market orientation has a positive impact on business performance. Such a relationship is highly plausible. Valuable information is only generated for the 
business community if we know the level of impact that the various drivers of market orientation have. The indicators should be actionable, which implies that they must form a construct and not reflect it . As such, the purpose of studies with reflective or formative indicators is different. This perspective is also echoed by Hair Jr and Hult (2016). Success factors in marketing research bears strong resemblance to our study relating to success factors for HIE because our study is mainly concerned with "actionable indicators," as opposed to the benefits of HIE implementation. Based on the above-mentioned criteria, we operationalize the constructs of top management support and use/continue intentions as reflected constructs, and model the other constructs as formative.

Measurement Model Assessment - Reflective

The reflective measurement model assessment is largely based on classic testing theory (Campbell and Fiske 1959, Nunnally and Bernstein 1994). Churchill (1979) recommended using multiple item measures because single item measure is subject to its idiosyncratic error of the item and will not be reliable (Albers 2010). Multiple item measures, on the other hand, tend to balance out the idiosyncratic errors. This allows a researcher to separate the relationships between various constructs from their measurement errors (Albers 2010).

For reflective models, measures represent the effects (or manifestations) of an underlying construct. Reflective indicators (effect indicators) can be viewed as a representative sample of all the possible items available within the 
conceptual domain of the construct (Nunnally and Bernstein 1994). Since a reflective measure dictates that all indicator items are caused by the same construct (i.e., they stem from the same domain), indicators associated with a particular construct should be highly correlated with each other (Hair Jr and Hult 2016). In addition, individual items should be interchangeable, and any single item can generally be left out without changing the meaning of the construct, as long as the construct has sufficient reliability (Hair Jr and Hult 2016). The fact that the relationship goes from the construct to its measures implies that if the evaluation of the latent trait changes (e.g., because of a change in the standard of comparison), all indicators will change simultaneously (Hair Jr and Hult 2016).

Reflective scales follow well-established guidelines for construct specification, item selection and purification, and scale validation. Hair Jr and Hult (2016) consider that for CB-SEM (covariance based SEM), the most important measurement model metrics are reliability, convergent validity, and discriminant validity.

\section{Internal consistency reliability}

The reliability coefficient is used to assess the consistency of the entire scale of a measure, with Cronbach's alpha being the most widely used (Hair et al. 2010). Cronbach's alpha provides an estimate of the reliability based on the inter-correlations of observed indicator variables (Hair Jr and Hult 2016). If internal consistency is low, then the content of items may be so heterogeneous that the total score is not the best possible unit of analysis for the measure (Kline 2010). The values of Cronbach's alpha range between 0 and 1, with higher 
values indicating higher levels of reliability. The generally agreed upon lower limit for Cronbach's alpha is .70, although it may decrease to .60 in exploratory research (Hair et al. 2010).

Cronbach's alpha assumes that all indicators are equally reliable (i.e., all the indicators have equal outer loadings on the construct). But PLS-SEM prioritizes the indicators according to their individual reliability (Hair Jr and Hult 2016). Moreover, Cronbach's alpha is sensitive to the number of items in the scale and generally tends to underestimate the internal consistency reliability (Hair Jr and Hult 2016). The composite reliability takes into account the different outer loadings of the indicator variables. The composite reliability also varies between 0 and 1, with higher values indicating higher levels of reliability. Composite reliability values of 0.60 to 0.70 are acceptable in exploratory research, while in more advanced stages of research, values between 0.70 and 0.90 can be regarded as satisfactory (Hair Jr and Hult 2016). Values above 0.90 (and definitely above 0.95 ) are not desirable because they indicate that all the indicator variables are measuring the same phenomenon and are therefore not likely to be a valid measure of the construct. Specifically, such composite reliability values occur if one uses semantically redundant items by slightly rephrasing the very same question (Hair Jr and Hult 2016). Cronbach's alpha is a conservative measure of reliability whereas composite reliability tends to overestimate the internal consistency reliability. The true reliability usually lies between Cronbach's alpha (representing the lower bound) and the composite 
reliability (representing the upper bound) (Hair Jr and Hult 2016). The results of our data analysis met all these criteria.

\begin{tabular}{|l|r|r|l|r|}
\hline & \multicolumn{1}{|l|}{$\begin{array}{l}\text { Cronbach's } \\
\text { Alpha }\end{array}$} & \multicolumn{1}{|l|}{ rho_A } & $\begin{array}{l}\text { Composite } \\
\text { Reliability }\end{array}$ & $\begin{array}{l}\text { Average Variance } \\
\text { Extracted (AVE) }\end{array}$ \\
\hline Intent & 0.86 & 0.906 & 0.9 & 0.693 \\
\hline Support & 0.858 & 0.91 & 0.897 & 0.64 \\
\hline
\end{tabular}

Table 4: Internal consistency reliability values for reflective measures

\section{Convergent validity}

Convergent validity assesses the degree to which two measures of the same concept are correlated (Hair et al. 2010). Convergent validity and discriminant validity involve the evaluation of measures against each other instead of against an external standard. A set of variables presumed to measure the same construct shows convergent validity if their inter-correlations are at least moderate in magnitude (Kline 2010). For reflective measures, because the indicators are manifestations of (or caused by) the same construct, these indicators should share a high degree of covariance. Convergent validity is measured using outer loadings and average variance extracted (AVE).

Indicators from the same construct should have higher loadings on the same construct. To establish convergent validity, the standardized outer loadings should be. 5 or higher, and ideally .7 or higher (Hair et al. 2010). All indicators in the two reflective constructs met these criteria.

\begin{tabular}{|l|ll|l|}
\hline & Intent & Support \\
\hline Dv1Operation & & 0.822 & \\
\hline Dv2Vendor & & 0.794 & \\
\hline
\end{tabular}




\begin{tabular}{|l|r|r|}
\hline Dv3Mistake & 0.873 & \\
\hline Dv4switch & 0.839 & \\
\hline Top1Auto & & 0.568 \\
\hline Top2ITlead & & 0.876 \\
\hline Top3champ & & 0.874 \\
\hline Top4Under & & 0.865 \\
\hline Top5Willi & & 0.772 \\
\hline
\end{tabular}

Table 5: Outer loadings of reflective indicators

Average variance extracted (AVE) is another measure to check convergent validity. AVE should be .5 or greater to suggest adequate convergent validity (Hair et al. 2010). An AVE value of 0.50 or higher indicates that, on average, the construct explains more than half the variance of its indicators. Conversely, an AVE of less than 0.50 indicates that, on average, more variance remains in the error of the items than in the variance explained by the construct (Hair Jr and Hult 2016). Our data analysis showed that the two reflective constructs meet all these criteria.

\section{Discriminant validity}

Discriminant validity is the degree to which two conceptually similar concepts are distinct (Hair et al. 2010). In contrast to convergent validity, a set of variables presumed to measure different constructs show discriminant validity if their inter-correlations are not too high (Kline 2010). Discriminant validity is accessed using item cross-loadings, Fornell-Larcker criterion, and hetero-trait monotrait ratio (HTMT).

Discriminant validity is based on the rational that indicators should only load high on the "root" construct (from which the indicators are caused) and 
should not load high on any other constructs that do not cause the indicators. Examination of the cross-loadings shows that all indicators load high on their respective constructs and load low on all other constructs.

\begin{tabular}{|c|c|c|c|c|c|c|c|c|c|}
\hline & Absorb & HIEChar & Intent & Pressure & RA & Risk & Support & Trust & Uncer \\
\hline Dv1Operation & 0.357 & 0.386 & 0.822 & 0.23 & 0.369 & 0.316 & 0.26 & 0.478 & 0.07 \\
\hline Dv2Vendor & 0.12 & 0.201 & 0.794 & 0.081 & 0.181 & $0.181^{-}$ & 0.152 & 0.354 & 0.004 \\
\hline Dv3Mistake & 0.288 & 0.302 & 0.873 & 0.186 & 0.324 & 0.266 & 0.253 & 0.428 & 0.098 \\
\hline Dv4switch & 0.14 & 0.148 & 0.839 & -0.022 & 0.172 & -0.19 & 0.085 & 0.293 & 0.031 \\
\hline Top1Auto & 0.118 & 0.077 & $0.038^{-}$ & 0.089 & 0.069 & 0.159 & 0.568 & 0.115 & $0.228^{-}$ \\
\hline Top2ITlead & 0.175 & 0.237 & 0.127 & 0.109 & 0.082 & 0.336 & 0.876 & 0.281 & 0.061 \\
\hline Top3champ & 0.212 & 0.28 & 0.18 & 0.187 & 0.14 & 0.236 & 0.874 & 0.252 & 0.035 \\
\hline Top4Under & 0.079 & 0.173 & 0.188 & 0.114 & 0.055 & 0.196 & 0.865 & 0.185 & 0.015 \\
\hline Top5Willi & 0.271 & 0.317 & 0.374 & 0.181 & 0.32 & 0.292 & 0.772 & 0.386 & 0.033 \\
\hline
\end{tabular}

Table 6: Cross-loadings of reflective indicators

The Fornell-Larcker criterion compares the square root of the AVE values with the latent variable correlations. Specifically, the square root of each construct's AVE should be greater than its highest correlation with any other construct (Hair Jr and Hult 2016). To establish discriminant validity, the square root of each construct's AVE must be larger than its correlation with other constructs. The reflective constructs satisfied these requirements.

\begin{tabular}{|l|r|r|l|l|l|l|l|l|l|}
\hline & Absorb & HIEChar & Intent & Pressure & RA & Risk & Support & Trust & Uncer \\
\hline Absorb & & & & & & & & & \\
\hline HIEChar & 0.663 & & & & & & & & \\
\hline Intent & 0.305 & 0.341 & 0.832 & & & & & & \\
\hline Pressure & 0.588 & 0.553 & 0.174 & & & & & & \\
\hline RA & 0.729 & 0.644 & 0.343 & 0.614 & & & & & \\
\hline Risk & -0.343 & -0.344 & -0.305 & -0.17 & -0.33 & & & & \\
\hline
\end{tabular}




\begin{tabular}{|l|r|r|r|r|r|r|r|r|l|}
\hline Support & 0.237 & 0.299 & 0.248 & 0.179 & 0.198 & -0.325 & 0.8 & & \\
\hline Trust & 0.644 & 0.699 & 0.488 & 0.535 & 0.699 & -0.453 & 0.339 & & \\
\hline Uncer & 0.015 & 0.041 & -0.012 & 0.154 & 0.038 & 0.413 & -0.059 & -0.094 & \\
\hline
\end{tabular}

Table 7: Fornell-Larcker criterion

HTMT measures the ratio of the between-trait correlations to the withintrait correlations. HTMT is the mean of all correlations of indicators across constructs measuring different constructs (i.e., the heterotrait-heteromethod correlations) relative to the (geometric) mean of the average correlations of indicators measuring the same construct (Hair Jr and Hult 2016). A disattenuated correlation between two constructs that is greater than 0.9 indicates a lack of discriminant validity (Hair Jr and Hult 2016). PLS uses bootstrapping to derive a distribution of the HTMT statistic. To be conservative, 5,000 random subsamples were suggested to ensure reliability of results. Bootstrapping can calculate a bootstrap confidence interval. A confidence interval containing the value 1 indicates a lack of discriminant validity. Data analysis show that the correlation was 0.256 , and neither the confidence interval nor the confidence interval corrected included value of 1 . Thus, discriminant validity for the reflective measures were supported.

\begin{tabular}{|l|l|l|}
\hline & Intent & Support \\
\hline Intent & & \\
\hline Support & 0.256 & \\
\hline
\end{tabular}

Table 8: HTMT correlation

\begin{tabular}{|l|c|l|r|r|r|}
\hline & $\begin{array}{l}\text { Original } \\
\text { Sample } \\
(\mathrm{O})\end{array}$ & $\begin{array}{l}\text { Sample } \\
\text { Mean } \\
(\mathrm{M})\end{array}$ & $\begin{array}{l}\text { Standard } \\
\text { Deviation } \\
\text { (STDEV) }\end{array}$ & $\begin{array}{l}\text { T Statistics } \\
(|\mathrm{O} / \mathrm{STDEV}|)\end{array}$ & $\begin{array}{l}\mathrm{P} \\
\text { Values }\end{array}$ \\
\hline Support -> Intent & 0.256 & 0.29 & 0.068 & 3.765 & 0 \\
\hline
\end{tabular}

Table 9: HTMT statistic and significance 


\begin{tabular}{|l|l|l|l|l|}
\hline & $\begin{array}{l}\text { Original } \\
\text { Sample } \\
(\mathrm{O})\end{array}$ & $\begin{array}{l}\text { Sample } \\
\text { Mean } \\
(\mathrm{M})\end{array}$ & $2.50 \%$ & $97.50 \%$ \\
\hline $\begin{array}{l}\text { Support } \\
-> \\
\text { Intent }\end{array}$ & 0.256 & 0.29 & 0.181 & 0.447 \\
\hline
\end{tabular}

Table 10: HTMT confidence interval

\begin{tabular}{|l|l|l|l|l|l|}
\hline & $\begin{array}{l}\text { Original } \\
\text { Sample } \\
(\mathrm{O})\end{array}$ & $\begin{array}{l}\text { Sample } \\
\text { Mean } \\
(\mathrm{M})\end{array}$ & Bias & $2.50 \%$ & $97.50 \%$ \\
\hline $\begin{array}{l}\text { Support } \\
\text { Intent }\end{array}$ & 0.256 & 0.29 & 0.034 & 0.142 & 0.368 \\
\hline
\end{tabular}

Table 11: HTMT confidence interval bias corrected

Measurement Model Assessment—Formative

Formative indicators are observed variables that are assumed to cause a composite variable (Diamantopoulos and Winklhofer 2001; MacCallum and Browne 1993). A measurement perspective based on formative indicators reflects the notion that indicators cause rather than are caused by a latent variable (MacCallum and Browne 1993). Strictly speaking, when a construct is defined as having only causal indicators, the construct is not a "latent variable" in the traditional sense. Rather, it is a linear combination of observed causal indicators plus a disturbance term. This measurement model does not include error terms as causal indicators have (MacCallum and Browne 1993).

Assessing convergent validity and discriminant validity of formatively measured constructs using criteria similar to those associated with reflective measurement models is not meaningful (Chin, 1998).We followed the methodology proposed by Hair Jr and Hult (2016) to examine the measurement 
model. As the authors proposed, the evaluation of formative measurement models requires establishing the measures' convergent validity, assessing the indicators' collinearity, and analyzing the indicators' relative and absolute contributions, including their significance.

\section{Content validity}

Different from reflective measures, which uses indicator reliability to evaluate convergent validity, formative indicators need not have high internal consistency such as Cronbach's alpha (Chin 1998b). Rather, establishing content validity should be the first step to assess a measurement model (Hair Jr and Hult 2016). This step requires ensuring that the formative indicators capture all (or at least major) facets of the construct (Hair Jr and Hult 2016). Examination of content validity is to ensure that the indicators developed for a formative construct have captured the whole construct domain as defined by the researcher (Hair Jr and Hult 2016).

Because of the exploratory nature of our study, content validity is established based on extensive literature review, subject matter experts' interviews and iterative measure developments. In addition, a significant amount of effort was used to examine whether the literature definition and operational definition of constructs corresponds to the operationalizations of the items (Hair Jr and Hult 2016). To establish content validity, we solicited feedback from subject matter experts at the pilot testing phase of the study. The subject matter experts were asked of their opinion regarding the validity of the measures (e.g. if 
the measure made sense). No subject matter experts voiced concern about the items used in the survey, which indicated acceptable content validity.

\section{Multi-collinearity}

Multi-collinearity occurs when seemingly separate variables actually measure the same thing (Kline 2010). Researchers (Diamantopoulos and Winklhofer 2001) also consider that multi-collinearity to be a particular salient issue for formative indicators because a formative measurement model is based on multiple regression. Therefore, the stability of indicator coefficients is affected by sample size and strength of indicator inter-correlations. Multi-collinearity causes several problems. First, high multi-collinearity would render the assessment of indicator validity problematic (Diamantopoulos and Winklhofer 2001) or cause results to be statistically unstable (Kline 2010). Second, high multi-collinearity indicates that indicators contain redundant information and can therefore become a candidate for exclusion (Diamantopoulos and Winklhofer 2001).

Variance inflation factor (VIF) statistics is used to detect multi-collinearity (Gefen et al. 2000). VIF reflects the degree to which standard errors have been increased due to the presence of collinearity (Hair Jr and Hult 2016). In the context of PLS-SEM, a VIF value of 5 and higher indicates potential collinearity (Hair et al. 2011). Formative measurement models for collinearity of indicators are examined by the formative indicators' outer VIF values. The result of our analysis shows that all indicators has VIF values lower than 5 , suggesting our study does not have the issue with multi-collinearity. 


\begin{tabular}{|c|c|}
\hline & VIF \\
\hline Absor1Cando & 1.359 \\
\hline Absor2trainR & 1.039 \\
\hline Absor3Capab & 2.201 \\
\hline Absor4Route & 2.452 \\
\hline Char1Compa & 2.102 \\
\hline Char2CmplxR & 1.152 \\
\hline Char3Demo & 2.398 \\
\hline Char4Visib & 1.393 \\
\hline Char5Try & 1.114 \\
\hline Dv10peration & 1.541 \\
\hline Dv2Vendor & 2.534 \\
\hline Dv3Mistake & 2.248 \\
\hline Dv4switch & 2.936 \\
\hline Pres1Patie & 1.573 \\
\hline Pres2Cmpet & 1.578 \\
\hline Pres3gov & 1.48 \\
\hline Pres4provd & 1.704 \\
\hline Top1Auto & 1.283 \\
\hline Top2ITlead & 3.258 \\
\hline Top3champ & 3.843 \\
\hline Top4Under & 3.541 \\
\hline Top5Willi & 1.429 \\
\hline Trust1Integ & 2.946 \\
\hline Trust2Ability & 2.694 \\
\hline Trust3Bene & 2.894 \\
\hline Trust4HIE & 2.133 \\
\hline Uncertain1Policy & 1.386 \\
\hline Uncertain2Tech & 1.386 \\
\hline ra1Fina & 1.894 \\
\hline ra2Op & 3.523 \\
\hline ra3Tec & 2.998 \\
\hline rk1Fin & 1.919 \\
\hline rk2Op & 3.352 \\
\hline rk3Tec & 2.92 \\
\hline
\end{tabular}

Table 12: All Outer VIF Values 


\section{Significance and Relevance of the Formative Indicators}

Formative indicators collectively give meaning to a formative construct. The outer weight of an indicator can be used to measure the contribution of the indicator to a construct (Hair Jr and Hult 2016). The outer weight is the result of a multiple regression with the latent variable scores as the dependent variable and the formative indicators as the independent variables (Hair et al. 2010). The values of the outer weights are standardized and can therefore be compared to each other. They express each indicator's relative contribution to the construct, or its relative importance to forming the construct (Hair Jr and Hult 2016). In addition, to examine whether formative indicators truly contribute to forming the construct, bootstrapping should be used to test if the outer weights in formative measurement models are significantly different from zero.

\begin{tabular}{|l|r|r|r|r|r|}
\hline & $\begin{array}{l}\text { Original } \\
\text { Sample } \\
(\mathrm{O})\end{array}$ & $\begin{array}{l}\text { Sample } \\
\text { Mean } \\
\text { (M) }\end{array}$ & $\begin{array}{l}\text { Standard } \\
\text { Deviation } \\
\text { (STDEV) }\end{array}$ & $\begin{array}{l}\text { T Statistics } \\
(\text { (O/STDEV|) }\end{array}$ & \multicolumn{1}{l|}{$\begin{array}{l}\text { V } \\
\text { Values }\end{array}$} \\
\hline Absor1Cando -> Absorb & 0.11 & 0.11 & 0.118 & 0.931 & 0.352 \\
\hline Absor2trainR -> Absorb & -0.3 & -0.287 & 0.098 & 3.061 & 0.002 \\
\hline Absor3Capab -> Absorb & 0.595 & 0.579 & 0.187 & 3.18 & 0.001 \\
\hline Absor4Route -> Absorb & 0.31 & 0.313 & 0.193 & 1.61 & 0.108 \\
\hline Char1Compa -> HIEChar & -0.086 & -0.102 & 0.172 & 0.499 & 0.618 \\
\hline Char2CmplxR -> HIEChar & -0.107 & -0.088 & 0.189 & 0.566 & 0.572 \\
\hline Char3Demo -> HIEChar & 0.883 & 0.855 & 0.16 & 5.533 & 0 \\
\hline Char4Visib -> HIEChar & 0.278 & 0.257 & 0.161 & 1.732 & 0.083 \\
\hline Char5Try -> HIEChar & 0.11 & 0.11 & 0.158 & 0.694 & 0.488 \\
\hline Dv1Operation <- Intent & 0.412 & 0.405 & 0.124 & 3.333 & 0.001 \\
\hline Dv2Vendor <- Intent & 0.215 & 0.214 & 0.091 & 2.376 & 0.018 \\
\hline Dv3Mistake <- Intent & 0.356 & 0.351 & 0.072 & 4.92 & 0 \\
\hline Dv4switch <- Intent & 0.214 & 0.214 & 0.077 & 2.766 & 0.006 \\
\hline Pres1Patie -> Pressure & 0.847 & 0.787 & 0.181 & 4.67 & 0 \\
\hline Pres2Cmpet -> Pressure & 0.355 & 0.353 & 0.186 & 1.91 & 0.056 \\
\hline Pres3gov -> Pressure & -0.273 & -0.284 & 0.196 & 1.39 & 0.165 \\
\hline
\end{tabular}




\begin{tabular}{|l|r|r|r|r|r|}
\hline Pres4provd -> Pressure & 0.071 & 0.098 & 0.229 & 0.31 & 0.757 \\
\hline Top1Auto <- Support & 0.154 & 0.139 & 0.106 & 1.45 & 0.147 \\
\hline Top2ITlead <- Support & 0.295 & 0.284 & 0.073 & 4.029 & 0 \\
\hline Top3champ <- Support & 0.246 & 0.241 & 0.049 & 5.017 & 0 \\
\hline Top4Under <- Support & 0.176 & 0.165 & 0.078 & 2.241 & 0.025 \\
\hline Top5Willi <- Support & 0.372 & 0.388 & 0.162 & 2.3 & 0.022 \\
\hline Trust1Integ -> Trust & 0.087 & 0.128 & 0.233 & 0.374 & 0.708 \\
\hline Trust2Ability -> Trust & 0.529 & 0.447 & 0.279 & 1.892 & 0.059 \\
\hline Trust3Bene -> Trust & -0.185 & -0.171 & 0.239 & 0.772 & 0.44 \\
\hline Trust4HIE -> Trust & 0.642 & 0.648 & 0.134 & 4.791 & 0 \\
\hline Uncertain1Policy -> Uncer & -0.046 & -0.008 & 0.334 & 0.138 & 0.891 \\
\hline Uncertain2Tech -> Uncer & 1.023 & 0.954 & 0.238 & 4.307 & 0 \\
\hline ra1Fina -> RA & 0.269 & 0.236 & 0.16 & 1.684 & 0.092 \\
\hline ra2Op -> RA & 0.654 & 0.7 & 0.191 & 3.425 & 0.001 \\
\hline ra3Tec -> RA & 0.167 & 0.135 & 0.159 & 1.054 & 0.292 \\
\hline rk1Fin -> Risk & 0.372 & 0.392 & 0.221 & 1.684 & 0.092 \\
\hline rk2Op -> Risk & 0.267 & 0.254 & 0.256 & 1.045 & 0.296 \\
\hline rk3Tec -> Risk & 0.478 & 0.443 & 0.272 & 1.762 & 0.078 \\
\hline
\end{tabular}

Table 13: Outer weights of all indicators

With larger numbers of formative indicators used to measure a single construct (e.g. risk and relative advantage), it becomes more likely that one or more indicators will have low or even non-significant outer weights. Unlike reflective measurement models, where the number of indicators has little bearing on the measurement results, formative measurement has an inherent limit to the number of indicators that can retain a statistically significant weight (Cenfetelli \& Bassellier, 2009; Hair Jr and Hult 2016). Mathematically, the maximum possible outer weight declines as the number of indicators increase. Consequently, the average value of outer weights declines as the numbers of items increase. Thus, it becomes more likely that additional formative indicators will become nonsignificant (Hair et al. 2010). As such, items with low or non-significant outer 
weights should not be automatically considered for exclusion. Rather, these items should be examined based on their theoretical contributions to the construct. Researchers suggest that if the theory-driven conceptualization of the construct strongly supports retaining the indicator (e.g., by means of expert assessment), it should be kept in the formative measurement model (Hair Jr and Hult 2016).

\section{Test of the Structural Model}

Coefficient of determination

Coefficient of determination $\left(R^{2}\right)$ measures the amount of variance in the dependent variable explained by independent variables (Kutner et al. 2004). $R^{2}$ is used to characterize the ability of the model to explain and predict the endogenous latent variables (Ringle et al. 2012). An SEM structural model is able to test the significance of path coefficients as well as the coefficient of determination (Hair Jr and Hult 2016). The authors also suggest that $R^{2}$ is the most commonly used measure to evaluate the structural model. An adjusted coefficient of determination can be used as the criterion to avoid bias toward complex models (Hair Jr and Hult 2016). As a modified measure of the coefficient of determination, it takes into account the number of predictor constructs (Hair Jr and Hult 2016).

\begin{tabular}{|l|c|r|r|r|r|}
\hline & $\begin{array}{l}\text { Original } \\
\text { Sample } \\
(\mathrm{O})\end{array}$ & $\begin{array}{l}\text { Sample } \\
\text { Mean } \\
(\mathrm{M})\end{array}$ & \multicolumn{1}{|c|}{ Bias } & $2.50 \%$ & $97.50 \%$ \\
\hline Intent & 0.159 & 0.208 & 0.049 & 0.043 & 0.25 \\
\hline RA & 0.653 & 0.69 & 0.037 & 0.476 & 0.72 \\
\hline
\end{tabular}




\begin{tabular}{|l|l|l|l|l|l|}
\hline Risk & 0.386 & 0.446 & 0.059 & 0.191 & 0.476 \\
\hline
\end{tabular}

Table 14: $\mathrm{R}$ square values

\begin{tabular}{|l|c|c|r|r|r|}
\hline & $\begin{array}{l}\text { Original } \\
\text { Sample } \\
(\mathrm{O})\end{array}$ & $\begin{array}{l}\text { Sample } \\
\text { Mean } \\
(\mathrm{M})\end{array}$ & $\begin{array}{l}\text { Standard } \\
\text { Deviation } \\
(\text { STDEV) }\end{array}$ & $\begin{array}{l}\text { T Statistics } \\
(\text { (O/STDEV|) }\end{array}$ & $\begin{array}{l}\text { P } \\
\text { Values }\end{array}$ \\
\hline Intent & 0.144 & 0.194 & 0.072 & 2.011 & 0.044 \\
\hline RA & 0.634 & 0.673 & 0.056 & 11.375 & 0 \\
\hline Risk & 0.353 & 0.416 & 0.079 & 4.441 & 0 \\
\hline
\end{tabular}

Table 15: $R$ square values adjusted

Path coefficients

In $\mathrm{H} 1$ and $\mathrm{H} 2$, we posited that top management support would positively affect relative advantage and negatively impact risk. Our path model shows that both relationships were in the proposed directions, but the path from top management support to relative advantage was not significant. Therefore, the results support $\mathrm{H} 1$ but not $\mathrm{H} 2$.

\begin{tabular}{|l|r|r|r|r|r|}
\hline & $\begin{array}{l}\text { Original } \\
\text { Sample } \\
(\mathrm{O})\end{array}$ & $\begin{array}{l}\text { Sample } \\
\text { Mean } \\
(\mathrm{M})\end{array}$ & $\begin{array}{l}\text { Standard } \\
\text { Deviation } \\
(\text { STDEV) }\end{array}$ & $\begin{array}{l}\text { T Statistics } \\
(\mid \text { O/STDEV|) }\end{array}$ & $\begin{array}{l}\text { P } \\
\text { Values }\end{array}$ \\
\hline Absorb -> RA & 0.368 & 0.337 & 0.099 & 3.736 & 0 \\
\hline Absorb -> Risk & -0.126 & -0.109 & 0.109 & 1.153 & 0.249 \\
\hline HIEChar -> RA & 0.088 & 0.113 & 0.11 & 0.794 & 0.427 \\
\hline HIEChar -> Risk & -0.078 & -0.1 & 0.129 & 0.604 & 0.546 \\
\hline Pressure -> RA & 0.181 & 0.167 & 0.09 & 2.013 & 0.044 \\
\hline Pressure -> Risk & 0.056 & 0.059 & 0.127 & 0.445 & 0.656 \\
\hline RA -> Intent & 0.272 & 0.275 & 0.137 & 1.99 & 0.047 \\
\hline Risk -> Intent & -0.215 & -0.244 & 0.132 & 1.63 & 0.103 \\
\hline Support -> RA & -0.056 & -0.048 & 0.062 & 0.904 & 0.366 \\
\hline Support -> Risk & -0.174 & -0.173 & 0.084 & 2.057 & 0.04 \\
\hline Trust -> RA & 0.326 & 0.351 & 0.129 & 2.528 & 0.011 \\
\hline Trust -> Risk & -0.254 & -0.26 & 0.15 & 1.692 & 0.091 \\
\hline Uncer -> RA & 0.028 & 0.039 & 0.073 & 0.387 & 0.699 \\
\hline Uncer -> Risk & 0.375 & 0.357 & 0.128 & 2.94 & 0.003 \\
\hline
\end{tabular}

Table 16: Path coefficients and significance 
H3 states that absorptive capacity positively affects relative advantage. This relationship is strongly supported (at 0.01 level). We have observed that healthcare providers need to have a higher level of absorptive capacity to implement HIE. For instance, the Patient Look-Up (PLU) HIE is a more advanced HIE in that it is a distributed database system. Accordingly, as specified by its manual for providers, it requires more sophisticated technical and hardware capabilities for a provider to join ("Patient Look-Up | Florida Health Information Exchange" n.d.). H4 proposes that absorptive capacity negatively affects Risk. The direction of the relationship was as proposed (negative) but it was not significant.

$\mathrm{H} 5$ posits that the greater a provider's trust, the greater the perceived relative advantage. $\mathrm{H} 6$ predicts that the greater a provider's trust, the lower perceived risk. Once again, the directions of both relationships were as suggested with $\mathrm{H} 6$ being significant. This provides support for our hypothesis that trust is vital in reducing risks for $\mathrm{HIE}$, both from a social exchange and a diffusion of innovation perspective.

$\mathrm{H} 7$ posits that the greater environmental uncertainty, the lower the perceived relative advantage. This relationship was not significant. H8 suggests that the greater environmental uncertainty, the greater the perceived risk. This relationship was strongly supported. H9 states that the greater adoption pressures, the greater the perceived relative advantage. $\mathrm{H} 10$ assumes that the greater adoption pressures, the lower the perceived risk. The results supported $\mathrm{H} 9$ but not $\mathrm{H} 10$. 
$\mathrm{H} 11$ and $\mathrm{H} 12$ posit that HIE characteristics as an innovation positively relate to relative advantage and negatively relate to risk, respectively. Both relationships were in the predicted directions but were not significant. Therefore, they were not supported. $\mathrm{H} 13$ asserts that the greater the perceived relative advantage, the greater the adoption/continuance intentions. This hypothesis was supported. H14 proposes that the greater the perceived risk, the lower the adoption/continuance intentions. The relationship was marginally supported $(p=0.1$ level). It is well established in literature that relative advantage is an antecedent for adoption intentions, the support for $\mathrm{H} 13$ is expected. We postulated that compared to relative advantage, risk would not be as salient a factor when healthcare providers consider adopting or continuously using HIE. In other words, the motivation for healthcare providers to use HIE may come mainly from perceived relative advantage of using it, rather than the avoidance of perceived risks that might incur with HIE usage. Indeed, the relative advantage of using HIE is well reflected in the operationalizations of the construct. The items used included not only major measures that appeared in traditional IS literature but also healthcare specific factors, such as the quadruple aim of HIE (Bodenheimer and Sinsky 2014). 


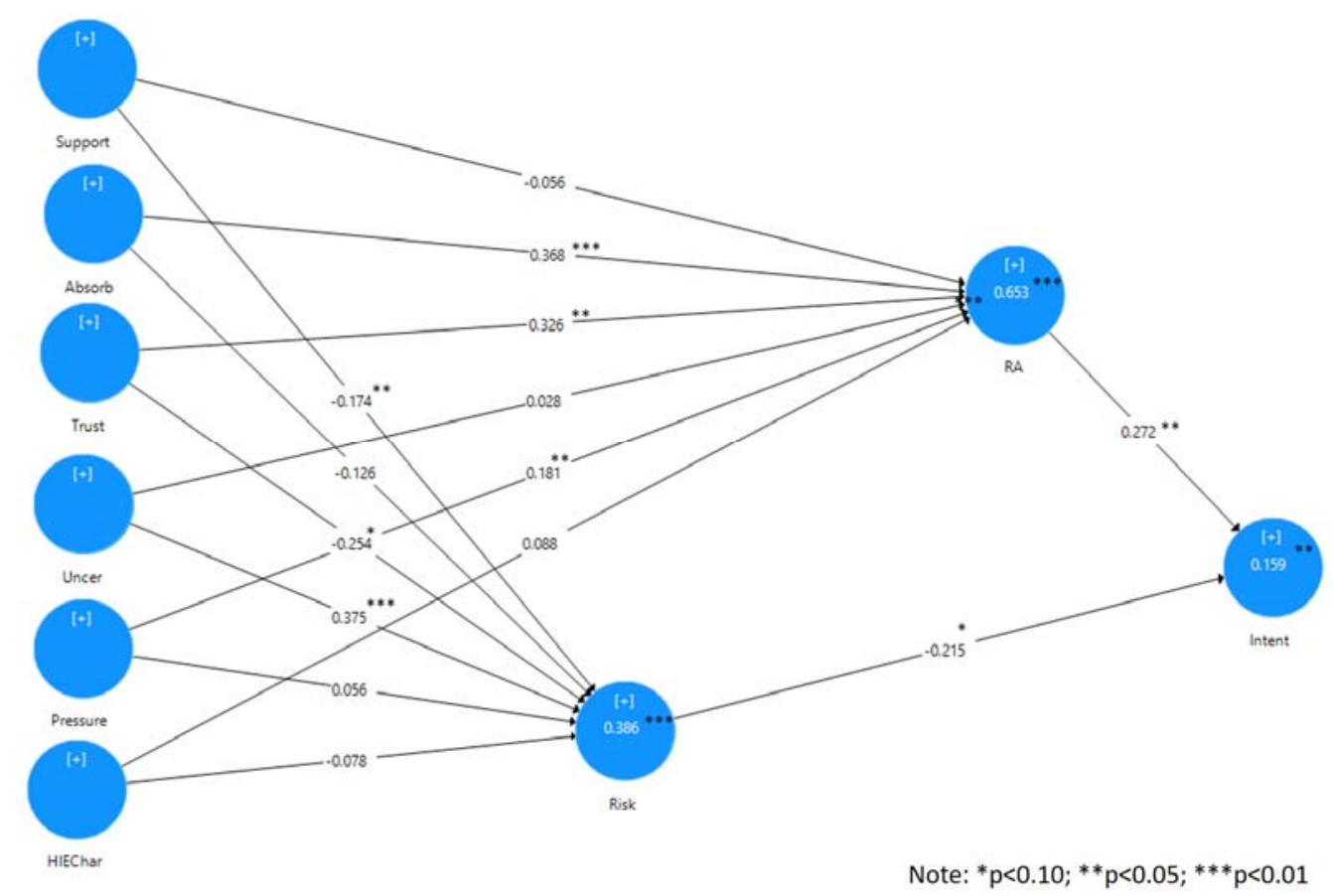

Figure 2: Path loadings and significance values

\section{Mediation}

Mediation occurs when a third variable, referred to as a mediator variable, intervenes between two related constructs. More precisely, a change in the exogenous construct results in a change of the mediator variable, which, in turn, changes the endogenous construct (Hair Jr and Hult 2016). Analyzing the strength between a mediating variable and other constructs allows substantiating mechanisms that underlie the cause-effect relationship between an exogenous construct and endogenous constructs (Hair Jr and Hult 2016). Thereby, a mediator variable governs the nature (i.e., the underlying mechanism or process) of the relationship between two constructs (Hair Jr and Hult 2016). 
Baron and Kenny (1986) propose two types of mediation: partial mediation and full mediation. A prevailing procedure to test mediation is the Sobel test (Sobel 1982). The Sobel test compares the indirect relationship between the independent variable and dependent variable that includes the mediation construct (Hair Jr and Hult 2016, Helm et al. 2010). Because the Sobel test assumes a normal distribution that is not consistent with the nonparametric PLSSEM method (Hair Jr and Hult 2016), it would not be appropriate to conduct mediation analysis using PLS models (Sattler et al. 2010). Instead, Hair Jr and Hult (2016) suggest the bootstrapping technique be used for PLS mediation analysis because bootstrapping makes no assumptions about sampling distributions.

This study uses the guideline by Hair Jr and Hult (2016) for multiple mediation analysis. By considering all mediators simultaneously in one model, we gain a more complete picture of the mechanisms through which an exogenous construct affects an endogenous construct. We first test the significance of each indirect effect (i.e., the specific indirect effects) and the direct effect between the exogenous construct and the endogenous construct, then we test whether the total indirect effect is significant.

\begin{tabular}{|l|r|r|r|r|r|}
\hline & $\begin{array}{l}\text { Original } \\
\text { Sample } \\
(\mathrm{O})\end{array}$ & $\begin{array}{l}\text { Sample } \\
\text { Mean } \\
(\mathrm{M})\end{array}$ & $\begin{array}{l}\text { Standard } \\
\text { Deviation } \\
\text { (STDEV) }\end{array}$ & $\begin{array}{l}\text { T Statistics } \\
(\text { (O/STDEV) })\end{array}$ & $\begin{array}{l}\text { P } \\
\text { Values }\end{array}$ \\
\hline Absorb -> Intent & 0.127 & 0.115 & 0.055 & 2.324 & 0.02 \\
\hline Absorb -> RA & 0.368 & 0.337 & 0.099 & 3.736 & 0 \\
\hline Absorb -> Risk & -0.126 & -0.109 & 0.109 & 1.153 & 0.249 \\
\hline HIEChar -> Intent & 0.041 & 0.053 & 0.049 & 0.829 & 0.407 \\
\hline HIEChar -> RA & 0.088 & 0.113 & 0.11 & 0.794 & 0.427 \\
\hline
\end{tabular}




\begin{tabular}{|l|r|r|r|r|r|}
\hline HIEChar -> Risk & -0.078 & -0.1 & 0.129 & 0.604 & 0.546 \\
\hline Pressure -> Intent & 0.037 & 0.021 & 0.052 & 0.72 & 0.472 \\
\hline Pressure -> RA & 0.181 & 0.167 & 0.09 & 2.013 & 0.044 \\
\hline Pressure -> Risk & 0.056 & 0.059 & 0.127 & 0.445 & 0.656 \\
\hline RA -> Intent & 0.272 & 0.275 & 0.137 & 1.99 & 0.047 \\
\hline Risk -> Intent & -0.215 & -0.244 & 0.132 & 1.63 & 0.103 \\
\hline Support -> Intent & 0.022 & 0.031 & 0.04 & 0.542 & 0.588 \\
\hline Support -> RA & -0.056 & -0.048 & 0.062 & 0.904 & 0.366 \\
\hline Support -> Risk & -0.174 & -0.173 & 0.084 & 2.057 & 0.04 \\
\hline Trust -> Intent & 0.143 & 0.178 & 0.066 & 2.153 & 0.031 \\
\hline Trust -> RA & 0.326 & 0.351 & 0.129 & 2.528 & 0.011 \\
\hline Trust -> Risk & -0.254 & -0.26 & 0.15 & 1.692 & 0.091 \\
\hline Uncer -> Intent & -0.073 & -0.068 & 0.057 & 1.279 & 0.201 \\
\hline Uncer -> RA & 0.028 & 0.039 & 0.073 & 0.387 & 0.699 \\
\hline Uncer -> Risk & 0.375 & 0.357 & 0.128 & 2.94 & 0.003 \\
\hline
\end{tabular}

Table 17: Indirect and total effects

SmartPLS shows that absorptive capacity has an indirect effect on intentions. The relationship between absorptive capacity and intentions has an Original Sample $(O)$ value of 0.127 with a $p$ value of 0.02 . Thus, there is a mediating relationship between the two variables. Further examination of direct effects shows that the relationship between absorptive capacity and relative advantage has an Original Sample $(\mathrm{O})$ value of 0.368 with a $p$ value of 0 . In addition, the relationship between relative advantage and intentions has an Original Sample $(O)$ value of 0.272 with a $p$ value of 0.047 . However, the relationship between absorptive capacity and risk is insignificant with a $p$ value of 0.249 , and the relationship between risk and intentions has an Original Sample (O) value of -0.215 with a $p$ value of 0.103 . As such, relative advantage mediates the relationship between absorptive capacity and intentions whereas risk does not. 
Similarly, the relationship between trust and intentions has an Original Sample $(0)$ value of 0.143 with a $p$ value of 0.031 . Consequently, there is a mediating relationship between trust and intentions. The direct relationship between trust and risk has an Original Sample (O) value of -0.254 with a $p$ value of 0.091 . Furthermore, the relationship between trust and relative advantage is significant, with the Original Sample $(0)$ value of 0.326 with a $p$ value of 0.011 . As such, relative advantage mediates the relationship between trust and intentions. Because the relationship between risk and intentions has an Original Sample (O) value of -0.214 with a $p$ value of 0.101 , risk does not mediate the relationship between trust and intentions.

What is interesting is that the rest of the relationships between IV and DV, namely HIE characteristics as innovation and intentions, adoption pressures and intentions, top management support and intentions, uncertainty and intentions were not significant. Among these, top management support and HIE characteristics as innovation do not have significant relationships with risk or relative advantage. Uncertainty, on the other hand, is positively $(O$ value $=0.391)$ and significantly $(p=0.001)$ associated with risk. Thus, risk fully mediates the relationship between uncertainty and intentions. Similarly, adoption pressures are significantly associated with relative advantage $(O$ value $=0.175 ; p=0.048)$. We thus conclude that relative advantage fully mediates the relationship between adoption pressures and intentions. 


\section{CHAPTER 6. DISCUSSION}

This study investigated factors influencing healthcare providers' intention to adopt or continuously use HIE. Realizing limitations of research about HIE adoption, we developed a holistic model to empirically test major factors that potentially impact healthcare providers' adoption and use intentions. Specifically, we examined the influence of intra-organizational, inter-organizational, and environmental factors, as well as HIE innovation characteristics on HIE's adoption or continuous intentions. We further hypothesize that the proposed relationships between those factors and adoption/use intentions are mediated by risk and relative advantage perceptions.

Our results suggest that most relationships were in the hypothesized directions. Specifically, top management support, absorptive capacity, trust, and HIE characteristics as innovation positively lead to relative advantage and negatively lead to risk. The positive relationships between 1 ). absorptive capacity and relative advantage 2). HIE characteristics as innovation and relative advantage were significant. In addition, relative advantage positively leads to adoption/continuance intentions, and risk negatively leads to adoption/continuance intentions, with the former being significant.

Compared to traditional IS literature, this study makes important contributions by considering factors not usually examined in IS literature. To better understand the study's result, it is necessary to review the uniqueness of the healthcare industry, which is crucial for interpretation of the study's findings. 


\section{Uniqueness of the healthcare industry}

\section{For-profit and not-for-profit organizations}

In management, there is a divided opinion regarding whether researchers should treat for-profit and not-for-profit organizations equally. Some scholars argue that public and private organizations are converging because they face similar constraints and challenges (Murray 1975). Murray (1975) holds that management always involves the following: defining purposes and objectives, planning, selecting managers, managing and motivating people, and controlling and measuring results. Another camp, led by researchers such as Rainey et al. (1976), contend that the difference between for-profit and not-for-profit organizations cannot be simplified and discounted. In addition, they believe that wide involvement of government in all aspects of life has caused a convergence or blurring for-profit and not-for-profit sectors (Caiden 1971). An example can be that a government's outsourcing its contracts to private businesses, such as utilizing private for-profit hospitals to provide services to Medicare patients.

Building upon the work of Rainey et al. (1976), Fottler (1981) identifies four classes of organizations along the continuum between classical private profit-making firms and strictly governmental agencies: private for-profit, private non-profit, private quasi-public, and public. As Rainey et al. (1976) pointed out, for every example of an organization in one sector, there exists an intermediate type in another sector that overlaps along various dimensions. Weidenbaum (1970) observes that some private corporations are so dependent on government contracts that they may take on certain attributes of a government agency. Many 
healthcare providers indeed have the majority of their patients indirectly from the government sources, such as Medicaid and Medicare patients.

Fottler (1981) considers that significant institutional differences (values, incentives, and constraints) differentiate the four organization prototypes and affect how essential functions of management are carried out. Each prototype receives support (economic and non-economic) from different subsectors of society and must be responsive to these subsectors. Because these subsectors have different goals, responding to them creates diverse incentives and constraints for management in each type of organization (Fottler, 1981).

Fottler (1981) contends that the four organization prototypes are dependent on different individuals, groups, and organizations in an external environment. Variability in their environmental dependence creates different values, incentives, and constraints in terms of how environmental dependence and internal operations are managed (Fottler, 1981). Resulting differences in how basic managerial processes are implemented may be more significant than a generic theory of management has acknowledged (Fottler, 1981). Consequently, management constraints vary markedly among public, not-for-profit and for-profit organizations (Fottler 1987).

In addition, Hull and Lio (2006) assert that "Non-profits and for-profit organizations have an intrinsic difference in motivation" (p.53). Hull and Lio (2006) discuss three major differences between for-profit and not-for-profit organizations-vision, strategic constraints and financial constraints. Because of 
the difference in these constraints, for-profit and not-for-profit organizations often behave differently when addressing innovation (Hull and Lio 2006).

When studying for profit organizations, analyses tend to be simpler because the foremost objective of such organizations is financial. Moore (2000) concludes that the "ultimate purpose of a for-profit enterprise should be to maximize, in the long run, the wealth of the shareholders of the firm" (p.186). The ultimate measurement of a for-profit organization is its financial performance, which guides the firm's strategic development (Moore 2000). For not-for-profit organizations, on the other hand, financial performance is usually only one of several goals to be considered. Indeed, as Moore (2000) argues: "both not-forprofit and government organizations define the value they produce in terms of the mission of the organization rather than in their financial performance" (p.189).

In healthcare settings, nonfinancial goals often include the quality of patient care as well as particular patient populations to be served. In addition, none-for-profit organizations often have different government policies (such as government reimbursement). Many healthcare providers are governmental organizations and for these entities, for-profit maximization might be a very low priority (Sloan 2000).

In reality, different healthcare providers have different motivations in terms of HIE adoption. They have various degrees of freedom in deciding to adopt HIE, ranging from total autonomy to total policy compliance. The management structure and routines are also different depending on the healthcare providers' for-profit status. Our research does not differentiate different motivations to adopt 
HIE based on profit and not-for-profit status as this is beyond the scope of our study. It is however important for scholars to be aware of this difference because its potential impact on providers' adoption behaviors. To illustrate, our model proposes that factors influence healthcare providers' HIE intentions through risk and relative advantage perceptions. The measure of relative advantage can be construed as objectives to satisfy a healthcare provider's different stakeholders, such as patients and medical staff. Depending on a healthcare organization's forprofit status, various stakeholders have different priorities and goals. It is reasonable to expect that a for-profit should have a higher priority in terms of recuperating investment from HIE.

\section{Complexity of healthcare industry}

We further argue that healthcare organizations are unique compared to other industries. This distinction was discussed by Fottler (1981):

1. Defining and measuring output is difficult.

2. The work involved is highly variable and complex, highly specialized, and highly interdependent, requiring a high degree of coordination among diverse professional groups.

3. The work often involves emergency or non-deferrable activities, permits little tolerance for ambiguity or error, and utilizes professionals whose primary loyalty belongs to the profession rather than to the organization.

4. Most health organizations tend to be "loosely coupled" in the sense that organizational segments are only mildly responsive to one another and to the 
environment. Their organizational goals are frequently vague (Howell and Wall 1983).

5. The political, legal, and financial environments that confront health organizations are extremely complex and pluralistic requiring the development and maintenance of complicated intra- and inter-system linkages (Fottler, 1987).

6. The preservation and enhancement of human life supersedes purely "rational" administrative concerns. When the two conflict, services must be individualized to a greater extent than those of other human service organizations (Fottler, 1987).

Although some of the characteristics discussed above can be found in industries other than healthcare (such as education), health organizations are unique because they have all of these characteristics (Fottler, 1987). The political, legal, and financial environments confronting health organizations are complex. The mechanisms (institutions, agencies, and programs) involved in bringing the system's users and providers together are pluralistic. Because of all these factors, a series of complicated intra- and inter-system relationships must be developed, rationalized, and maintained.

Healthcare organizations operate in "institutionalized environments" (Fottler, 1987), which refers to elaborate sets of rules and requirements imposed upon them by social, legal, and political contexts. Conformity to normative expectations of powerful professional and interest groups results in the societal support and legitimacy which is pivotal for their survival (Zucker 1977). Rather than rewarding efficiency and effectiveness, institutional environments often 
encourage conformity to powerful institutional rules, myths, and structures (Meyer and Rowan 1977). This may lead healthcare organizations to adopt structures or processes for symbolic reasons rather than for functional utility. Hence, healthcare organizations may respond to internal and external stakeholders' expectations and pressures by various non-functional responses designed to appease various stakeholders (Fottler, 1987).

Healthcare organizations have a wide range of stakeholders, ranging from patients, healthcare professionals to governments. Internal and external stakeholders often have different goals which creates pressures on the organization. Moreover, different expectations and pressures from various stakeholders might not be compatible (Fottler, 1987). For example, healthcare organizations' top management and government funding agencies are often concerned with cost efficiency, whereas patients and physicians are more concerned with clinical quality and patient satisfaction. In comparison, boards of trustees are concerned with financial outcomes (Fottler, 1987). Conflicting goals of stakeholders lead to compromised decision making and idiosyncratic behavior of healthcare organizations, which is difficult to predict and study.

We argue that HIE adoption faces the same challenges. Adopting a new innovation is often a compromising act to satisfy multiple stakeholders' needs. The understanding of it not only helps interpret the study's results but also provides the industry with new insights. 


\section{Policy influence in healthcare industry}

The healthcare industry is strongly influenced by government policy. This is true for the United States as well as for many other countries. For example, the behavior of healthcare providers is strongly influenced by taxation and insurance (Pauly 1986). Some industries such as telecommunications, electricity, water, oil, gas, and banking are also "subject to an unusual degree of intervention and policy risk"(García-Canal and Guillén 2008) (p.1097). One reason that government treats the healthcare industry differently is that its outcome is directly linked to the well-being of the population.

Policy influence of the healthcare industry is different from other industries in several ways. First, the healthcare industry often has elaborate and stringent requirements regarding how individual businesses should operate. For example, HIPAA of 1996 has detailed stipulations about how patients' records should be handled (The United States Congress, 1996). The regulations apply to both electronic and paper records. A physician is covered by the regulations if he or she conducts any medical business electronically, including billing, even if the physician outsources his/her operations. This means that most practicing physicians are covered by the Act, because most physicians accept private health insurance, are members of one or more health plans, receive payment from Medicare or Medicaid, or otherwise do business electronically (Annas 2003). In addition, all of the HIPAA rules include an implicit requirement that the amount of individually identifiable health information released or requested for any specific purpose - except for disclosures authorized by the patient, those to another healthcare provider involved in treatment, or those required by law - 
should be the "minimum" to accomplish the purpose. Outside the context of treatment, a patient's entire medical record can seldom be lawfully disclosed without a patient's written authorization (Annas 2003). Government control in other industries is rarely seen at this level of scrutiny and influence.

Second, government often makes changes to healthcare policy within a relatively short period, as between administrations. In comparison, policies and regulations in other industries tend to stay unchanged for longer periods. Indeed, the past decade has seen drastic changes in the healthcare sector (e.g. Blumenthal 2010). For example, in order to encourage HIT adoption, the HITECH Act made funds available to healthcare providers within a very short period of time and markedly changed hospitals' HIT adoption behavior. Jha et al. (2011) reported that as of 2011 , more than 15 percent of U.S. hospitals had adopted at least a basic EHR, representing nearly 75 percent growth since 2008 . The HITECH Act also committed almost $\$ 650$ million of government funding to create a network of up to 70 Regional Health Information Technology Extension Centers (Jha et al. 2011) to facilitate EHR adoption. Such policy changes, although not at all surprising, are common in healthcare. In comparison, most other industries do not experience such strong government intervention within a short period of time.

\section{Inter-organizational relationship in healthcare industry}

HIE is complex because the implementation of HIE is based on interorganizational relationships. To be sure, research in inter-organizational relations has a long tradition. Early studies usually focused on values creation and benefits of networks, based often on transaction cost economics (Coase 1937, 
Williamson 1979). The past two decades have seen a growing amount of studies on inter-organizational relations using inter-organizational information systems (IOS) (e.g. Chatfield and Bjørn-Andersen 1997). Although there are many similarities between earlier research in IOS and contemporary HIE, distinctions exist. One difference is that for both organizational networks and IOS, participating organizations reaps mutual benefits from the relationship, even though the degree of benefit often varies. For example, Uzzi (1997)'s study investigates the importance of inter-organizational networks by examining a supply chain of the garment industry. Business partners in a network, namely buyers and contractors, helped each other because it was a "win-win" situation (p.51). As the author noted: "You'll do things for friends... Friends will be there with you through the bad times and good" (p. 52). A network exists because everybody wins in the relationship.

For HIE participants, namely healthcare providers, a win-win situation is sometimes not the case. The reason resides in the fact that healthcare economy is different from other industries. Anecdotal evidence shows that participating HIE providers sometimes found that they are locked in a zero-sum gain situation. For example, one of the important performance indicators of healthcare providers is duplicated testing. As negative as it is, duplicated testing generates revenue for a healthcare provider. This problem might not be corrected by patients due to the agency problem (Jensen and Meckling 1976). Because an effective HIE can significantly reduce duplicated testing, participation in HIE can cause a hospital to potentially lose revenue. In a truly interoperable HIE network, any provider can 
retrieve a patient's data. This allows the patient more freedom to visit other providers in the network, without worrying about his or her medical records access. HIE thus has the potential drawback of causing a provider to lose patients, which is often unacceptable especially for financially competing healthcare providers in the same market.

\section{Interpretation of results}

This study proposes four higher-order factors that influence organizations' risk or relative advantage perceptions, which in turn influence HIE's adoption and use. Specifically, this study presumes that intra-organizational, interorganizational, and environmental factors, as well as HIE characteristics impact risk or relative advantage. In the ensuing section, we examine each of these factors.

\begin{tabular}{|l|l|}
\hline \multicolumn{1}{|c|}{ Hypotheses } & \multicolumn{1}{|c|}{ Results } \\
\hline $\begin{array}{l}\text { H1: Top management support positively affects relative } \\
\text { advantage. }\end{array}$ & Not supported \\
\hline H2: Top management support negatively affects Risk. & Supported \\
\hline H3: Absorptive capacity positively affects relative advantage. & Supported \\
\hline H4: Absorptive capacity negatively affects Risk. & Not supported \\
\hline $\begin{array}{l}\text { H5: The greater a provider's trust, the greater relative } \\
\text { advantage. }\end{array}$ & Supported \\
\hline H6: The greater a provider's trust, the lesser risk. & Supported \\
\hline $\begin{array}{l}\text { H7: The greater the environmental uncertainty, the lower the } \\
\text { perceived relative advantage. }\end{array}$ & Not supported \\
\hline $\begin{array}{l}\text { H8: The greater the environmental uncertainty, the greater the } \\
\text { perceived risk. }\end{array}$ & Supported \\
\hline $\begin{array}{l}\text { H9: The greater adoption pressures, the greater relative } \\
\text { advantage. }\end{array}$ & Supported \\
\hline
\end{tabular}




\begin{tabular}{|l|l|}
\hline H10: The greater adoption pressures, the lesser risk. & Not supported \\
\hline $\begin{array}{l}\text { H11: The greater HIE characteristics as an innovation, the } \\
\text { greater the perceived relative advantage. }\end{array}$ & Not supported \\
\hline $\begin{array}{l}\text { H12: The greater HIE characteristics as an innovation, the } \\
\text { lower the perceived risk. }\end{array}$ & Not supported \\
\hline $\begin{array}{l}\text { H13: The greater the relative advantage, the greater the } \\
\text { adoption/continuance intentions }\end{array}$ & Supported \\
\hline $\begin{array}{l}\text { H14: The greater the risk, the lower the adoption/continuance } \\
\text { intentions. }\end{array}$ & Supported * \\
\hline
\end{tabular}

Table 18: Hypothesis testing results

${ }^{*}$ At $p=0.01$ level

Intra-organizational factors include top management support and absorptive capacity. The relationship between top management support and risk was significant. Both empirical evidence and research acknowledge the importance of top management support in IT adoption (Shao et al. 2016). Researchers argue that successful IS implementation occurs when an organization has sufficient resources, such as funding and technical skills (Thong et al. 1996; Kwon and Zmud 1987). What is interesting is that the negative relationship between top management support and risk is significant whereas the positive relationship between top management support and relative advantage is insignificant. The reason might be that HIE is generally considered a risky IT initiative. This is a reasonable assumption given the high failure occurrences with many HIE initiatives. Top management support is thus more important in mitigating risks associated with adoption and implementation.

The relationship between absorptive capacity and relative advantage was significant. Data analysis also finds that relative advantage partially mediates the 
relationship between absorptive capacity and intentions. These findings affirm previous studies on the importance of absorptive capacity in IT adoption. For instance, an investigation about data warehouse adoption found that absorptive capacity positively led to relative advantage, which in turn positively impacted IT adoption. Another study found that absorptive capacity leads to firm innovativeness (Chang et al. 2013). Our research adds evidence that absorptive capacity is equally important in HIT adoption.

Inter-organizational factors include two types of trust: trust among healthcare providers and trust toward the broad HIE system. The study shows that the greater a provider's trust, the greater the perceived relative advantage. In addition, relative advantage mediates the relationship between trust and intentions. The contribution of these findings is twofold. First, the findings attest to the pivotal role that trust plays in successful social exchange relationships. Considering that few studies in SET are in the domain of healthcare, this research reaffirms the generalizability of the theory. Second, as we argued earlier, both academics and practitioners still have limited understanding of HIE. This study shows that the context of HIE, namely the social exchange relationship, is an important factor to be considered. Building upon this study, we suggest that future research should continue to examine other essential factors in SET to broaden the understanding of HIE.

Environmental factors in the study consist of environmental uncertainty and adoption pressures. Results of the study show that the greater environmental uncertainty, the greater the perceived risk. This finding is not 
surprising because environmental uncertainty is generally perceived as negative. We also found that the greater the adoption pressures, the greater perceived relative advantage. This finding is interesting because adoption pressures can be interpreted to be either positive or negative. Specifically, four questions were asked to measure adoption pressures: 1). Our patients expect us to use HIE; 2). Many providers believe using HIE is inevitable; 3). We are pressured to use HIE because many of our competitors use it; 4). We are pressured by the government's policy to adopt HIE. The study results show that the majority of healthcare providers construe adoption pressures as positive. In other words, healthcare providers view adoption pressures as an opportunity to adopt and use HIE, rather than a threat to disrupt this status quo. This result has profound implications. Because adoption pressures are external, HIE proponents should critically examine resources at their disposal and channel those resources to facilitate HIE adoption and use. For example, government policy makers should consider how to frame policies relating to HIE to encourage healthcare providers' participation.

\section{Contributions}

This study makes important contributions to both academia and the industry. First, this study is grounded on the authors' five years of subject knowledge, extensive literature review and interviews with industrial experts. The study thus combines both academic rigor and practical insights. Second, we were able to holistically examine factors leading to perceived risk and relative advantage, which in turn impact HIE adoption. We found support for both risk 
and relative advantage as important factors leading to both HIE adoption and continuance intentions. Considering the complexity of the healthcare industry, we included some traditionally neglected and yet vital factors in IS research, such as government policy's impact. This study helps both policy makers and the industry to widen their scope of examination regarding factors impacting HIE success. It is hoped that this broad angle of examination should also set forth and spur more expansive research in the IS field.

Yet another contribution of the study is that we empirically developed and refined constructs for the healthcare context. Considering that implementation of HIE still faces many challenges, practitioners need guidelines and assessment tools to help them determine their best course of action in terms of HIE adoption. With our study pioneering several newly developed and refined measurement tools, providers can readily utilize the newly developed measures to guide their future HIE efforts. These tools can be instrumental to increase success and avoid pitfalls. While this dissertation was developed, several state HIEs who partnered with us for the study already started to use our measures to gain insights for their HIE implementation.

\section{Limitations}

As with any research, this study is not without limitations. First, to the best of our knowledge, this study is one of the earliest attempts to holistically and empirically examine how multiple factors (intra-organizational factors, interorganizational factors, environmental factors, and HIE innovation characteristics) impact healthcare providers' HIE adoption or use intentions. Because of the 
newness and explorative nature of the study (e.g. we empirically developed and refined several key constructs relating to HIE), not all hypothesized relationships were supported. We suspect this is partially due to the nascent nature of the study in healthcare settings. Scales that were newly developed include risk, adoption pressures, and uncertainty. Grounded on earlier research, scales such as relative advantage (Moore and Benbasat 1991) were augmented to improve the richness of the measure and fit the context of the study. Newly developed measures often exhibit relatively lower level of validity and reliability (Nunnally and Bernstein 1994), which in turn may exert undue influence on model fits (Kline 2010). This might explain some of the insignificant relationships in the model. To remedy it, continuous iterative measure refinement is needed to gradually improve measures' validity and reliability (Nunnally and Bernstein 1994). On the other hand, this study found that all relationships were in predicted directions while half were significant. Given that the sample size of the study was marginally smaller than what is required by the 10 times rule (Barclay et al. 1995), our research findings add additional evidence to support the validity of the study design. Future continued exploration and refinement of these constructs should improve the validity of these measures and produce more significant results. Our study thus sets a solid foundation for future academics to build their research.

The second limitation is relating to data collection. This study collected data from multiple resources with the majority of responses obtained from a national healthcare providers' registry, where we were able to calculate data 
quality parameters such as response rates. Other sources of data nonetheless did not provide us with enough information for precise calculation. One such data source were respondents to whom we reached out using social media, although data collection through this channel has the advantage of good respondent coverage. In such situations, based on information that we had, we tried to make best estimates of response rate for those parameters. Despite these limitations, this project is one of the first empirical explorations for HIE. Based on what we have learned from the study, future researchers should improve and overcome these limitations. 


\section{REFERENCES}

Adebesin, F., Foster, R., Kotzé, P., and Van Greunen, D. 2013. "A review of interoperability standards in e-health and imperatives for their adoption in africa," (available at http://researchspace.csir.co.za/dspace/handle/10204/6950).

Adler-Milstein, J., and Jha, A. 2012. "Sharing clinical data electronically: A critical challenge for fixing the health care system," JAMA (307:16), pp. 1695-1696 (doi: 10.1001/jama.2012.525).

Agarwal, R., and Prasad, J. 1997. "The role of innovation characteristics and perceived voluntariness in the acceptance of information technologies," Decision Sciences; Atlanta (28:3), pp. 557-582.

Agrawal, R., Bayardo, R., Faloutsos, C., Kiernan, J., Rantzau, R., and Srikant, R. 2004. "Auditing compliance with a hippocratic database," (available at http://repository.cmu.edu/compsci/539/).

Ahuja, M. K., and Thatcher, J. B. 2005. "Moving beyond Intentions and toward the Theory of Trying: Effects of Work Environment and Gender on PostAdoption Information Technology Use," MIS Quarterly (29:3), pp. 427-459.

Albers, S. 2010. "PLS and success factor studies in marketing," Handbook of partial least squares, pp. 409-425. 
Allen, D. K., Colligan, D., Finnie, A., and Kern, T. 2000. "Trust, power and interorganizational information systems: the case of the electronic trading community TransLease," Information Systems Journal (10:1), pp. 21-40.

Ammenwerth, E., Gräber, S., Herrmann, G., Bürkle, T., and König, J. 2003. "Evaluation of health information systems_problems and challenges," (available at http://www.elske-ammenwerth.de/Publikationen/z19.pdf).

Anderson, J. C., and Gerbing, D. W. 1988. "Structural equation modeling in practice: A review and recommended two-step approach," Psychological Bulletin;Psychological Bulletin (103:3), pp. 411-423 (doi: 10.1037/00332909.103.3.411).

Anderson, J. C., and Narus, J. A. 1984. "A Model of the Distributor's Perspective of Distributor-Manufacturer Working Relationships," Journal of Marketing (48:4), pp. 62-74 (doi: 10.2307/1251511).

Anderson, J. C., and Narus, J. A. 1990. "A Model of Distributor Firm and Manufacturer Firm Working Partnerships," Journal of Marketing (54:1), pp. 42-58 (doi: 10.2307/1252172).

Annas, G. J. 2003. "HIPAA regulations-a new era of medical-record privacy?," New England Journal of Medicine (348:15), pp. 1486-1490.

Aspden, P., Corrigan, J. M., Wolcott, J., Erickson, S. M., and others. 2004. Patient Safety: Achieving a New Standard for Care, National Academies Press (available at 
https://books.google.com/books?hl=en\&lr=\&id=NL4tCmhUmulC\&oi=fnd\&p g=PR1\&ots=SOdNNAtj-Y\&sig=APf3WBewy2LXACVqupUtzvq_o3k).

Auerbach, D. I., and Kellermann, A. L. 2011. "A Decade Of Health Care Cost Growth Has Wiped Out Real Income Gains For An Average US Family," Health Affairs (30:9), pp. 1630-1636 (doi: 10.1377/hlthaff.2011.0585).

Bailey, J. E., Pope, R. A., Elliott, E. C., Wan, J. Y., Waters, T. M., and Frisse, M. E. 2013. "Health Information Exchange Reduces Repeated Diagnostic Imaging for Back Pain," Annals of Emergency Medicine (62:1), pp. 16-24 (doi: 10.1016/j.annemergmed.2013.01.006).

Bailey, J. E., Wan, J. Y., Mabry, L. M., Landy, S. H., Pope, R. A., Waters, T. M., and Frisse, M. E. 2012. "Does Health Information Exchange Reduce Unnecessary Neuroimaging and Improve Quality of Headache Care in the Emergency Department?," Journal of General Internal Medicine (28:2), pp. 176-183 (doi: 10.1007/s11606-012-2092-7).

Baron, R. M., and Kenny, D. A. 1986. "The moderator-mediator variable distinction in social psychological research: Conceptual, strategic, and statistical considerations," Journal of Personality and Social Psychology (51:6), pp. 1173-1182 (doi: 10.1037/0022-3514.51.6.1173).

Berkowitz, E. 2008. "Medicare and Medicaid: The Past as Prologue," HealtH Care FinanCing review (29:3), p. 81. 
Bhattacherjee, A. 2001. "An empirical analysis of the antecedents of electronic commerce service continuance," Decision support systems (32:2), pp. 201214.

Bhattacherjee, A., Perols, J., and Sanford, C. 2008. "Information technology continuance: A theoretic extension and empirical test," Journal of Computer Information Systems (49:1), pp. 17-26.

Bierstedt, R. 1965. "Exchange and Power in Social Life," American Sociological Review (30:5), pp. 789-790 (doi: 10.2307/2091154).

Blair, J. D., and Hunt, J. G. 1986. "Getting inside the head of the management researcher one more time: Context-free and context-specific orientations in research," Journal of Management (12:2), pp. 147-166.

Blalock, H. M. 1971. "Causal models involving unmeasured variables in stimulusresponse situations," Causal models in the social sciences, pp. 335-347.

Blau, P. M. 1964. Exchange and power in social life, Transaction Publishers.

Blau, P. M. 1968. "Interaction: social exchange," International encyclopedia of the social sciences (7:2000), pp. 452-458.

Blumenthal, D. 2010. "Launching HITECH," New England Journal of Medicine (362:5), pp. 382-385. 
Bodenheimer, T., and Sinsky, C. 2014. "From triple to quadruple aim: care of the patient requires care of the provider," Annals of Family Medicine (12:6), pp. 573-576 (doi: 10.1370/afm.1713).

Bollen, K. A. 2007. "Interpretational confounding is due to misspecification, not to type of indicator: comment on Howell, Breivik, and Wilcox (2007).," (available at http://psycnet.apa.org/journals/met/12/2/219/).

Bozeman, B., and Bretschneider, S. 1986. "Public Management Information Systems: Theory and Prescription," Public Administration Review (46), pp. 475-487 (doi: 10.2307/975569).

Brailer, D. J. 2005. "Interoperability: the key to the future health care system," Health affairs (24), p. W5.

Bretschneider, S. 1990. "Management Information Systems in Public and Private Organizations: An Empirical Test," Public Administration Review (50:5), pp. 536-545 (doi: 10.2307/976784).

Bright, T. J., Wong, A., Dhurjati, R., Bristow, E., Bastian, L., Coeytaux, R. R., Samsa, G., Hasselblad, V., Williams, J. W., Musty, M. D., Wing, L., Kendrick, A. S., Sanders, G. D., and Lobach, D. 2012. "Effect of Clinical Decision-Support Systems A Systematic Review," Annals of Internal Medicine (157), pp. 29-U77.

Brinker, P. A., and Walker, B. 1962. "The Hill-Burton Act: 1948-1954," The Review of Economics and Statistics (44:2), pp. 208-212 (doi: 10.2307/1928204). 
Bromiley, P., and Cummings, L. L. 1995. "Transactions costs in organizations with trust," Research on negotiation in organizations (5), pp. 219-250.

Brown, S. H., Lincoln, M. J., Groen, P. J., and Kolodner, R. M. 2003. "VistA—US department of veterans affairs national-scale HIS," International journal of medical informatics (69:2), pp. 135-156.

Bunduchi, R. 2008. "Trust, power and transaction costs in B2B exchanges - A socio-economic approach," Industrial Marketing Management (37:5), pp. 610-622 (doi: 10.1016/j.indmarman.2007.05.003).

Buntin, M. B., Burke, M. F., Hoaglin, M. C., and Blumenthal, D. 2011. "The Benefits Of Health Information Technology: A Review Of The Recent Literature Shows Predominantly Positive Results," Health Affairs (30), pp. 464-471 (doi: 10.1377/hlthaff.2011.0178).

Caiden, G. E. 1971. The dynamics of public administration: Guidelines to current transformations in theory and practice, Holt, Rinehart and Winston.

Camisón, C., and Forés, B. 2010. "Knowledge absorptive capacity: New insights for its conceptualization and measurement," Journal of Business Research (63:7), pp. 707-715 (doi: 10.1016/j.jbusres.2009.04.022).

Campbell, D. T., and Fiske, D. W. 1959. "Convergent and discriminant validation by the multitrait-multimethod matrix.," Psychological bulletin (56:2), p. 81. 
Caudle, S. L., Gorr, W. L., and Newcomer, K. E. 1991. "Key Information Systems Management Issues for the Public Sector," MIS Quarterly (15:2), pp. 171188 (doi: $10.2307 / 249378)$.

Chadwick-Jones, J. K. 1976. Social exchange theory: its structure and influence in social psychology, Published in cooperation with European Association of Experimental Social Psychology by Academic Press.

Chang, S., Gong, Y., Way, S. A., and Jia, L. 2013. "Flexibility-Oriented HRM Systems, Absorptive Capacity, and Market Responsiveness and Firm Innovativeness," Journal of Management (39:7), pp. 1924-1951 (doi: 10.1177/0149206312466145).

Chatfield, A. T., and Bjørn-Andersen, N. 1997. "The Impact of IOS-Enabled Business Process Change on Business Outcomes: Transformation of the Value Chain of Japan Airlines," Journal of Management Information Systems (14:1), pp. 13-40.

Chin, W. W. 1998a. "The partial least squares approach to structural equation modeling," Modern methods for business research (295:2), pp. 295-336.

Chin, W. W. 1998b. "Issues and Opinion on Structural Equation Modeling," MIS Quarterly, pp. 1-1.

Choudhury, V., and Karahanna, E. 2008. "The Relative Advantage of Electronic Channels: A Multidimensional View," MIS Quarterly (32:1), pp. 179-200. 
Churchill, G. A., Jr. 1979. "A Paradigm for Developing Better Measures of Marketing Constructs," Journal of Marketing Research (16:1), pp. 64-73 (doi: $10.2307 / 3150876)$.

Claassen, M. J., van Weele, A. J., and van Raaij, E. M. 2008. "Performance outcomes and success factors of vendor managed inventory (VMI)," Supply Chain Management: An International Journal (406), p. 414.

Coase, R. H. 1937. "The Nature of the Firm," Economica (4:16), p. 386 (doi: $10.2307 / 2626876)$.

Cochran, G. L., Lander, L., Morien, M., Lomelin, D. E., Sayles, H., and Klepser, D. G. 2015. "Health care provider perceptions of a query-based health information exchange: barriers and benefits," Journal of Innovation in Health Informatics (22:2), pp. 302-308 (doi: 10.14236/jhi.v22i2.135).

Cohen, W. M., and Levinthal, D. A. 1989. "Innovation and learning: the two faces of R \& D," The economic journal (99:397), pp. 569-596.

Cohen, W. M., and Levinthal, D. A. 1990. "Absorptive Capacity: A New Perspective on Learning and Innovation," Administrative Science Quarterly (35:1), pp. $128-152$.

Coiera, E. 2009. "Building a national health IT system from the middle out," Journal of the American Medical Informatics Association (16:3), pp. 271-273. 
Coleman, J. S. 1988. "Social capital in the creation of human capital," American journal of sociology, pp. 95-120.

Cook, K. S. 1977. "Exchange and Power in Networks of Interorganizational Relations," The Sociological Quarterly (18:1), pp. 62-82.

Cropanzano, R., and Mitchell, M. S. 2005. "Social exchange theory: An interdisciplinary review," Journal of management (31:6), pp. 874-900.

Cutler, D. M., and Sahni, N. R. 2013. "If Slow Rate of Health Care Spending Growth Persists, Projections May be Off by $\$ 770$ Billion," Health Affairs (32:5), pp. 841-850 (doi: 10.1377/hlthaff.2012.0289).

Czepiel, J. A. 1974. "Word-of-Mouth Processes in the Diffusion of a Major Technological Innovation," Journal of Marketing Research (JMR) (11:2), pp. 172-180.

Daniel, O. E., and Mensah, E. K. 2015. "Effects of HIE/HIT Implementation and Coordination of Care on Health Outcomes and Quality," AMIA Annual Symposium Proceedings (2015), p. 532.

Das, T. K., and Teng, B.-S. 2001. "Trust, control, and risk in strategic alliances: An integrated framework," Organization studies (22:2), pp. 251-283.

Das, T. K., and Teng, B.-S. 2002. "Alliance Constellations: A Social Exchange Perspective," The Academy of Management Review (27:3), pp. 445-456 (doi: $10.2307 / 4134389)$. 
Davis, F. D. 1989. "Perceived Usefulness, Perceived Ease of Use, and User Acceptance of Information Technology," MIS Quarterly (13:3), pp. 319-340 (doi: 10.2307/249008).

Davis, G. F., and Cobb, J. A. 2010. "Resource dependence theory: Past and future," Research in the Sociology of Organizations (28), pp. 21-42.

Dawes, S. S., Pardo, T. A., Simon, S., Cresswell, A. M., LaVigne, M., Andersen, D., and Bloniarz, P. A. 2004. Making smart IT choices: Understanding value and risk in government IT investments, the Center (available at https://www.ctg.albany.edu/publications/guides/smartit2?chapter=\&PrintVe rsion=2).

Deltek. (n.d.). "Federal Health Information Technology Market, 2014-2019," (available at http://more.deltek.com/Federal-Health-InformationTechnology-Market?sourceid=11\&utm_source=pressrelease\&utm_medium=press-release\&cmp=press-release_press-release; retrieved July 22, 2016).

Detmer, D. E. 2003. "Building the national health information infrastructure for personal health, health care services, public health, and research," $B M C$ Medical Informatics and Decision Making (3), p. 1.

Diamantopoulos, A., and Winklhofer, H. M. 2001. "Index Construction with Formative Indicators: An Alternative to Scale Development," Journal of Marketing Research (38:2), pp. 269-277. 
Dick, R. S., Steen, E. B., Detmer, D. E., and others. 1997. The Computer-Based Patient Record: An Essential Technology for Health Care, National $\begin{array}{llll}\text { Academies } & \text { Press available }\end{array}$ https://books.google.com/books?hl=en\&lr=\&id=AZ_la21BosC\&oi=fnd\&pg=PT23\&ots=it4Lj9hDFk\&sig=fS9j0P51n9nFrSfX4oYroNxl Pvw).

Dwyer, F. R., Schurr, P. H., and Oh, S. 1987. "Developing Buyer-Seller Relationships," Journal of Marketing (51:2), pp. 11-27 (doi: $10.2307 / 1251126)$.

Dwyer III, S. J., Weaver, A. C., and Hughes, K. K. 2004. "Health Insurance Portability and Accountability Act," Security Issues in the Digital Medical Enterprise (72:2), pp. 9-18.

Dyer, J. H., and Singh, H. 1998. "The Relational View: Cooperative Strategy and Sources of Interorganizational Competitive Advantage," The Academy of Management Review (23:4), pp. 660-679 (doi: 10.2307/259056).

Eden, K. B., Totten, A. M., Kassakian, S. Z., Gorman, P. N., McDonagh, M. S., Devine, B., Pappas, M., Daeges, M., Woods, S., and Hersh, W. R. 2016. "Barriers and facilitators to exchanging health information: a systematic review," International Journal of Medical Informatics (88), pp. 44-51 (doi: 10.1016/j.jmedinf.2016.01.004). 
Eisenhardt, K. M. 1989. "Agency Theory: An Assessment and Review," The Academy of Management Review (14:1), pp. 57-74 (doi: 10.2307/258191).

Ekeh, P. P. 1974. Social exchange theory: the two traditions, Harvard University Press.

Emerson, R. M. 1962. "Power-Dependence Relations," American Sociological Review (27:1), pp. 31-41 (doi: 10.2307/2089716).

Emerson, R. M. 1976. "Social Exchange Theory," Annual Review of Sociology (2), pp. 335-362.

Ermann, D., and Gabel, J. 1986. "Investor-owned multihospital systems: a synthesis of research findings," For-profit enterprise in health care (474), p. 491.

Florida-hie.net. (n.d.). "Florida Health Information Exchange," (available at https://www.florida-hie.net/; retrieved April 23, 2014).

Fontaine, P., Ross, S. E., Zink, T., and Schilling, L. M. 2010. "Systematic review of health information exchange in primary care practices," The Journal of the American Board of Family Medicine (23:5), pp. 655-670.

Fornell, C., Lorange, P., and Roos, J. 1990. "The cooperative venture formation process: A latent variable structural modeling approach," Management science (36:10), pp. 1246-1255. 
Fottler, M. D. 1981. "Is Management Really Generic?," The Academy of Management Review (6:1), pp. 1-12 (doi: 10.2307/257135).

Fottler, M. D. 1987. "Health care organizational performance: Present and future research," Journal of Management (13:2), pp. 367-391.

Frohlich, J., Karp, S., Smith, M. D., and Sujansky, W. 2007. "Retrospective: lessons learned from the Santa Barbara project and their implications for health information exchange," Health Affairs (26:5), pp. w589-w591.

Gandhi, T. K., Weingart, S. N., Borus, J., Seger, A. C., Peterson, J., Burdick, E., Seger, D. L., Shu, K., Federico, F., Leape, L. L., and Bates, D. W. 2003. "Adverse Drug Events in Ambulatory Care," New England Journal of Medicine (348:16), pp. 1556-1564 (doi: 10.1056/NEJMsa020703).

García-Canal, E., and Guillén, M. F. 2008. "Risk and the strategy of foreign location choice in regulated industries," Strategic Management Journal (29:10), pp. 1097-1115 (doi: 10.1002/smj.692).

Garde, S., Knaup, P., Hovenga, E. J., and Heard, S. 2007. "Towards Semantic Interoperability for Electronic Health Records-Domain Knowledge Governance for open EHR Archetypes," Methods of information in medicine (46:3), pp. 332-343.

Gartenfeld, E. 1978. "The Community Health Information Network," Library Journal (103:17), p. 1911. 
Gawthorp, L. 1971. Administrative policies and social change, New York: St. Martin's Press,.

Gefen, D., Straub, D., and Boudreau, M.-C. 2000. "Structural Equation Modeling and Regression: Guidelines for Research Practice," Communications of the Association for Information Systems (4:1), p. 7.

Granovetter, M. 1985. "Economic Action and Social Structure: The Problem of Embeddedness," American Journal of Sociology (91:3), pp. 481-510.

Greenberger, M. 2015. “Understanding health information exchange:," Nursing Management (Springhouse) (46:12), pp. 14-15 (doi: 10.1097/01.NUMA.0000473511.61549.90).

Gunn, P. P., Fremont, A. M., Bottrell, M., Shugarman, L. R., Galegher, J., and Bikson, T. 2004. "The Health Insurance Portability and Accountability Act Privacy Rule: A Practical Guide for Researchers," Medical Care (42:4), pp. $321-327$.

Hair, J. F. J., Black, W. C., Babin, B. J., and Anderson, R. E. 2010. "Multivariate Data Analysis Seventh Edition Prentice Hall.,"

Hair, J. F., Ringle, C. M., and Sarstedt, M. 2011. "PLS-SEM: Indeed a silver bullet," Journal of Marketing theory and Practice (19:2), pp. 139-152.

Hair Jr, J. F., and Hult, G. T. M. 2016. A primer on partial least squares structural equation modeling (PLS-SEM), Sage Publications (available at 
https://books.google.com/books?hl=en\&lr=\&id=Xn-

LCwAAQBAJ\&oi=fnd\&pg=PA9\&dq=A+Primer+on+Partial+Least+Squares

+Structural+Equation+Modeling\&ots=s198xXIMUF\&sig=Q1WwyBe7oc2mi

aGubHIYMyo34u0).

Hallén, L., Johanson, J., and Seyed-Mohamed, N. 1991. "Interfirm Adaptation in Business Relationships," Journal of Marketing (55:2), pp. 29-37 (doi: 10.2307/1252235).

Hamilton, S., and Chervany, N. L. 1981. "Evaluating Information System Effectiveness - Part I: Comparing Evaluation Approaches," MIS Quarterly (5:3), pp. 55-69 (doi: 10.2307/249291).

Hammond, W. E. 1994. "The Health Care Professional WorkstationThe role of standards in creating a health information infrastructure," International Journal of Bio-Medical Computing (34:1), pp. 29-44 (doi: 10.1016/00207101(94)90008-6).

Hansen, J. V., and Hill, N. C. 1989. "Control and Audit of Electronic Data Interchange," MIS Quarterly (13:4), pp. 403-413 (doi: 10.2307/248724).

HealthIT. (n.d.). "HITECH Act," (available at http://www.healthit.gov/policyresearchers-implementers/hitech-act-0; retrieved December 6, 2013).

HealthIT.gov. (n.d.). "What is HIE?," (available at https://www.healthit.gov/providers-professionals/health-informationexchange/what-hie; retrieved April 14, 2016 a). 
HealthIT.gov. (n.d.). "About ONC," (available at https://www.healthit.gov/newsroom/about-onc; retrieved April 15, 2016 b).

Heiler, S. 1995. "Semantic Interoperability," ACM Comput. Surv. (27:2), pp. 271273 (doi: 10.1145/210376.210392).

Helm, S., Eggert, A., and Garnefeld, I. 2010. "Modeling the Impact of Corporate Reputation on Customer Satisfaction and Loyalty Using Partial Least Squares," in Handbook of Partial Least SquaresSpringer Handbooks of Computational Statistics, V. E. Vinzi, W. W. Chin, J. Henseler, and H. Wang (eds.), Springer Berlin Heidelberg, pp. 515-534 (doi: 10.1007/978-3-54032827-8_23).

Hersh, W. R. 2015. "Outcomes From Health Information Exchange: Systematic Review and Future Research Needs," JMIR (3:4), p. e39.

HHS. 2001. "Information for Health: A Strategy for Building the National Health Information Infrastructure," ASPE (available at https://aspe.hhs.gov/legacypage/information-health-strategy-building-national-health-informationinfrastructure-151686; retrieved July 16, 2016).

Hill, C. W. L. 1995. "National Institutional Structures, Transaction Cost Economizing and Competitive Advantage: The Case of Japan," Organization Science (6:1), pp. 119-131.

Hillestad, R., Bigelow, J., Bower, A., Girosi, F., Meili, R., Scoville, R., and Taylor, R. 2005. "Can Electronic Medical Record Systems Transform Health Care? 
Potential Health Benefits, Savings, And Costs," Health Affairs (24:5), pp. 1103-1117 (doi: 10.1377/hlthaff.24.5.1103).

Hillestad, R., Bigelow, J. H., Chaudhry, B., Dreyer, P., Greenberg, M. D., Meili, R. C., Ridgely, M. S., Rothenberg, J., and Taylor, R. 2008. Identity Crisis: An Examination of the Costs and Benefits of a Unique Patient Identifier for the US Health Care System (Santa Monica, CA: Rand, 2008), RAND Corporation.

HIMSS. 2013. "Early CHINs and HIE Organizations: Lessons for the Next Evolution," HIMSS, August 11 (available at http://www.himss.org/earlychins-and-hie-organizations-lessons-next-evolution; retrieved August 1, 2016).

HIMSS. 2016. "What is Interoperability?," HIMSS, March 9 (available at http://www.himss.org/library/interoperability-standards/what-isinteroperability; retrieved July 15, 2016).

Homans, G. C. 1958. "Social Behavior as Exchange," American Journal of Sociology (63:6), pp. 597-606.

Homans, G. C. 1961. Social behavior: its elementary forms, Routledge \& Kegan Paul.

Howell, J. P., and Wall, L. C. 1983. "Executive leadership in an organized anarchy: the case of HSOs.," Health care management review (8:2), pp. 17-26. 
Hull, C. E., and Lio, B. H. 2006. "Innovation in non-profit and for-profit organizations: Visionary, strategic, and financial considerations," Journal of Change Management (6:1), pp. 53-65 (doi: 10.1080/14697010500523418).

Hulland, J. 1999. "Use of Partial Least Squares (PLS) in Strategic Management Research: A Review of Four Recent Studies," Strategic Management Journal (20:2), pp. 195-204.

Hussain, A., Rivers, P., Stewart, L., and Munchus, G. 2015. "Health Information Exchange: Current Challenges and Impediments to Implementing National Health Information Infrastructure," Journal of Health Care Finance (42:1) (available http://www.healthfinancejournal.com/index.php/johcf/article/view/32).

Hwang, Y. 2005. "Investigating enterprise systems adoption: uncertainty avoidance, intrinsic motivation, and the technology acceptance model," European journal of information systems (14:2), pp. 150-161.

lacovou, C. L., Benbasat, I., and Dexter, A. S. 1995. "Electronic Data Interchange and Small Organizations: Adoption and Impact of Technology," MIS Quarterly (19:4), pp. 465-485 (doi: 10.2307/249629).

Iroju, O., Soriyan, A., Gambo, I., and Olaleke, J. 2013. "Interoperability in healthcare: benefits, challenges and resolutions," International Journal of Innovation and Applied Studies (3:1), pp. 262-270. 
Jacob, J. 2015a. "GAO Issues Report on Health Information Interoperability," JAMA (314:18), pp. 1906-1906 (doi: 10.1001/jama.2015.15025).

Jacob, J. 2015b. "On the Road to Interoperability, Public and Private Organizations Work to Connect Health Care Data," JAMA (314:12), pp. 1213-1215 (doi: 10.1001/jama.2015.5930).

Jarvis, C. B., MacKenzie, S. B., and Podsakoff, P. M. 2003. "A Critical Review of Construct Indicators and Measurement Model Misspecification in Marketing and Consumer Research," Journal of Consumer Research (30:2), pp. 199218 (doi: 10.1086/jcr.2003.30.issue-2).

Jaworski, B. J., and Kohli, A. K. 1993. "Market Orientation: Antecedents and Consequences," Journal of Marketing (57:3), pp. $53-70$ (doi: 10.2307/1251854).

Jensen, M. C., and Meckling, W. H. 1976. "Theory of the Firm: Managerial Behavior, Agency Costs and Ownership Structure," Journal of Financial Economics (3:4), pp. 305-360.

Jha, A. K., Burke, M. F., DesRoches, C., Joshi, M. S., Kralovec, P. D., Campbell, E. G., and Buntin, M. B. 2011. “Progress Toward Meaningful Use: Hospitals' Adoption of Electronic Health Records," Mathematica Policy Research Reports No. d926cb2d284c44088cf4302f4fe9436e, , Mathematica Policy Research (available at 
https://ideas.repec.org/p/mpr/mprres/d926cb2d284c44088cf4302f4fe9436 e.html).

Jin, J., Ahn, G.-J., Hu, H., Covington, M. J., and Zhang, X. 2009. "Patient-centric Authorization Framework for Sharing Electronic Health Records," in Proceedings of the 14th ACM Symposium on Access Control Models and TechnologiesSACMAT '09, New York, NY, USA: ACM, pp. 125-134 (doi: 10.1145/1542207.1542228).

Johnston, M. E., Langton, K. B., Haynes, R. B., and Mathieu, A. 1994. "Effects of Computer-based Clinical Decision Support Systems on Clinician Performance and Patient Outcome," Annals of Internal Medicine (120:2), pp. $135-142$.

Kaelber, D. C., and Bates, D. W. 2007. "Health information exchange and patient safety," Journal of Biomedical Informatics (40), pp. S40-S45.

Karahanna, E., Straub, D. W., and Chervany, N. L. 1999. "Information Technology Adoption Across Time: A Cross-Sectional Comparison of Pre-Adoption and Post-Adoption Beliefs," MIS Quarterly (23:2), pp. 183-213 (doi: 10.2307/249751).

Kaushal, R., Shojania, K. G., and Bates, D. W. 2003. "Effects of computerized physician order entry and clinical decision support systems on medication safety - A systematic review," Archives of Internal Medicine (163), pp. 14091416 (doi: 10.1001/archinte.163.12.1409). 
Kawamoto, K., Houlihan, C. A., Balas, E. A., and Lobach, D. F. 2005. "Improving Clinical Practice Using Clinical Decision Support Systems: A Systematic Review Of Trials To Identify Features Critical To Success," BMJ: British Medical Journal (330:7494), pp. 765-768.

Kelley, H. H., and Thibaut, J. W. 1978. Interpersonal relations: a theory of interdependence, Wiley.

Kern, L. M., Barrón, Y., Dhopeshwarkar, R. V., Kaushal, R., and others. 2012. "Health information exchange and ambulatory quality of care," Appl Clin Inform (3:2), pp. 197-209.

Kern, L. M., and Kaushal, R. 2007. "Health information technology and health information exchange in New York State: New initiatives in implementation and evaluation," Journal of Biomedical Informatics (40:6, Supplement), pp. S17-S20 (doi: 10.1016/j.jbi.2007.08.010).

Khajouei, R., and Jaspers, M. W. M. 2010. "The Impact of CPOE Medication Systems' Design Aspects on Usability, Workflow and Medication Orders A Systematic Review," Methods of Information in Medicine (49), pp. 3-19 (doi: 10.3414/Me0630).

Kho, A. N., Lemmon, L., Commiskey, M., Wilson, S. J., and McDonald, C. J. 2008. "Use of a Regional Health Information Exchange to Detect Crossover of Patients with MRSA between Urban Hospitals," Journal of the American 
Medical Informatics Association (15:2), pp. 212-216 (doi: 10.1197/jamia.M2577).

Khurshid, A., Diana, M. L., and Jain, R. 2015. "Health Information Exchange Readiness for Demonstrating Return on Investment and Quality of Care," Perspectives in Health Information Management (12:Fall) (available at http://www.ncbi.nIm.nih.gov/pmc/articles/PMC4632873/).

Kline, R. B. 2010. Principles and Practice of Structural Equation Modeling, Third Edition, Guilford Press.

Kohn, L. T., Corrigan, J. M., and Donaldson, M. S. 2000. "To Err Is Human," (available

at https://www.researchgate.net/profile/Molla_Donaldson/publication/200656 918_To_Err_is_Human_Building_a_Safer_Health_System/links/556dde96 08aeab7772269c2e.pdf).

Kuperman, G. J., Bobb, A., Payne, T. H., Avery, A. J., Gandhi, T. K., Burns, G., Classen, D. C., and Bates, D. W. 2007. "Medication-related Clinical Decision Support in Computerized Provider Order Entry Systems: A Review," Journal of the American Medical Informatics Association (14:1), pp. 29-40 (doi: 10.1197/jamia.M2170).

Kuperman, G. J., and McGowan, J. J. 2013. "Potential unintended consequences of health information exchange," Journal of general internal medicine (28:12), pp. 1663-1666. 
Kutner, M., Nachtsheim, C., Neter, J., and Li, W. 2004. Applied Linear Statistical Models (5th edition.), Boston: McGraw-Hill/Irwin.

Kwon, T. H., and Zmud, R. W. 1987. "Critical Issues in Information Systems Research,"R. J. Boland Jr. and R. A. Hirschheim (eds.), New York, NY, USA: John Wiley \& Sons, Inc., pp. 227-251 (available at http://dl.acm.org/citation.cfm?id=54905.54915).

L'Abate, L. 1979. "Interpersonal Relations (Book)," Journal of Personality Assessment (43:6), p. 655.

LaBorde, D. V., Griffin, J. A., Smalley, H. K., Keskinocak, P., and Mathew, G. 2011. "A framework for assessing patient crossover and health information exchange value," Journal of the American Medical Informatics Association (18:5), pp. 698-703.

Lambe, C. J., Wittmann, C. M., and Spekman, R. E. 2001. "Social exchange theory and research on business-to-business relational exchange," Journal of Business-to-Business Marketing (8:3), pp. 1-36.

Lazarou J, Pomeranz BH, and Corey PN. 1998. "Incidence of adverse drug reactions in hospitalized patients: A meta-analysis of prospective studies," JAMA (279:15), pp. 1200-1205 (doi: 10.1001/jama.279.15.1200).

Leape LL, and Berwick DM. 2005. "Five years after to err is human: What have we learned?," JAMA (293:19), $\quad$ pp. 2384-2390 (doi: 10.1001/jama.293.19.2384). 
Lee, J.-N., and Kim, Y.-G. 1999. "Effect of Partnership Quality on IS Outsourcing Success: Conceptual Framework and Empirical Validation," Journal of Management Information Systems (15:4), pp. 29-61.

Lee, Y., and Kozar, K. A. 2008. "An empirical investigation of anti-spyware software adoption: A multitheoretical perspective," Information \& Management (45:2), pp. 109-119.

Levine, S., and White, P. E. 1961. "Exchange as a Conceptual Framework for the Study of Interorganizational Relationships," Administrative Science Quarterly (5:4), pp. 583-601 (doi: 10.2307/2390622).

Lichtenthaler, U. 2009. "Absorptive Capacity, Environmental Turbulence, and the Complementarity of Organizational Learning Processes," Academy of $\begin{array}{lllll}\text { Management Journal } & (52: 4), \quad \text { pp. } & \text { 822-846 }\end{array}$ 10.5465/AMJ.2009.43670902).

Litvin, C. B. 2007. "In the Dark - The Case for Electronic Health Records," New England Journal of Medicine (356:24), pp. 2454-2455 (doi: 10.1056/NEJMp068283).

Lorenzi, N. M. 2003. "Strategies for Creating Successful Local Health Information $\begin{array}{llll}\text { Infrastructure Initiatives," } & \text { (available at }\end{array}$ http://www.aspe.hhs.gov/sp/nhii/LHII-Lorenzi-12.16.03.pdf).

MacAvoy, P. W. 1979. "THE REGULATED INDUSTRIES AND THE ECONOMY," (available at https://trid.trb.org/view.aspx?id=151632). 
MacCallum, R. C., and Browne, M. W. 1993. "The use of causal indicators in covariance structure models: Some practical issues.," Psychological Bulletin (114:3), pp. 533-541 (doi: 10.1037/0033-2909.114.3.533).

Magrabi, F., Aarts, J., Nohr, C., Baker, M., Harrison, S., Pelayo, S., Talmon, J., Sittig, D. F., and Coiera, E. 2012. "A comparative review of patient safety initiatives for national health information technology," Int J Med Inform (doi: 10.1016/j.jmedinf.2012.11.014).

Mahajan, V., Muller, E., and Srivastava, R. K. 1990. "Determination of Adopter Categories by Using Innovation Diffusion Models," Journal of Marketing Research (JMR) (27:1), pp. 37-50.

Marchibroda, J. M. 2007. "Health information exchange policy and evaluation," Journal of Biomedical Informatics (40:6, Supplement), pp. S11-S16 (doi: 10.1016/j.jbi.2007.08.008).

Maslove, D. M., Rizk, N., and Lowe, H. J. 2011. "Computerized physician order entry in the critical care environment: a review of current literature," $\mathrm{J}$ Intensive Care Med (26), pp. 165-71 (doi: 10.1177/0885066610387984).

Mayer, R. C., Davis, J. H., and Schoorman, F. D. 1995. "An Integrative Model of Organizational Trust," The Academy of Management Review (20:3), pp. 709-734 (doi: 10.2307/258792).

McFadden, K. L., Henagan, S. C., and Gowen III, C. R. 2009. "The patient safety chain: Transformational leadership's effect on patient safety culture, 
initiatives, and outcomes," Journal of Operations Management (27:5), pp. 390-404 (doi: 10.1016/j.jom.2009.01.001).

McKnight, D. H., Cummings, L. L., and Chervany, N. L. 1998. "Initial Trust Formation in New Organizational Relationships," The Academy of Management Review (23:3), pp. 473-490 (doi: 10.2307/259290).

Meyer, J. W., and Rowan, B. 1977. "Institutionalized Organizations: Formal Structure as Myth and Ceremony," American Journal of Sociology (83:2), pp. 340-363.

Miller, R. H., and Miller, B. S. 2007. "The Santa Barbara County care data exchange: what happened?," Health Affairs (26:5), pp. w568-w580.

Miller, R., and Luft, H. 1994. "Managed care plan performance since 1980: A literature analysis," JAMA (271:19), pp. 1512-1519 (doi: 10.1001/jama.1994.03510430066037).

Mishra, V. m. 1996. "Diffusion of Innovations, 4th ed (Book)," Journalism \& Mass Communication Quarterly (73:1), pp. 249-250.

Molm, L. D. 1991. "Affect and Social Exchange: Satisfaction in Power-Dependence Relations," American Sociological Review (56:4), pp. 475-493 (doi: 10.2307/2096269).

Molm, L. D., and Cook, K. S. 1995. "Social exchange and exchange networks," Sociological perspectives on social psychology (2), pp. 209-235. 
Moore, G. C., and Benbasat, I. 1991. "Development of an Instrument to Measure the Perceptions of Adopting an Information Technology Innovation," Information Systems Research (2:3), pp. 192-222.

Moore, M. H. 2000. "Managing for Value: Organizational Strategy in For-Profit, Nonprofit, and Governmental Organizations," Nonprofit and Voluntary Sector Quarterly (29:suppl 1), pp. 183-208 (doi: 10.1177/089976400773746391).

Morgan, R. M. 1991. "Relationship commitment and trust in marketing," Ph.D., , United States -- Texas: Texas Tech University (available at http://search.proquest.com/docview/303941278/41C47D7159994C9APQ/ $5)$.

Moses III, H., Matheson, D. H., Dorsey, E. R., George, B. P., Sadoff, D., and Yoshimura, S. 2013. "The Anatomy of Health Care in the United States," JAMA (310:18), pp. 1947-1963.

Mukhopadhyay, T., Kekre, S., and Kalathur, S. 1995. "Business Value of Information Technology: A Study of Electronic Data Interchange," MIS Quarterly (19:2), pp. 137-156 (doi: 10.2307/249685).

Murray, M. A. 1975. "Comparing Public and Private Management: An Exploratory Essay," Public Administration Review (35:4), pp. 364-371 (doi: 10.2307/974538). 
Muthusamy, S. K., and White, M. A. 2005. "Learning and knowledge transfer in strategic alliances: a social exchange view," Organization Studies (26:3), pp. $415-441$.

Narasimhan, R., Nair, A., Griffith, D. A., Arlbjørn, J. S., and Bendoly, E. 2009. "Lock-in situations in supply chains: A social exchange theoretic study of sourcing arrangements in buyer-supplier relationships," Journal of Operations Management (27:5), pp. 374-389.

Nebeker, J. R., Hoffman, J. M., Weir, C. R., Bennett, C. L., and Hurdle, J. F. 2005. "High rates of adverse drug events in a highly computerized hospital," Archives of Internal Medicine (165), pp. 1111-1116 (doi: 10.1001/archinte.165.10.1111).

Newkirk, H. E., and Lederer, A. L. 2006. "The effectiveness of strategic information systems planning under environmental uncertainty," Information \& Management (43:4), pp. 481-501 (doi: 10.1016/j.im.2005.12.001).

Nunnally, J. C., and Bernstein, I. H. 1994. Psychometric Theory (3rd edition.), New York: McGraw-Hill.

Ouchi, W. G. 1980. "Markets, Bureaucracies, and Clans," Administrative Science Quarterly (25:1), pp. 129-141 (doi: 10.2307/2392231).

Overhage, J. M. 2007. "Health Information Exchange: 'Lex Parsimoniae,"” Health Affairs (26:5), pp. w595-w597 (doi: 10.1377/hlthaff.26.5.w595). 
Panel on Understanding Cross-National Health Differences Among High-Income Countries, Committee on Population, Division of Behavioral and Social Sciences and Education, National Research Council, Board on Population Health and Public Health Practice, and Institute of Medicine. 2013. U.S. Health in International Perspective: Shorter Lives, Poorer Health, National Academies Press.

"Patient Look-Up | Florida Health Information Exchange.," (n.d.). (available at https://www.florida-hie.net/plu/index.html; retrieved June 24, 2017).

Pauly, M. V. 1986. "Taxation, health insurance, and market failure in the medical economy," Journal of Economic Literature, pp. 629-675.

Payne, T. H., Bates, D. W., Berner, E. S., Bernstam, E. V., Covvey, H. D., Frisse, M. E., Graf, T., Greenes, R. A., Hoffer, E. P., Kuperman, G., Lehmann, H. P., Liang, L., Middleton, B., Omenn, G. S., and Ozbolt, J. 2013. "Healthcare information technology and economics," Journal of the American Medical Informatics Association (20:2), pp. 212-217 (doi: 10.1136/amiajnl-2012000821).

Payton, F. C., and Ginzberg, M. J. 2001. "Interorganizational health care systems implementations: An exploratory study of early electronic commerce initiatives," Health Care Management Review (26:2), pp. 20-32.

Pfeffer, J., and Salancik, G. R. 1978. The external control of organizations: a resource dependence perspective, New York: Harper \& Row. 
Pouloudi, A. 1999. "Information technology for collaborative advantage in healthcare revisited," Information \& Management (35:6), pp. 345-356 (doi: 10.1016/S0378-7206(98)00099-8).

Rahurkar, S., Vest, J. R., and Menachemi, N. 2015. "Despite The Spread Of Health Information Exchange, There Is Little Evidence Of Its Impact On Cost, Use, And Quality Of Care," Health Affairs (34:3), pp. 477-483 (doi: 10.1377/hlthaff.2014.0729).

Rai, A., and Patnayakuni, R. 1996. "A Structural Model for CASE Adoption Behavior," Journal of Management Information Systems (13:2), pp. 205234.

Rai, A., and Tang, X. 2010. "Leveraging IT Capabilities and Competitive Process Capabilities for the Management of Interorganizational Relationship Portfolios," Information Systems Research (21:3), pp. 516-542 (doi: 10.1287/isre.1100.0299).

Rainey, H. G., Backoff, R. W., and Levine, C. H. 1976. "Comparing Public and Private Organizations," Public Administration Review (36:2), pp. 233-244 (doi: 10.2307/975145).

Ranji, S. R., Rennke, S., and Wachter, R. M. 2013. "Computerized Provider Order Entry With Clinical Decision Support Systems: Brief Update Review," (available at http://www.ncbi.nlm.nih.gov/books/NBK133383/). 
Reckmann, M. H., Westbrook, J. I., Koh, Y., Lo, C., and Day, R. O. 2009. “Does Computerized Provider Order Entry Reduce Prescribing Errors for Hospital Inpatients? A Systematic Review," Journal of the American Medical Informatics Association (16), pp. 613-623 (doi: 10.1197/Jamia.M3050).

Ringle, C. M., Sarstedt, M., and Straub, D. W. 2012. "A Critical Look at the Use of PLS-SEM in MIS Quarterly," MIS Quarterly (36:1), p. iiv-8.

Roberts, N., Galluch, P. S., Dinger, M., and Grover, V. 2012. "Absorptive capacity and information systems research: Review, synthesis, and directions for future research.," MIS quarterly (36:2), pp. 625-648.

Rogers, E. M. 1962. Diffusion of innovations, Free Press of Glencoe.

Rogers, E. M. 1983. Diffusion of innovations, New York; London: Free Press; Collier Macmillan.

Rogers, E. M. 1995. Diffusion of innovations, New York; London: Free Press; Collier Macmillan.

Rogers, E. M. 2003. Diffusion of innovations, New York: Free Press.

Rogers, E. M., and Kincaid, D. L. 1981. Communication networks: toward a new paradigm for research, Free Press.

Ross, S. E., Radcliff, T. A., LeBlanc, W. G., Dickinson, L. M., Libby, A. M., and Nease, D. E. 2013. "Effects of health information exchange adoption on 
ambulatory testing rates," Journal of the American Medical Informatics Association (20:6), pp. 1137-1142.

van Rosse, F., Maat, B., Rademaker, C. M., van Vught, A. J., Egberts, A. C., and Bollen, C. W. 2009. "The effect of computerized physician order entry on medication prescription errors and clinical outcome in pediatric and intensive care: a systematic review," Pediatrics (123), pp. 1184-90 (doi: 10.1542/peds.2008-1494).

Rubenstein, G. 2013. "New Health Rankings: Of 17 Nations, U.S. Is Dead Last," The Atlantic (available at http://www.theatlantic.com/health/archive/2013/01/new-health-rankings-of17-nations-us-is-dead-last/267045/).

Rudin, R. S., Motala, A., Goldzweig, C. L., and Shekelle, P. G. 2014. "Usage and Effect of Health Information Exchange," Annals of Internal Medicine (161:11), pp. 803-811 (doi: 10.7326/M14-0877).

Rudin, R. S., Salzberg, C. A., Szolovits, P., Volk, L. A., Simon, S. R., and Bates, D. W. 2011. "Care transitions as opportunities for clinicians to use data exchange services: how often do they occur?," Journal of the American Medical Informatics Association (18:6), pp. 853-858.

Rudin, R. S., Simon, S. R., Volk, L. A., Tripathi, M., and Bates, D. 2009. "Understanding the Decisions and Values of Stakeholders in Health 
Information Exchanges: Experiences From Massachusetts," American Journal of Public Health (99:5), pp. 950-5.

Rust, R. T., and Zahorik, A. J. 1993. "Customer satisfaction, customer retention, and market share," Journal of retailing (69:2), pp. 193-215.

Sahin, I., and Thompson, A. 2006. "Using Rogers' theory to interpret instructional computer use by COE faculty," Journal of Research on Technology in Education (39:1), pp. 81-104.

Sattler, H., Völckner, F., Riediger, C., and Ringle, C. M. 2010. "The impact of brand extension success drivers on brand extension price premiums," International Journal of Research in Marketing (27:4), pp. 319-328.

Shao, Z., Feng, Y., and Hu, Q. 2016. "Effectiveness of top management support in enterprise systems success: a contingency perspective of fit between leadership style and system life-cycle," European Journal of Information Systems (25:2), pp. 131-153 (doi: 10.1057/ejis.2015.6).

Sia, C.-L., Teo, H.-H., Tan, B. C. Y., and Wei, K.-K. 2004. "Effects of environmental uncertainty on organizational intention to adopt distributed work arrangements," IEEE Transactions on Engineering Management (51:3), pp. 253-267 (doi: 10.1109/TEM.2004.830859).

Sloan, F. A. 2000. "Chapter 21 Not-for-profit ownership and hospital behavior,"B.H. of H. Economics (ed.) (Vol. 1, Part B), Elsevier, pp. 1141-1174 (available at http://www.sciencedirect.com/science/article/pii/S1574006400800347). 
Sobel, M. E. 1982. "Asymptotic confidence intervals for indirect effects in structural equation models," Sociological methodology (13), pp. 290-312.

Son, J.-Y. 2001. "Explaining EDI-based electronic cooperation in customersupplier interfirm relationships: An empirical study," United States -Georgia: Georgia Institute of Technology (available at http://search.proquest.com/docview/252092123/abstract/99AE09851D104 17BPQ/1).

Son, J.-Y., Narasimhan, S., and Riggins, F. J. 2005. "Effects of relational factors and channel climate on EDI usage in the customer-supplier relationship," Journal of Management Information Systems (22:1), pp. 321-353.

Spanos, Y. E. 2012. "Absorptive capacity and the propensity to adopt advanced technology: the case of computer integrated manufacturing (CIM) systems," International Journal of Information Technology and Management (11:4), pp. 323-346.

Spiller, J., Vlasic, A., and Yetton, P. 2007. "Post-adoption behavior of users of Internet Service Providers," Information \& Management (44:6), pp. 513-523 (doi: 10.1016/j.im.2007.01.003).

Srinivasan, K., Kekre, S., and Mukhopadhyay, T. 1994. "Impact of Electronic Data Interchange Technology on JIT Shipments," Management Science (40:10), pp. $1291-1304$. 
Staggers, N., Thompson, C., and Snyder-Halpern, R. 2001. "History and trends in clinical information systems in the United States," Journal of Nursing Scholarship (33:1), pp. 75-81.

Steber, C. (n.d.). "IT Spending in Healthcare on the Rise, Growing Fast Towards 2019," (available at http://www.cfrinc.net/cfrblog/it-spending-in-healthcareon-the-rise-growing-fast-towards-2019; retrieved July 5, 2016).

Steensma, H. K., and Lyles, M. A. 2000. "Explaining IJV survival in a transitional economy through social exchange and knowledge-based perspectives," Strategic Management Journal (21:8), pp. 831-851.

Steinbrook, R. 2009. "Health Care and the American Recovery and Reinvestment Act," The New England Journal of Medicine (360:11), pp. 1057-60 (doi: http://dx.doi.org/10.1056/NEJMp0900665).

Stephane Bignoux. 2006. "Short-term strategic alliances: a social exchange perspective," Management Decision (44:5), pp. 615-627 (doi: $10.1108 / 00251740610668879)$.

Stewart, B. A., Fernandes, S., Rodriguez-Huertas, E., and Landzberg, M. 2010. "A preliminary look at duplicate testing associated with lack of electronic health record interoperability for transferred patients," Journal of the American Medical Informatics Association (17:3), pp. 341-344 (doi: 10.1136/jamia.2009.001750). 
T., J., and Gullahorn, J. E. 1962. "Review," The Sociological Quarterly (3:4), pp. 357-358.

Takahashi, N. 2000. "The Emergence of Generalized Exchange," American Journal of Sociology (105:4), pp. 1105-1134.

Tanskanen, K. 2015. "Who wins in a complex buyer-supplier relationship? A social exchange theory based dyadic study," International Journal of Operations \& Production Management (35:4), pp. 577-603 (doi: 10.1108/IJOPM-102012-0432)

The Commonwealth Fund. 2014. "US Health System Ranks Last Among Eleven Countries on Measures of Access, Equity, Quality, Efficiency, and Healthy Lives," (available at http://www.commonwealthfund.org/publications/pressreleases/2014/jun/us-health-system-ranks-last; retrieved April 9, 2016).

The United States Congress. 1996. "Health insurance portability and accountability act of 1996," Public law (104), p. 191.

The White House. (n.d.). "Executive Order: Incentives for the Use of Health Information Technology and Establishing the Position of the National Health Information Technology Coordinator," (available at https://georgewbushwhitehouse.archives.gov/news/releases/2004/04/20040427-4.html; retrieved April 15, 2016).

Thibaut, J. W., and Kelley, H. H. 1959. "The social psychology of groups.," (available at http://psycnet.apa.org/psycinfo/1960-04214-000). 
Thompson. 1967. "Organizations in Action ori.,"

Thong, J. Y. L., Yap, C.-S., and Raman, K. S. 1996. "Top Management Support, External Expertise and Information Systems Implementation in Small Businesses," Information Systems Research (7:2), pp. 248-267.

Tremblay, M. C., and Deckard, G. J. 2014. "Health Information Exchange Project Evaluation Annual Report 2014.,"

Tsai, W. 2001. "Knowledge Transfer in Intraorganizational Networks: Effects of Network Position and Absorptive Capacity on Business Unit Innovation and Performance," Academy of Management Journal (44:5), pp. 996-1004 (doi: 10.2307/3069443).

Turner, R. H. 1961. "Review," American Sociological Review (26:4), pp. 635-636 (doi: 10.2307/2090265).

Uzzi, B. 1997. "Social Structure and Competition in Interfirm Networks: The Paradox of Embeddedness," Administrative Science Quarterly (42:1), pp. 35-67 (doi: 10.2307/2393808).

Van Laere, J., and Aggestam, L. 2016. "Understanding Champion Behaviour in a Health-Care Information System Development Project-How Multiple Champions and Champion Behaviours Build a Coherent Whole," European Journal of Information Systems (25:1), pp. 47-63. 
Van Slyke, C., Belanger, F., and Comunale, C. L. 2004. "Factors influencing the adoption of web-based shopping: the impact of trust," ACM Sigmis Database (35:2), pp. 32-49.

Veltman, K. H. 2001. "Syntactic and semantic interoperability: new approaches to knowledge and the semantic web," New Review of Information Networking (7:1), pp. 159-183.

Venkatesh, V., and Bala, H. 2012. "Adoption and impacts of interorganizational business process standards: Role of partnering synergy," Information Systems Research (23:4), pp. 1131-1157.

Vest, J. R., and Gamm, L. D. 2010. "Health information exchange: persistent challenges and new strategies," Journal of the American Medical Informatics Association (17:3), pp. 288-294 (doi: 10.1136/jamia.2010.003673).

Vest, J. R., Jr, T. R. C., Kaushal, R., and Investigators, for the H. 2013. "Challenges, Alternatives, and Paths to Sustainability for Health Information Exchange Efforts," Journal of Medical Systems (37:6), pp. 1-8 (doi: 10.1007/s10916-013-9987-7).

Vest, J. R., and Kash, B. A. 2016. "Differing Strategies to Meet Information-Sharing Needs: Publicly Supported Community Health Information Exchanges Versus Health Systems' Enterprise Health Information Exchanges," The Milbank Quarterly (94:1), pp. 77-108 (doi: 10.1111/1468-0009.12180). 
Vinzi, V. E., Chin, W. W., Henseler, J., and Wang, H. 2010. Handbook of partial least squares: Concepts, methods and applications, Springer Science \& $\begin{array}{llll}\text { Business } & \text { Media }\end{array}$ https://books.google.com/books?hl=en\&lr=\&id=PPUbvBUvmWoC\&oi=fnd $\& p g=P R 3 \& d q=+$ Handbook + of + partial+least + squares,$+2010 \&$ ots $=8$ Ts $08 \mathrm{H}$ Zdqu\&sig=HjuBCVjp9ktGOfHeJpRnkVSTxDk).

Vitale, M. R., and Johnson, H. R. 1988. "Creating competitive advantage with interorganizational information systems," MIS Quart (12:2), pp. 152-165.

Wager, K. A., Lee, F. W., and Glaser, J. P. 2013. Health Care Information Systems: A Practical Approach for Health Care Management, John Wiley \& Sons.

Waldman, D. A., Ramírez, G. G., House, R. J., and Puranam, P. 2001. "Does Leadership Matter? CEO Leadership Attributes and Profitability under Conditions of Perceived Environmental Uncertainty," The Academy of Management Journal (44:1), pp. 134-143 (doi: 10.2307/3069341).

Walker, J., Pan, E., Johnston, D., Adler-Milstein, J., Bates, D. W., and Middleton, B. 2005. "The Value of Health Care Information Exchange and Interoperability," HEALTH AFFAIRS-MILLWOOD VA THEN BETHESDA MA- (24), p. W5.

Wang, Wenguang, Tolk, A., and Wang, Weiping. 2009. "The levels of conceptual interoperability model: applying systems engineering principles to M\&S," in Proceedings of the 2009 Spring Simulation Multiconference, Society for 
Computer Simulation International, p. 168 (available at http://dl.acm.org/citation.cfm?id=1655398).

Weber, R. 2001. "Understanding Information Systems Continuance: An Expectation-Confirmation Model," MIS Quarterly (25:3), pp. 321-321.

Weidenbaum, M. L. 1970. Modern Public Sector: New Ways of Doing the Government's Business, Basic Books Inc.,U.S.

Werling, J., Nyhus, D., Horst, R., Meade, D., and Wittek, T. 2014. “The Supply Side of Health Care," (available at http://inforumweb.umd.edu/papers/publishedwork/articles/SupplySideOfHe althCareWorkingPaper.pdf).

Wilcox, A. B., Kuperman, G. J., Dorr, D. A., Hripcsak, G., Narus, S. P., Thornton, S. N., and Evans, R. S. 2006. "Architectural strategies and issues with health information exchange.," in AMIA (available at https://intermountainhealthcare.org/ /media/Files/Research/medicalinformatics-arch-strategies-and-hie.pdf).

Williams, C., Mostashari, F., Mertz, K., Hogin, E., and Atwal, P. 2012. "From The Office Of The National Coordinator: The Strategy For Advancing The Exchange Of Health Information," Health Affairs (31:3), pp. 527-536 (doi: 10.1377/hlthaff.2011.1314).

Williamson, O. E. 1975. "The Limits of Organization (Book)," Journal of Business (48:3), pp. 452-453. 
Williamson, O. E. 1979. "Transaction-Cost Economics: The Governance of Contractual Relations," Journal of Law and Economics (22:2), pp. 233-261.

Wolfstadt, J. I., Gurwitz, J. H., Field, T. S., Lee, M., Kalkar, S., Wu, W., and Rochon, P. A. 2008. "The Effect of Computerized Physician Order Entry with Clinical Decision Support on the Rates of Adverse Drug Events: A Systematic Review," Journal of General Internal Medicine (23:4), pp. 451458 (doi: 10.1007/s11606-008-0504-5).

Wu, H., and Larue, E. 2015. "Barriers and Facilitators of Health Information Exchange (HIE) Adoption in the United States," in 2015 48th Hawaii International Conference on System Sciences (HICSS), Presented at the 2015 48th Hawaii International Conference on System Sciences (HICSS), , January, pp. 2942-2949 (doi: 10.1109/HICSS.2015.356).

Xia, W., and Lee, G. 2005. "Complexity of Information Systems Development Projects: Conceptualization and Measurement Development," Journal of Management Information Systems (22:1), pp. 45-83.

Yamagishi, T., and Cook, K. S. 1993. "Generalized Exchange and Social Dilemmas," Social Psychology Quarterly (56:4), pp. 235-248 (doi: $10.2307 / 2786661)$.

Yaraghi, N. 2015. "An empirical analysis of the financial benefits of health information exchange in emergency departments," Journal of the American Medical Informatics Association, p. ocv068. 
Yaraghi, N., Du, A. Y., Sharman, R., Gopal, R. D., and Ramesh, R. 2014. "Health Information Exchange as a Multisided Platform: Adoption, Usage, and Practice Involvement in Service Co-Production," Information Systems Research (26:1), pp. 1-18 (doi: 10.1287/isre.2014.0547).

Yasnoff, W. A., Humphreys, B. L., Overhage, J. M., Detmer, D. E., Brennan, P. F., Morris, R. W., Middleton, B., Bates, D. W., and Fanning, J. P. 2004. "A Consensus Action Agenda for Achieving the National Health Information Infrastructure," Journal of the American Medical Informatics Association (11:4), pp. 332-338 (doi: 10.1197/jamia.M1616).

Zahra, S. A., and George, G. 2002. "Absorptive Capacity: A Review, Reconceptualization, and Extension," The Academy of Management Review (27:2), pp. 185-203 (doi: 10.2307/4134351).

Zeitlin, I. M. 1975. "Social Behavior: Its Elementary Forms (Book)," Social Forces (54:2), pp. 474-475.

Zucker, L. G. 1977. "The Role of Institutionalization in Cultural Persistence," American Sociological Review (42:5), pp. 726-743. 


\section{APPENDIX}

\section{A. All survey questionnaire items}

\begin{tabular}{|c|c|c|c|}
\hline Constructs & $\begin{array}{l}\text { Item } \\
\text { ID }\end{array}$ & Items & $\begin{array}{l}\text { Key } \\
\text { references }\end{array}$ \\
\hline $\begin{array}{l}\text { HIE adoption } \\
\text { intention }\end{array}$ & Adop & $\begin{array}{l}\text { 1. Within a year, we intend to use HIE to collaborate } \\
\text { with other organizations. } \\
\text { 2. Within a year, we intend to incorporate HIE into } \\
\text { our operations. } \\
\text { 3. We should use HIE soon. } \\
\text { 4. We are actively seeking to adopt and use HIE. }\end{array}$ & $\begin{array}{l}\text { (Lee and } \\
\text { Kozar } \\
\text { 2008) }\end{array}$ \\
\hline $\begin{array}{l}\text { Absorptive } \\
\text { capacity }\end{array}$ & Absor & $\begin{array}{l}\text { In our organization, people ... } \\
\text { 1. understand what HIE can do for us. } \\
\text { 2. need extensive training to develop skills to } \\
\text { properly use HIE.* } \\
\text { 3. can make good use of HIE capabilities. } \\
\text { 4. can easily incorporate HIE into their work routines. }\end{array}$ & $\begin{array}{l}\text { (Cohen and } \\
\text { Levinthal } \\
\text { 1989) }\end{array}$ \\
\hline $\begin{array}{l}\text { Top } \\
\text { management } \\
\text { support }\end{array}$ & Top & $\begin{array}{l}\text { Our top management ... } \\
\text { 1. allows autonomy in IT management. } \\
\text { 2. provides strong IT leadership. } \\
\text { 3. champions IT innovations. } \\
\text { 4. understands how IT supports our organization's } \\
\text { goals. } \\
\text { is willing to invest in HIE even without government } \\
\text { financial incentives. }\end{array}$ & $\begin{array}{l}\text { (Rai and } \\
\text { Patnayakun } \\
\text { i 1996) }\end{array}$ \\
\hline Trust & & & \\
\hline
\end{tabular}




\begin{tabular}{|c|c|c|c|}
\hline $\begin{array}{l}\text { Trust in HIE } \\
\text { partner's } \\
\text { ability }\end{array}$ & TrAb & $\begin{array}{l}\text { Our potential HIE partners (other healthcare providers } \\
\text { who would use the same HIE platform to exchange } \\
\text { information with your organization) ... } \\
\text { 1. would be competent and effective in their } \\
\text { interactions with us. } \\
\text { 3. would perform all of their roles very well. } \\
\text { 4. would be capable and proficient. } \\
\text { exchange operations. }\end{array}$ & $\begin{array}{l}\text { (Venkatesh } \\
\text { and Bala } \\
\text { 2012) } \\
\text { (Muthusam } \\
\text { y and White } \\
\text { 2005) }\end{array}$ \\
\hline $\begin{array}{l}\text { Trust in HIE } \\
\text { partner's } \\
\text { benevolence }\end{array}$ & TrBe & $\begin{array}{l}\text { 1. would act in our best interest. } \\
\text { 2. would do their best to provide assistance } \\
\text { whenever we need their help. } \\
\text { 3. would be interested in our well-being rather than } \\
\text { just their own. } \\
\text { would be generous in accommodating our needs. }\end{array}$ & $\begin{array}{l}\text { (Venkatesh } \\
\text { and Bala } \\
\text { 2012) } \\
\text { (Muthusam } \\
\text { y and White } \\
\text { 2005) }\end{array}$ \\
\hline $\begin{array}{l}\text { Trust in HIE } \\
\text { partner's } \\
\text { integrity }\end{array}$ & Trln & $\begin{array}{l}\text { 1. would be honest. } \\
\text { 2. would be truthful in their dealings with us. } \\
\text { 3. would adhere to high professional standards. } \\
\text { 4. would be consistent in keeping their commitments. }\end{array}$ & $\begin{array}{l}\text { (Venkatesh } \\
\text { and Bala } \\
\text { 2012) } \\
\text { (Muthusam } \\
\text { y and White } \\
\text { 2005) }\end{array}$ \\
\hline $\begin{array}{l}\text { Trust in the } \\
\text { broad HIE } \\
\text { platform }\end{array}$ & TrSy & $\begin{array}{l}\text { 1. We trust our potential HIE partners. } \\
\text { 2. We trust the HIE system. } \\
\text { 3. We trust government policy's support of HIE. } \\
\text { 4. We trust HIE vendor(s). }\end{array}$ & $\begin{array}{l}\text { Self- } \\
\text { developed }\end{array}$ \\
\hline $\begin{array}{l}\text { Environmenta } \\
\text { I Uncertainty }\end{array}$ & & & \\
\hline
\end{tabular}




\begin{tabular}{|c|c|c|c|}
\hline $\begin{array}{l}\text { Government } \\
\text { policy } \\
\text { uncertainty }\end{array}$ & UcPo & $\begin{array}{l}\text { Relating to HIE, government policies ... } \\
\text { 1. change frequently. } \\
\text { 2. are often ambiguous. } \\
\text { 3. create uncertainty for our industry if they change. } \\
\text { 4. are often inconsistent. }\end{array}$ & $\begin{array}{l}\text { (Waldman } \\
\text { et al. 2001) }\end{array}$ \\
\hline $\begin{array}{l}\text { Environmenta } \\
\text { I technology } \\
\text { uncertainty }\end{array}$ & $\begin{array}{l}\text { UcTe } \\
\text { c }\end{array}$ & $\begin{array}{l}\text { 1. Technologies relating to HIE frequently change. } \\
\text { 2. Technology changes create uncertainty for the } \\
\text { industry. } \\
\text { 3. Technological trends in our industry are difficult to } \\
\text { predict. } \\
\text { 4. The existence of many HIE technologies creates } \\
\text { uncertainty for our industry. }\end{array}$ & $\begin{array}{l}\text { (Newkirk } \\
\text { and Lederer } \\
2006)\end{array}$ \\
\hline $\begin{array}{l}\text { Adoption } \\
\text { pressures }\end{array}$ & Pres & $\begin{array}{l}\text { 1. Our patients expect us to use HIE. } \\
\text { 2. We are pressured to use HIE because many of our } \\
\text { competitors use it. } \\
\text { 3. We are pressured by the government's policy to } \\
\text { adopt HIE. } \\
\text { 4. Many providers believe using HIE is inevitable. }\end{array}$ & $\begin{array}{l}\text { (Moore and } \\
\text { Benbasat } \\
\text { 1991) } \\
\text { (Van Slyke } \\
\text { et al. 2004) }\end{array}$ \\
\hline $\begin{array}{l}\text { HIE } \\
\text { characteristic } \\
\text { s as an } \\
\text { innovation }\end{array}$ & Char & $\begin{array}{l}\text { 1. HIE is compatible with our existing systems. } \\
\text { 2. HIE is complex to use.* } \\
\text { 3. The results of using HIE can be easily } \\
\text { demonstrated. } \\
\text { 4. We would be able to try out HIE before actual } \\
\text { adoption. } \\
\text { Other providers' HIE use is visible (can be } \\
\text { commonly seen) in our industry. }\end{array}$ & $\begin{array}{l}\text { (Rogers } \\
1962)\end{array}$ \\
\hline
\end{tabular}




\begin{tabular}{|c|c|c|c|}
\hline $\begin{array}{l}\text { Risk of the } \\
\text { organization }\end{array}$ & & & \\
\hline $\begin{array}{l}\text { Risk of the } \\
\text { organization- } \\
\text { financial } \\
\text { aspect }\end{array}$ & RkFn & $\begin{array}{l}\text { For our organization, HIE might ... } \\
\text { 1. require too much investment. } \\
\text { 2. end up financially unsustainable once government } \\
\text { funding support runs out. } \\
\text { 3. cause us financial losses when we share patients' } \\
\text { information with other providers. }\end{array}$ & $\begin{array}{l}\text { (Vest et al. } \\
\text { 2013) }\end{array}$ \\
\hline $\begin{array}{l}\text { Risk of the } \\
\text { organization - } \\
\text { operational } \\
\text { aspect }\end{array}$ & RkOp & $\begin{array}{l}\text { 1. compromise our patients' information. } \\
\text { 2. make coordination with other HIE partners difficult. } \\
\text { 3. constrain our operations because it does not } \\
\text { include many providers we work with. } \\
\text { 4. cause work flow interruptions. } \\
\text { 5. make our work process cumbersome. }\end{array}$ & $\begin{array}{l}\text { (Iroju et al. } \\
\text { 2013) } \\
\text { (Lorenzi } \\
\text { 2003) }\end{array}$ \\
\hline $\begin{array}{l}\text { Risk of the } \\
\text { organization- } \\
\text { technological } \\
\text { aspect }\end{array}$ & RkTe & $\begin{array}{l}\text { 1. be technologically difficult to implement. } \\
\text { 2. cause technological interoperability problems. } \\
\text { 3. lead to patient information security breaches. } \\
\text { 4. fail to deliver its promised technical capabilities. }\end{array}$ & $\begin{array}{l}\text { (Detmer } \\
\text { 2003) } \\
\text { (Iroju et al. } \\
2013 \text { ) } \\
\text { (Rudin et al. } \\
2014 \text { ) }\end{array}$ \\
\hline $\begin{array}{l}\text { Relative } \\
\text { Advantage }\end{array}$ & & & \\
\hline $\begin{array}{l}\text { Relative } \\
\text { advantage - } \\
\text { financial } \\
\text { aspect }\end{array}$ & RaFn & $\begin{array}{l}\text { By joining HIE, we would... } \\
\text { 1. gain a financial advantage. } \\
\text { 2. reduce our patient care costs. } \\
\text { 3. leverage on government financial incentives. }\end{array}$ & $\begin{array}{l}\text { (Moore and } \\
\text { Benbasat } \\
\text { 1991) }\end{array}$ \\
\hline
\end{tabular}




\begin{tabular}{|c|c|c|c|}
\hline & & 4. make financial gains by expanding our services. & \\
\hline $\begin{array}{l}\text { Relative } \\
\text { advantage - } \\
\text { operational } \\
\text { aspect }\end{array}$ & $\mathrm{RaOp}$ & $\begin{array}{l}\text { Using HIE would... } \\
\text { 1. improve our work efficiency. } \\
\text { 2. improve our patient care quality. } \\
\text { 3. improve our collaboration with other providers. } \\
\text { 4. improve our patients' satisfaction. } \\
\text { 5. improve our patients' healthcare outcomes. } \\
\text { 6. improve our medical staffs' experience. } \\
\text { 7. make it easier to take care our patients. } \\
\text { 8. give us greater control over our work. }\end{array}$ & $\begin{array}{l}\text { (Moore and } \\
\text { Benbasat } \\
\text { 1991) } \\
\text { (Kuperman } \\
\text { and } \\
\text { McGowan } \\
\text { 2013) }\end{array}$ \\
\hline $\begin{array}{l}\text { Relative } \\
\text { advantage - } \\
\text { technological } \\
\text { aspect }\end{array}$ & RaTc & $\begin{array}{l}\text { Using HIE would... } \\
\text { 1. improve our technological infrastructure. } \\
\text { 2. make us more technologically efficient. } \\
\text { 3. make us more technologically competitive. } \\
\text { 4. make our healthcare delivery more technologically } \\
\text { secure. }\end{array}$ & $\begin{array}{l}\text { (Jaworski } \\
\text { and Kohli } \\
\text { 1993) }\end{array}$ \\
\hline
\end{tabular}

Table A1: Operationalizations of all constructs for adopt intentions

${ }^{*}$ Reverse coded items.

\begin{tabular}{|c|c|c|c|}
\hline Constructs & $\begin{array}{l}\text { Item } \\
\text { ID }\end{array}$ & Items & $\begin{array}{l}\text { Key } \\
\text { references }\end{array}$ \\
\hline $\begin{array}{l}\text { HIE } \\
\text { continuous } \\
\text { intention }\end{array}$ & Cont & $\begin{array}{l}\text { 1. We intend to continuously use the HIE we are } \\
\text { using right now. } \\
\text { 2. We are actively looking for a new HIE vendor.* } \\
\text { 3. Joining the current HIE is a mistake for us.* } \\
\text { 4. We often discuss switching to a different HIE.* }\end{array}$ & $\begin{array}{l}\text { (Bhattacherje } \\
\text { e et al. 2008) }\end{array}$ \\
\hline
\end{tabular}




\begin{tabular}{|c|c|c|c|}
\hline $\begin{array}{l}\text { Absorptive } \\
\text { capacity** }^{*}\end{array}$ & Absor & $\begin{array}{l}\text { In our organization, people ... } \\
\text { 5. understand what HIE can do for us. } \\
\text { 6. need extensive training to develop skills to } \\
\text { properly use HIE.* } \\
\text { 7. can make good use of HIE capabilities. } \\
\text { 8. can easily incorporate HIE into their work } \\
\text { routines. }\end{array}$ & $\begin{array}{l}\text { (Cohen and } \\
\text { Levinthal } \\
\text { 1989) }\end{array}$ \\
\hline $\begin{array}{l}\text { Top } \\
\text { management } \\
\text { support }^{* *}\end{array}$ & Top & $\begin{array}{l}\text { Our top management ... } \\
\text { 6. allows autonomy in IT management. } \\
\text { 7. provides strong IT leadership. } \\
\text { 8. champions IT innovations. } \\
\text { 9. understands how IT supports our organization's } \\
\text { goals. } \\
\text { 10. is willing to invest in HIE even without } \\
\text { government financial incentives. }\end{array}$ & $\begin{array}{l}\text { (Rai and } \\
\text { Patnayakuni } \\
\text { 1996) }\end{array}$ \\
\hline Trust & & & \\
\hline $\begin{array}{l}\text { Trust in HIE } \\
\text { partner's } \\
\text { ability }\end{array}$ & TrAb & $\begin{array}{l}\text { Our HIE partners (other healthcare providers who } \\
\text { use the same HIE platform to exchange information } \\
\text { with your organization) ... } \\
\text { 5. are competent and effective in their interactions } \\
\text { with us. } \\
\text { 6. perform all of their roles very well. } \\
\text { 7. are capable and proficient. } \\
\text { 8. are knowledgeable about patient information } \\
\text { exchange operations. }\end{array}$ & $\begin{array}{l}\text { (Venkatesh } \\
\text { and Bala } \\
\text { 2012) } \\
\text { (Muthusamy } \\
\text { and White } \\
\text { 2005) }\end{array}$ \\
\hline
\end{tabular}




\begin{tabular}{|c|c|c|c|}
\hline $\begin{array}{l}\text { Trust in HIE } \\
\text { partner's } \\
\text { benevolence }\end{array}$ & $\mathrm{TrBe}$ & $\begin{array}{l}\text { 5. act in our best interest. } \\
\text { 6. do their best to provide assistance whenever we } \\
\text { need their help. } \\
\text { 7. are interested in our well-being rather than just } \\
\text { their own. } \\
\text { 8. are generous in accommodating our needs. }\end{array}$ & $\begin{array}{l}\text { (Venkatesh } \\
\text { and Bala } \\
\text { 2012) } \\
\text { (Muthusamy } \\
\text { and White } \\
\text { 2005) }\end{array}$ \\
\hline $\begin{array}{l}\text { Trust in HIE } \\
\text { partner's } \\
\text { integrity }\end{array}$ & Trln & $\begin{array}{l}\text { 5. are honest. } \\
\text { 6. are truthful in their dealings with us. } \\
\text { 7. adhere to high professional standards. } \\
\text { 8. are consistent in keeping their commitments. }\end{array}$ & $\begin{array}{l}\text { (Venkatesh } \\
\text { and Bala } \\
\text { 2012) } \\
\text { (Muthusamy } \\
\text { and White } \\
\text { 2005) }\end{array}$ \\
\hline $\begin{array}{l}\text { Trust in the } \\
\text { broad HIE } \\
\text { platform }\end{array}$ & TrSy & $\begin{array}{l}\text { 5. We trust our HIE partners. } \\
\text { 6. We trust the HIE system. } \\
\text { 7. We trust government policy's support of HIE. } \\
\text { 8. We trust our HIE vendor(s). }\end{array}$ & $\begin{array}{l}\text { Self- } \\
\text { developed }\end{array}$ \\
\hline $\begin{array}{l}\text { Environment } \\
\text { al Uncertainty }\end{array}$ & & & \\
\hline $\begin{array}{l}\text { Government } \\
\text { policy } \\
\text { uncertainty ** }\end{array}$ & UcPo & $\begin{array}{l}\text { Relating to HIE, government policies ... } \\
\text { 5. change frequently. } \\
\text { 6. are often ambiguous. } \\
\text { 7. create uncertainty for our industry if they change. } \\
\text { 8. are often inconsistent. }\end{array}$ & $\begin{array}{l}\text { (Waldman et } \\
\text { al. 2001) }\end{array}$ \\
\hline $\begin{array}{l}\text { Environment } \\
\text { al technology } \\
\text { uncertainty ** }\end{array}$ & $\begin{array}{l}\text { UcTe } \\
\text { c }\end{array}$ & $\begin{array}{l}\text { 5. Technologies relating to HIE frequently change. } \\
\text { 6. Technology changes create uncertainty for the } \\
\text { industry. }\end{array}$ & $\begin{array}{l}\text { (Newkirk and } \\
\text { Lederer } \\
\text { 2006) }\end{array}$ \\
\hline
\end{tabular}




\begin{tabular}{|c|c|c|c|c|}
\hline & & 8. & $\begin{array}{l}\text { Technological trends in our industry are difficult to } \\
\text { predict. } \\
\text { The existence of many HIE technologies creates } \\
\text { uncertainty for our industry. }\end{array}$ & \\
\hline $\begin{array}{l}\text { Adoption } \\
\text { pressures ** }\end{array}$ & Pres & 5. & $\begin{array}{l}\text { Our patients expect us to use HIE. } \\
\text { We are pressured to use HIE because many of } \\
\text { our competitors use it. } \\
\text { We are pressured by the government's policy to } \\
\text { adopt HIE. } \\
\text { Many providers believe using HIE is inevitable. }\end{array}$ & $\begin{array}{l}\text { (Moore and } \\
\text { Benbasat } \\
\text { 1991) } \\
\text { (Van Slyke et } \\
\text { al. 2004) }\end{array}$ \\
\hline $\begin{array}{l}\text { HIE } \\
\text { characteristic } \\
\text { S as an } \\
\text { innovation }\end{array}$ & Char & 7. & $\begin{array}{l}\text { Our HIE is compatible with our existing systems. } \\
\text { Our HIE is complex to use..* } \\
\text { The results of using HIE can be easily } \\
\text { demonstrated. } \\
\text { We were able to try out our HIE before actual } \\
\text { adoption. } \\
\text { Other providers' HIE use is visible (can be } \\
\text { commonly seen) in our industry. }\end{array}$ & $\begin{array}{l}\text { (Rogers } \\
1962 \text { ) }\end{array}$ \\
\hline $\begin{array}{l}\text { Risk of the } \\
\text { organization } \\
*\end{array}$ & & & & \\
\hline $\begin{array}{l}\text { Risk of the } \\
\text { organization- } \\
\text { financial } \\
\text { aspect ** }\end{array}$ & RkFn & 6. & $\begin{array}{l}\text { our organization, HIE might ... } \\
\text { require too much investment. } \\
\text { end up financially unsustainable once } \\
\text { government funding support runs out. } \\
\text { cause us financial losses when we share patients' } \\
\text { information with other providers. }\end{array}$ & $\begin{array}{l}\text { (Vest et al. } \\
\text { 2013) }\end{array}$ \\
\hline
\end{tabular}




\begin{tabular}{|c|c|c|c|}
\hline & & 8. fail to generate sufficient returns on investment. & \\
\hline $\begin{array}{l}\text { Risk of the } \\
\text { organization } \\
\text {-operational } \\
\text { aspect ** }\end{array}$ & $\mathrm{RkOp}$ & $\begin{array}{l}\text { 6. compromise our patients' information. } \\
\text { 7. make coordination with other HIE partners } \\
\text { difficult. } \\
\text { 8. constrain our operations because it does not } \\
\text { include many providers we work with. } \\
\text { 9. cause work flow interruptions. } \\
\text { 10. make our work process cumbersome. }\end{array}$ & $\begin{array}{l}\text { (Iroju et al. } \\
\text { 2013) } \\
\text { (Lorenzi } \\
2003 \text { ) }\end{array}$ \\
\hline $\begin{array}{l}\text { Risk of the } \\
\text { organization- } \\
\text { technological } \\
\text { aspect ** }\end{array}$ & RkTe & $\begin{array}{l}\text { 5. be technologically difficult to implement. } \\
\text { 6. cause technological interoperability problems. } \\
\text { 7. lead to patient information security breaches. } \\
\text { 8. fail to deliver its promised technical capabilities. }\end{array}$ & $\begin{array}{l}\text { (Detmer } \\
\text { 2003) } \\
\text { (Iroju et al. } \\
2013 \text { ) } \\
\text { (Rudin et al. } \\
2014 \text { ) }\end{array}$ \\
\hline $\begin{array}{l}\text { Relative } \\
\text { Advantage }\end{array}$ & & & \\
\hline $\begin{array}{l}\text { Relative } \\
\text { advantage - } \\
\text { financial } \\
\text { aspect }\end{array}$ & RaFn & $\begin{array}{l}\text { By joining HIE, we have ... } \\
\text { 5. gained a financial advantage. } \\
\text { 6. reduced our patient care costs. } \\
\text { 7. leveraged on government financial incentives. } \\
\text { 8. made financial gains by expanding our services. }\end{array}$ & $\begin{array}{l}\text { (Moore and } \\
\text { Benbasat } \\
\text { 1991) }\end{array}$ \\
\hline $\begin{array}{l}\text { Relative } \\
\text { advantage - } \\
\text { operational } \\
\text { aspect }\end{array}$ & $\mathrm{RaOp}$ & $\begin{array}{l}\text { Using HIE has ... } \\
9 . \text { improved our work efficiency. } \\
\text { 10. improved our patient care quality. } \\
\text { 11. improved our collaboration with other providers. } \\
\text { 12. improved our patients' satisfaction. } \\
\text { 13. improved our patients' healthcare outcomes. }\end{array}$ & $\begin{array}{l}\text { (Moore and } \\
\text { Benbasat } \\
\text { 1991) } \\
\text { (Kuperman } \\
\text { and }\end{array}$ \\
\hline
\end{tabular}




\begin{tabular}{|c|c|c|c|}
\hline & & $\begin{array}{l}\text { 14. improved our medical staffs' experience. } \\
\text { 15. made it easier to take care our patients. } \\
\text { 16. given us greater control over our work. }\end{array}$ & $\begin{array}{l}\text { McGowan } \\
\text { 2013) }\end{array}$ \\
\hline $\begin{array}{l}\text { Relative } \\
\text { advantage - } \\
\text { technological } \\
\text { aspect }\end{array}$ & RaTc & $\begin{array}{l}\text { Using HIE has ... } \\
\text { 5. improved our technological infrastructure. } \\
\text { 6. made us more technologically efficient. } \\
\text { 7. made us more technologically competitive. } \\
\text { 8. made our healthcare delivery more } \\
\text { technologically secure. }\end{array}$ & $\begin{array}{l}\text { (Jaworski and } \\
\text { Kohli 1993) }\end{array}$ \\
\hline
\end{tabular}

Table A2: Operationalizations of all constructs for continuous intentions

${ }^{*}$ Reverse coded items.

** The construct has the same operationalizations as adoption intentions 


\section{B. Descriptive statistics}

\begin{tabular}{|c|c|c|c|c|c|}
\hline & $\mathrm{N}$ & Minimum & Maximum & Mean & Std. Deviation \\
\hline Top1Auto & 117 & 1 & 7 & 5.128205128 & 1.793371231 \\
\hline Top2ITlead & 117 & 1 & 7 & 5.435897436 & 1.683513441 \\
\hline Top3champ & 117 & 1 & 7 & 5.47008547 & 1.739860525 \\
\hline Top4Under & 117 & 1 & 7 & 5.547008547 & 1.610823983 \\
\hline Top5Willi & 117 & 1 & 7 & 5.170940171 & 1.66759479 \\
\hline Absor1Cando & 117 & 1 & 7 & 4.846153846 & 1.664100589 \\
\hline Absor2trainR & 117 & 1 & 7 & 3.025641026 & 1.572728458 \\
\hline Absor3Capab & 117 & 1 & 7 & 5.05982906 & 1.588159845 \\
\hline Absor4Route & 117 & 1 & 7 & 4.803418803 & 1.743160607 \\
\hline Char1Compa & 117 & 1 & 7 & 4.863247863 & 1.681060743 \\
\hline Char2CmplxR & 117 & 1 & 7 & 3.717948718 & 1.639207934 \\
\hline Char3Demo & 117 & 1 & 7 & 4.726495726 & 1.774454417 \\
\hline Char4Visib & 117 & 1 & 7 & 4.222222222 & 1.767089518 \\
\hline Char5Try & 117 & 1 & 7 & 4.384615385 & 1.701146438 \\
\hline UcPo1Chage & 117 & 1 & 7 & 4.547008547 & 1.556386877 \\
\hline UcPo2Ambi & 117 & 1 & 7 & 4.863247863 & 1.547556377 \\
\hline UcPo3Uncer & 117 & 1 & 7 & 5.05982906 & 1.577266286 \\
\hline UcPo4Cnsis & 117 & 1 & 7 & 4.846153846 & 1.606105724 \\
\hline UcTec1Chage & 117 & 1 & 7 & 4.829059829 & 1.657223469 \\
\hline UcTec2Uncer & 117 & 1 & 7 & 4.683760684 & 1.659089762 \\
\hline UcTec3Trend & 117 & 1 & 7 & 4.811965812 & 1.496729906 \\
\hline UcTec4Many & 117 & 1 & 7 & 4.863247863 & 1.596904241 \\
\hline Pres1Patie & 117 & 1 & 7 & 3.803418803 & 1.912929313 \\
\hline Pres2Cmpet & 117 & 1 & 7 & 3.675213675 & 1.933502538 \\
\hline Pres3gov & 117 & 1 & 7 & 4.675213675 & 1.883819761 \\
\hline
\end{tabular}




\begin{tabular}{|c|c|c|c|c|c|}
\hline Pres4provd & 117 & 1 & 7 & 4.658119658 & 1.866965051 \\
\hline Trln1Hnst & 117 & 1 & 7 & 5.324786325 & 1.38855581 \\
\hline TrAb1cmpt & 117 & 1 & 7 & 4.846153846 & 1.430067424 \\
\hline TrAb2prfrm & 117 & 1 & 7 & 4.52991453 & 1.584257955 \\
\hline TrAb3Cpabl & 117 & 1 & 7 & 5 & 1.401969059 \\
\hline TrAb4knwlg & 117 & 1 & 7 & 4.948717949 & 1.490464831 \\
\hline TrBe1Intst & 117 & 1 & 7 & 4.384615385 & 1.574835261 \\
\hline TrBe2help & 117 & 1 & 7 & 4.786324786 & 1.455246512 \\
\hline TrBe3welbe & 117 & 1 & 7 & 4.341880342 & 1.576565413 \\
\hline TrBe4gnous & 117 & 1 & 7 & 4.512820513 & 1.489129488 \\
\hline Trln2truth & 117 & 1 & 7 & 5.401709402 & 1.320004108 \\
\hline Trln3stnda & 117 & 1 & 7 & 5.230769231 & 1.373295906 \\
\hline Trln4comit & 117 & 1 & 7 & 4.64957265 & 1.403912263 \\
\hline TrSy1systm & 117 & 1 & 7 & 5.008547009 & 1.572915843 \\
\hline TrSy2gov & 117 & 1 & 7 & 4.367521368 & 1.812781681 \\
\hline TrSy3vendr & 117 & 1 & 7 & 4.709401709 & 1.592329832 \\
\hline TrSy4partnr & 117 & 1 & 7 & 5.008547009 & 1.63736398 \\
\hline RkFn1Invest & 117 & 1 & 7 & 4.572649573 & 1.78265706 \\
\hline RkFn2Stan & 117 & 1 & 7 & 4.641025641 & 1.840453179 \\
\hline RkFn3loss & 117 & 1 & 7 & 3.47008547 & 1.689586001 \\
\hline RkFn4retun & 117 & 1 & 7 & 4.230769231 & 1.728985229 \\
\hline RkOp1Info & 117 & 1 & 7 & 3.487179487 & 1.73511097 \\
\hline RkOp2cordi & 117 & 1 & 7 & 3.666666667 & 1.553638666 \\
\hline RkOp3stran & 117 & 1 & 7 & 4.393162393 & 1.629243875 \\
\hline RkOp4Flow & 117 & 1 & 7 & 4.205128205 & 1.778891855 \\
\hline RkOp5cmber & 117 & 1 & 7 & 4.358974359 & 1.734346436 \\
\hline RkTe1implem & 117 & 1 & 7 & 4.299145299 & 1.728388512 \\
\hline
\end{tabular}




\begin{tabular}{|c|c|c|c|c|c|}
\hline RkTe2Intero & 117 & 1 & 7 & 4.307692308 & 1.678780029 \\
\hline RkTe3brech & 117 & 1 & 7 & 3.991452991 & 1.719541471 \\
\hline RkTe4dliver & 117 & 1 & 7 & 4.35042735 & 1.758311491 \\
\hline RaFn1finadv & 117 & 1 & 7 & 3.897435897 & 1.657712463 \\
\hline RaFn2cost & 117 & 1 & 7 & 4.076923077 & 1.692548813 \\
\hline RaFn3lever & 117 & 1 & 7 & 4.564102564 & 1.626211036 \\
\hline RaFn4xpan & 117 & 1 & 7 & 4.11965812 & 1.687491472 \\
\hline RaOp1efficy & 117 & 1 & 7 & 4.641025641 & 1.615984479 \\
\hline RaOp2qualty & 117 & 1 & 7 & 5.145299145 & 1.609588496 \\
\hline RaOp3colab & 117 & 1 & 7 & 5.222222222 & 1.462821501 \\
\hline RaOp4satify & 117 & 1 & 7 & 4.846153846 & 1.573571518 \\
\hline RaOp5outcm & 117 & 1 & 7 & 5.025641026 & 1.44712282 \\
\hline RaOp6expern & 117 & 1 & 7 & 4.743589744 & 1.543360899 \\
\hline RaTe1infra & 117 & 1 & 7 & 4.769230769 & 1.476158898 \\
\hline RaTe2efient & 117 & 1 & 7 & 4.88034188 & 1.554539477 \\
\hline RaTe3compe & 117 & 1 & 7 & 4.752136752 & 1.650005135 \\
\hline RaOp7care & 117 & 1 & 7 & 4.905982906 & 1.591913325 \\
\hline RaTe4secur & 117 & 1 & 7 & 4.683760684 & 1.512303408 \\
\hline RaOp8cntrl & 117 & 1 & 7 & 4.564102564 & 1.577780061 \\
\hline Cont1conti & 57 & 1 & 7 & 5.228070175 & 1.812826757 \\
\hline Cont2vnderR & 57 & 1 & 7 & 5.087719298 & 2.037862165 \\
\hline Cont3mistkeR & 57 & 1 & 7 & 5.456140351 & 1.743049211 \\
\hline Cont4SwichR & 57 & 1 & 7 & 4.701754386 & 2.179161964 \\
\hline Adop1colab & 60 & 1 & 7 & 4.65 & 1.929476964 \\
\hline Adop2incorp & 60 & 1 & 7 & 4.516666667 & 1.891028477 \\
\hline Adop3useson & 60 & 1 & 7 & 4.6 & 1.91514924 \\
\hline Adop4seek & 60 & 1 & 7 & 4.416666667 & 1.9596927 \\
\hline
\end{tabular}




\begin{tabular}{|l|l|l|l|l|l|}
\hline Dv1Operation & 117 & 1 & 7 & 4.863247863 & 1.879590853 \\
\hline Dv2Vendor & 117 & 1 & 7 & 4.837606838 & 1.982497836 \\
\hline Dv3Mistake & 117 & 1 & 7 & 5.042735043 & 1.877237343 \\
\hline Dv4switch & 117 & 1 & 7 & 4.555555556 & 2.065498372 \\
\hline Uncertain1Policy & 117 & 1 & 7 & 4.829059829 & 1.283872767 \\
\hline Uncertain2Tech & 117 & 1 & 7 & 4.797008547 & 1.286506406 \\
\hline Trust1Integ & 117 & 1 & 7 & 5.151709402 & 1.137126817 \\
\hline Trust2Ability & 117 & 1 & 7 & 4.831196581 & 1.303521862 \\
\hline Trust3Bene & 117 & 1 & 7 & 4.506410256 & 1.368700908 \\
\hline Trust4HIE & 117 & 1 & 7 & 4.773504274 & 1.420289745 \\
\hline rk1Fin & 117 & 1 & 7 & 4.228632479 & 1.457210317 \\
\hline rk2Op & 117 & 1 & 7 & 4.022222222 & 1.271647798 \\
\hline rk3Tec & 117 & 1 & 7 & 4.237179487 & 1.398446704 \\
\hline ra1Fina & 117 & 1 & 7 & 4.164529915 & 1.343551967 \\
\hline ra2Op & 117 & 1 & 7 & 4.886752137 & 1.345388727 \\
\hline ra3Tec & 117 & 1 & 7 & 4.771367521 & 1.365986385 \\
\hline Valid N (listwise) & 0 & & & & \\
\hline
\end{tabular}

Table B1: Descriptive statistics of all items 


\section{SmartPLS graphic outputs}

(Green color indicating values are within acceptable range)

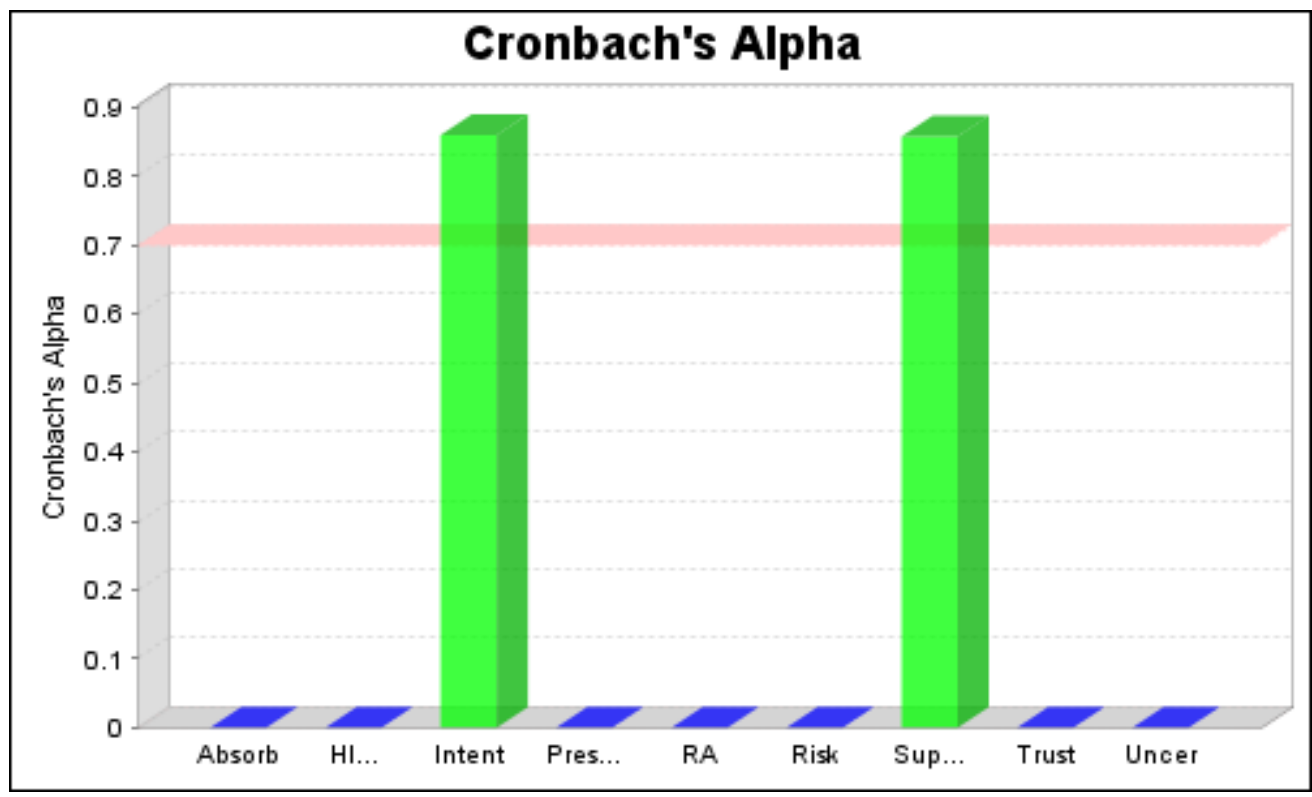

Figure C1: Cronbach's Alpha Values

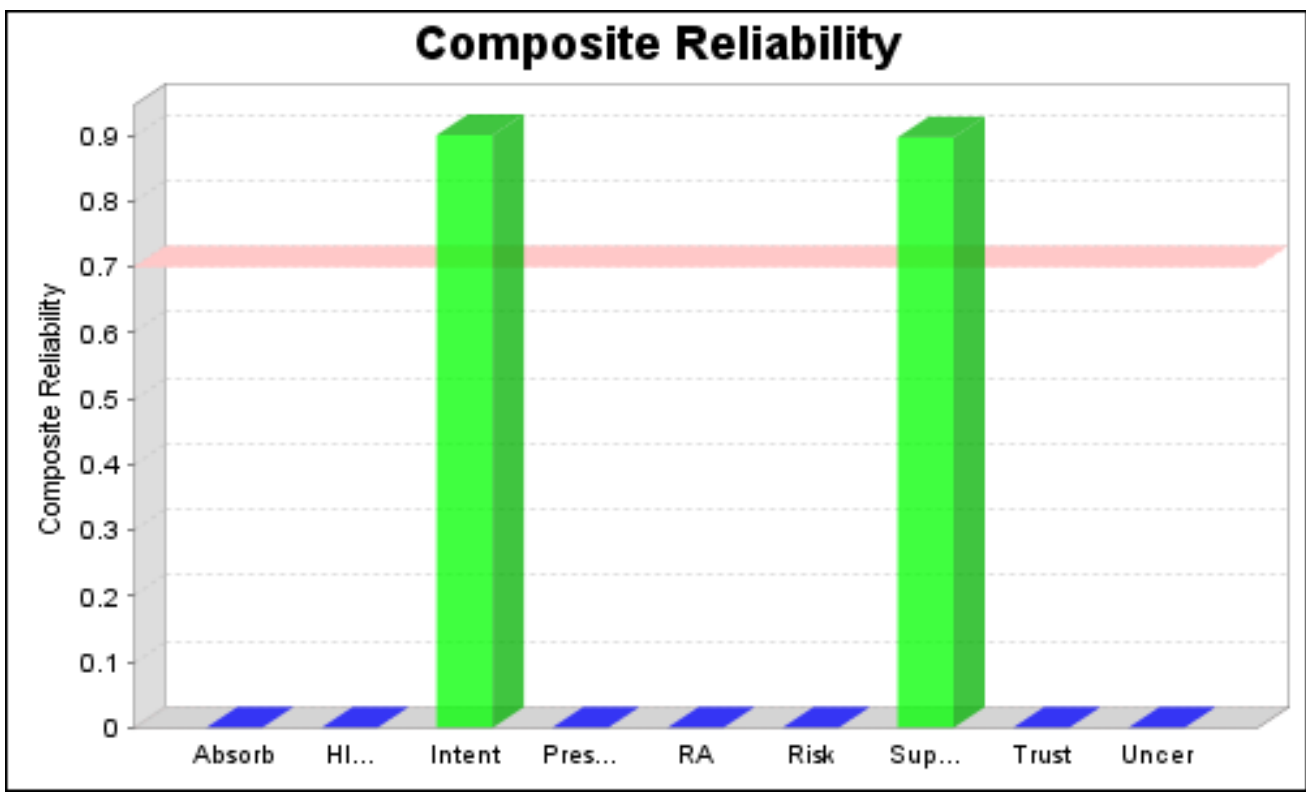

Figure C2: Composite Reliability Values 


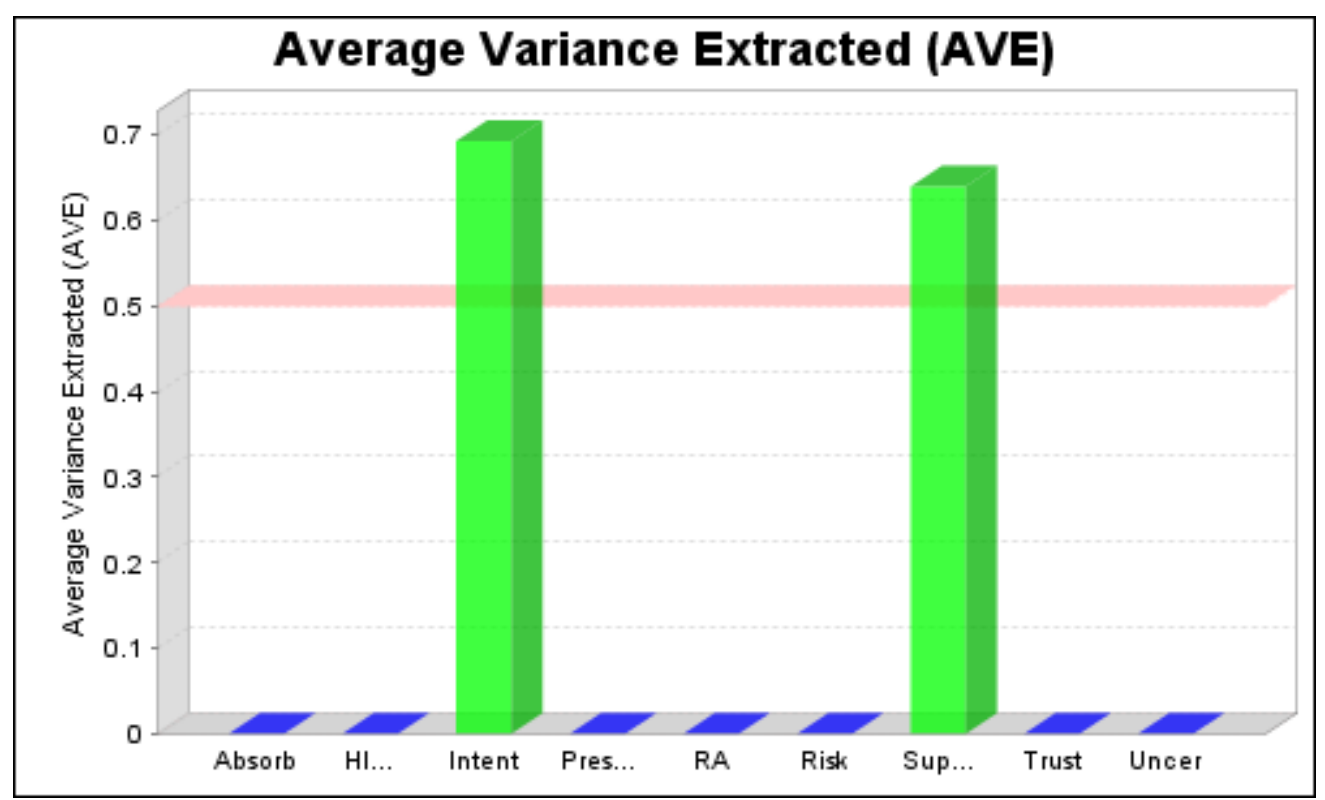

Figure C3: AVE Values

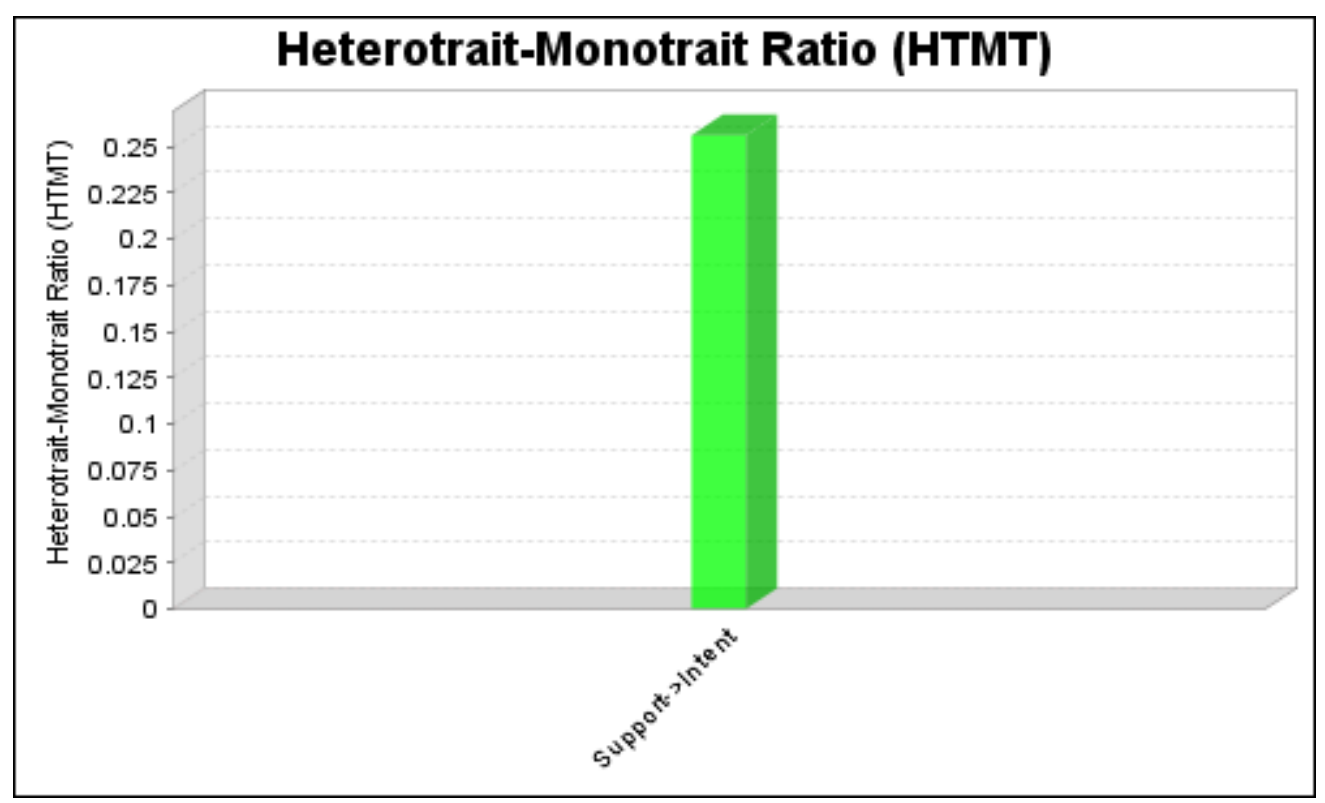

Figure C4: HTMT Values 


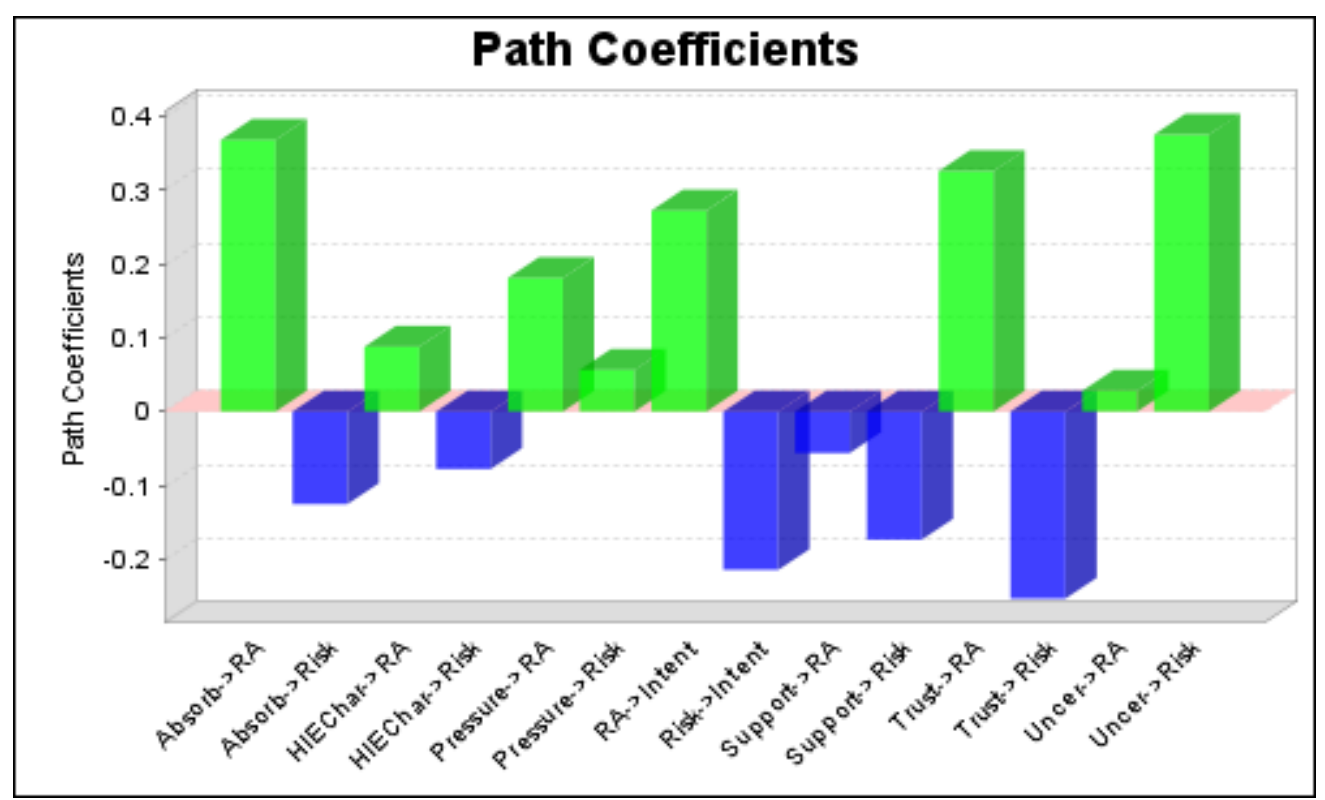

Figure C5: Path Coefficients Values

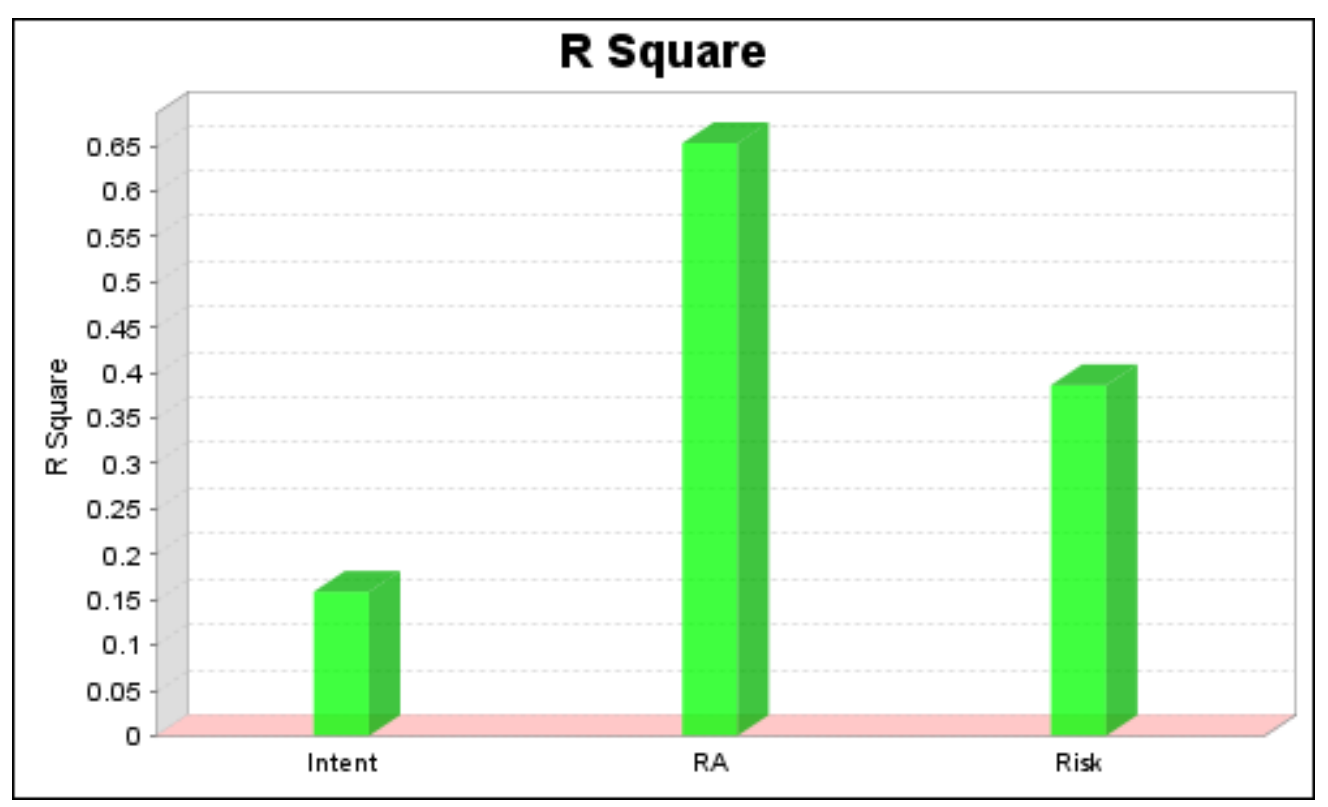

Figure C6: R Square Values 


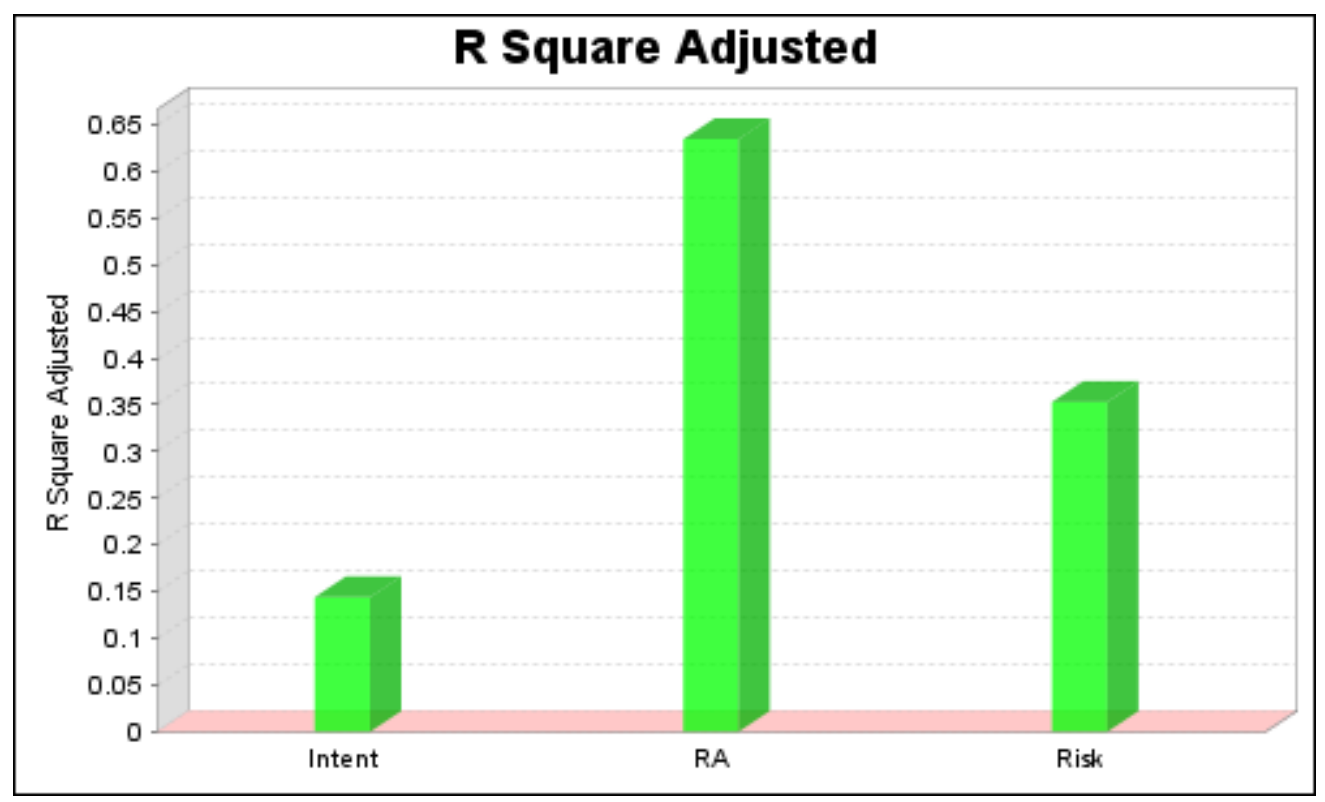


PENG ZHANG

Born, Shenyang, Liaoning, China

1993-1999

Clinical Medicine

Shenyang Medical College

Shenyang, Liaoning, China

2002-2006

Founder and CEO for IHI Inc., China

2006-2008

Master in Business Administration

Indiana Wesleyan University

Marion, Indiana

2012-2017

Doctoral Candidate

Florida International University

Miami, Florida

PUBLICATIONS AND PRESENTATIONS

Akinlade, D., Lambert, J.R., \& Zhang, "Warm" and "Competent" or "Deferential" and "Cooperative": A Conceptual Framework of Immigrant Status and Race on Labor Exploitation, paper accepted and to be published at Southern Management Association 2017 proceedings.

Zhang, P., Tremblay, M., and Klein, R., 2016, December. "An Empirical Investigation of Health Information Exchange Success Factors," paper published at the International Conference on Information Systems 2016.

Zhang, P., Wang, J., 2016, August. "Family Work Conflict and Information Security Policy Compliance-An Empirical Study," paper published at 2016 Americas Conference on Information Systems proceedings.

Zhang, P., Klein, R. 2016, August. "Old Theory and New Technology_ Information Technology's Impact on Transaction Cost Economics," paper published at 2016 Americas Conference on Information Systems proceedings.

Tremblay, M., and Deckard, G., Zhang, P., 2015, November. Lack of Unique Healthcare Identifier in Healthcare Information Exchanges: A Field Study. poster presented at the American Medical Informatics Association 2015 Annual Symposium.

Akinlade, D., Lambert, J.R., \& Zhang, P., 2015 "The Impact of Immigrant Status and Race on Discrimination, Exploitation, and Hiring Decisions," paper presented at the 2015 Midwest Academy of Management Conference. 
Zhang, P., Tremblay, M., and Deckard, G. 2015, August. "A Multi-Agent Approach for HIE Design and Implementation," paper published at 2016 Americas Conference on Information Systems proceedings.

Zhang, P., Tremblay, M., and Deckard, G. 2014, November. "A Quest for HIE Success - Agency Theory and Technology Mutual Adaptation Framework," poster presented at the 20th American Medical Informatics Association 2014 Annual Symposium. 